Florida International University

FIU Digital Commons

$5-21-2019$

\title{
Self-Concept in Children and Adolescents as A Lever for Change in Academic Success for Under-Served Youth
}

Robert Ray Ogle

rogle001@fiu.edu

Follow this and additional works at: https://digitalcommons.fiu.edu/etd

Part of the Child Psychology Commons, and the Clinical Psychology Commons

\section{Recommended Citation}

Ogle, Robert Ray, "Self-Concept in Children and Adolescents as A Lever for Change in Academic Success for Under-Served Youth" (2019). FIU Electronic Theses and Dissertations. 4277.

https://digitalcommons.fiu.edu/etd/4277

This work is brought to you for free and open access by the University Graduate School at FIU Digital Commons. It has been accepted for inclusion in FIU Electronic Theses and Dissertations by an authorized administrator of FIU Digital Commons. For more information, please contact dcc@fiu.edu. 


\title{
FLORIDA INTERNATIONAL UNIVERSITY
}

Miami, Florida

\section{SELF-CONCEPT IN CHILDREN AND ADOLESCENTS AS A LEVER FOR CHANGE IN ACADEMIC SUCCESS FOR UNDER-SERVED YOUTH}

\author{
A dissertation submitted in partial fulfillment of the \\ requirements for the degree of \\ DOCTOR OF PHILOSOPHY \\ in \\ PSYCHOLOGY
}

by

Robert R. Ogle

2019 
To: Dean Michael R. Heithaus

College of Arts, Sciences and Education

This dissertation, written by Robert R. Ogle, and entitled Self-Concept in Children and Adolescents as a Lever for Change in Academic Success for Under-served Youth, having been approved in respect to style and intellectual content, is referred to you for judgment.

We have read this dissertation and recommend that it be approved.

Jonathan Comer

Margaret H. Sibley

Stefany Coxe

Stacy L. Frazier, Major Professor

Date of Defense: May 21, 2019

The dissertation of Robert R. Ogle is approved.

Dean Michael R. Heithaus

College of Arts, Sciences and Education

Andrés G. Gil

Vice President for Research and Economic Development and Dean of the University Graduate School

Florida International University, 2019 
(C) Copyright 2019 by Robert R. Ogle

All rights reserved. 


\section{DEDICATION}

For my parents, Peter and Cara Ogle, and my grandparents, Arthur and Irene Ray, who showed me what it means to work diligently and selflessly in the pursuit of service to others. 


\section{ACKNOWLEDGMENTS}

Many thanks are due for the support, collaboration and encouragement received during the completion of the work presented here. First and foremost, I want to thank the students, faculty and staff of Hialeah-Miami Lakes High School for their partnership and participation in the design and execution of this research, particularly Odalys Acosta, who in one person exemplifies the tenacity, caring, empathy and intelligence needed to change the lives of students for the better.

I also wish to thank Dr. Stacy Frazier, who opened the door to a career in clinical science research to me and offered me peerless guidance at every stage of my graduate career, and to all the members of Team Awesome, whose assistance and collaborative spirit makes them truly worthy of that name.

Finally, and most importantly, I thank my family — my parents, Peter and Cara, my parents-in-law, Michael and Rona, my wife Gila, and my children, Aria, Isaac and Arthur, who have sacrificed much to help me arrive at this point- - you all deserve credit for this work being completed and I could not have done it without you. 


\title{
ABSTRACT OF THE DISSERTATION \\ SELF-CONCEPT IN CHILDREN AND ADOLESCENTS AS A LEVER FOR \\ CHANGE IN ACADEMIC SUCCESS FOR UNDER-SERVED YOUTH
}

\author{
by \\ Robert R. Ogle \\ Florida International University, 2019 \\ Miami, Florida \\ Professor Stacy L. Frazier, Major Professor
}

Children and adolescents in under-resourced urban communities simultaneously experience higher rates of major life stressors, including mental health problems, and less access to the services needed to address these concerns. The combination of high need and few resources makes identifying broadly effective, resource-minimal interventions a critical goal. Amongst potential targets for intervention, academic success, particularly graduating from high school, predicts positive life outcomes across a wide range of health factors. To be effective in supporting academic success in under-served communities, an intervention must be universally applicable, inexpensive, and easy to deliver with fidelity. The current study examined the promise of self-concept as a potential lever for change in academic success for underserved youth. Beginning with an examination of the proposed theoretical model, which suggests that changes in non-academic self-concept in children and teens can lead to improved academic outcomes by improving academic self-concept and reducing mental health symptoms, the study then reports the findings of a randomized controlled trial testing a self-guided journal writing intervention targeting non-academic self-concept for students in a diverse, under-resourced urban high school. 
The intervention was delivered as a classroom assignment, and 89 ninth grade students consented to provide academic data (75 also agreed to provide self-report data) and were randomized to the intervention or an active control condition. Findings did not indicate a significant effect of the intervention on student GPA at the end of the academic year; however, evidence for the validity of the theoretical model emerged. Thus, the current study offers implications for future research and intervention design targeting underserved adolescents in urban high schools. 


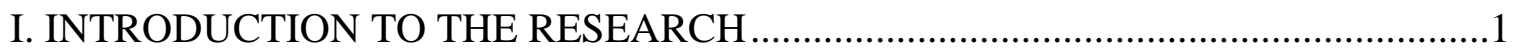

II. NON-ACADEMIC SELF-CONCEPT FOR URBAN YOUTH: ASSOCIATIONS

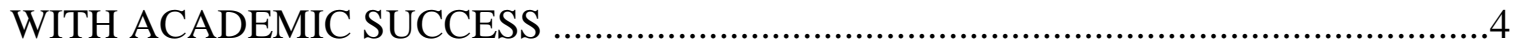

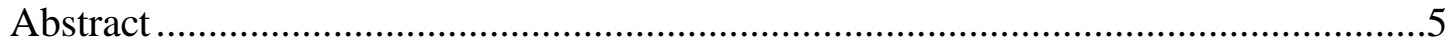

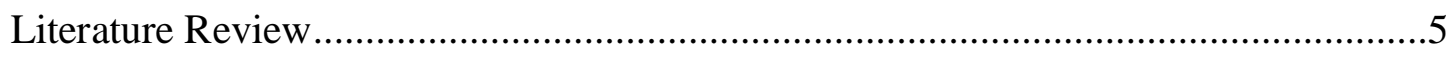

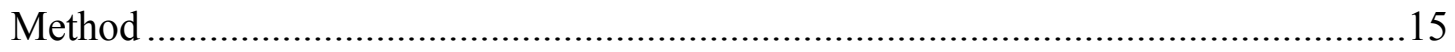

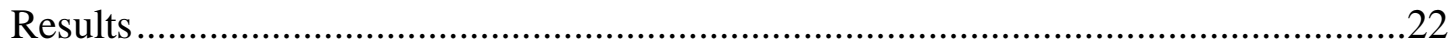

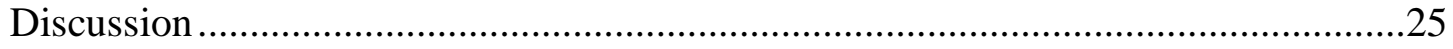

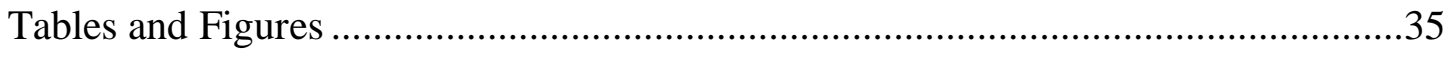

III. NON-ACADEMIC SELF-CONCEPT IN ADOLESCENCE: ASSOCIATIONS

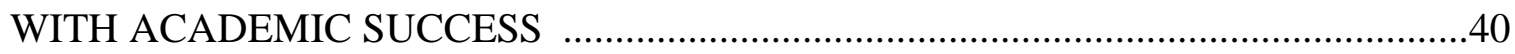

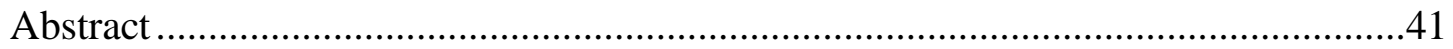

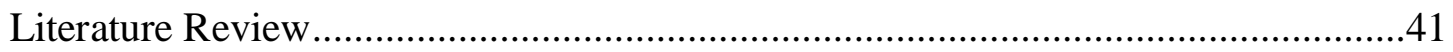

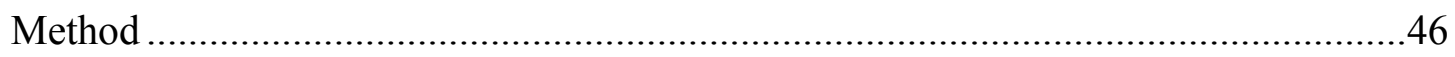

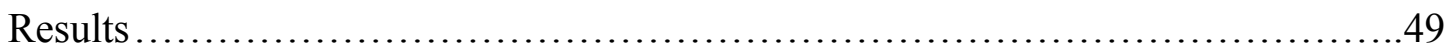

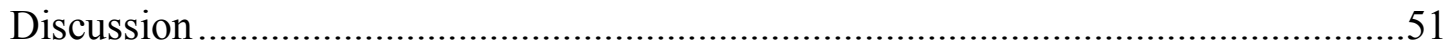

Tables and Figures ……………………………………...................................62

IV. RANDOMIZED CONTROLLED TRIAL OF A SELF-GUIDED SELF-CONCEPT WRITING INTERVENTION TO PROMOTE ACADEMIC SUCCESS IN URBAN UNDER-RESOURCED PUBLIC HIGH SCHOOLS .................................................66

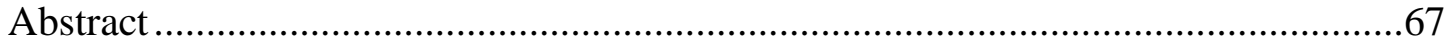

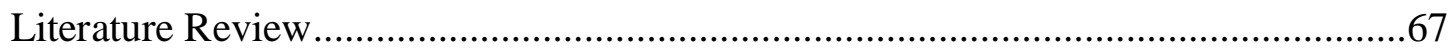

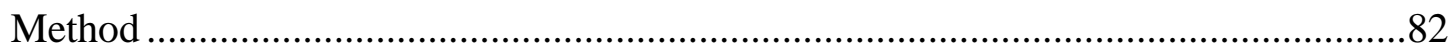

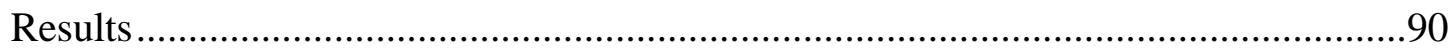

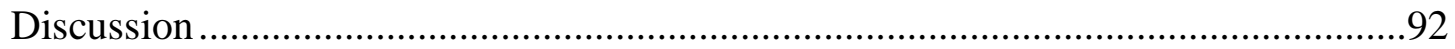

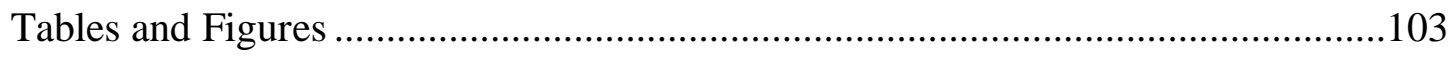

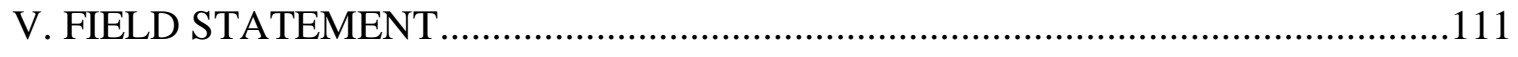

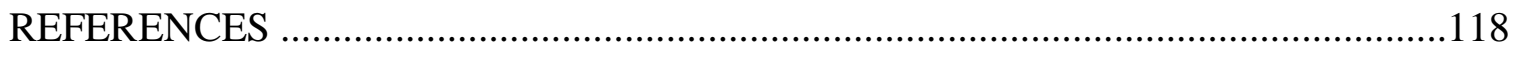

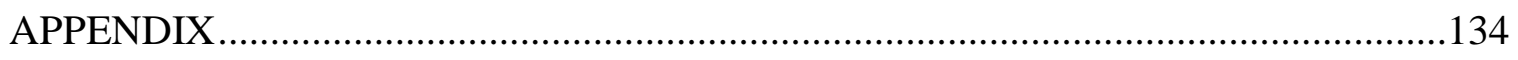

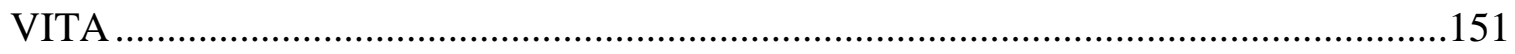




\section{LIST OF TABLES}

CHAPTER

PAGE

II. NON-ACADEMIC SELF-CONCEPT FOR URBAN YOUTH: ASSOCIATIONS WITH ACADEMIC SUCCESS ....................................................................

Table A1. Correlations among and descriptive statistics for key study variables ......34

III. NON-ACADEMIC SELF-CONCEPT IN ADOLESCENCE: ASSOCIATIONS

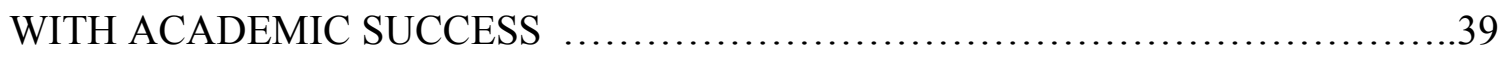

Table B1. Original measurement model results ................................................61

IV. RANDOMIZED CONTROLLED TRIAL OF A SELF-GUIDED SELF-CONCEPT WRITING INTERVENTION TO PROMOTE ACADEMIC SUCCESS IN URBAN UNDER-RESOURCED PUBLIC HIGH SCHOOLS ...............................................65

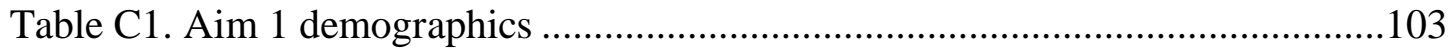

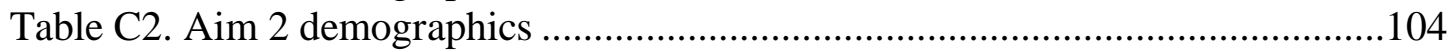

Table C3. Correlation table for time 1 variables..................................................... 105

Table C4. Correlation of scholastic competence and PPSA at time 1 .....................106

Table C5. Correlation of emotional difficulties and PPSA at time 1.......................107

Table C6. Prediction of end of year GPA by PPSA, emotional difficulties and

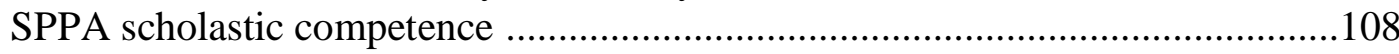




\section{LIST OF FIGURES}

FIGURE

PAGE

II. NON-ACADEMIC SELF-CONCEPT FOR URBAN YOUTH: ASSOCIATIONS WITH ACADEMIC SUCCESS ......................................................................

Figure A1. Example self-aspect map for a hypothetical student, rachel. ....................35

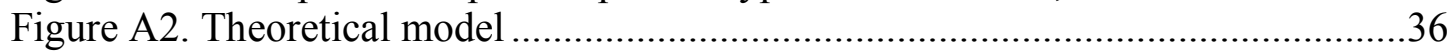

Figure A3. Predicted associations among social and behavioral self-concept, academic self-concept and motivation, mental health symptomatology, and

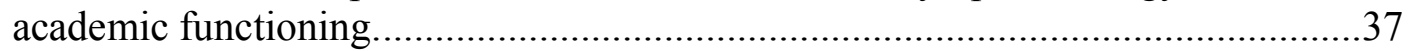

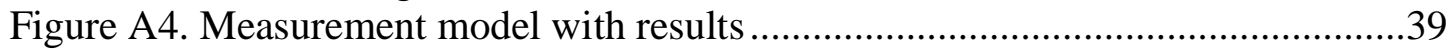

III. NON-ACADEMIC SELF-CONCEPT IN ADOLESCENCE: ASSOCIATIONS

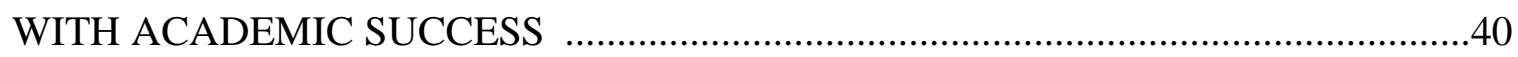

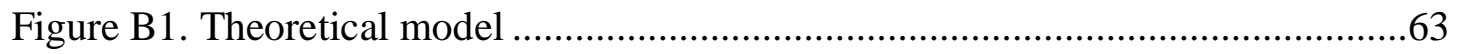

Figure B2. Path model ..............................................................................64

Figure B3. Path model with unstandardized path coefficients ...............................65

IV. RANDOMIZED CONTROLLED TRIAL OF A SELF-GUIDED SELF-CONCEPT WRITING INTERVENTION TO PROMOTE ACADEMIC SUCCESS IN URBAN UNDER-RESOURCED PUBLIC HIGH SCHOOLS ............................................66

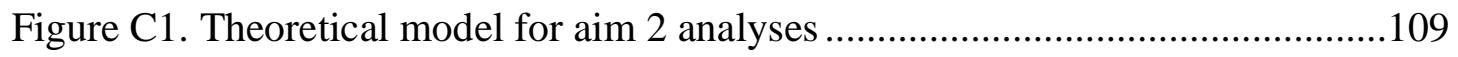

Figure C2. Measurement model for aim 1 growth curve analyses ...........................110 


\section{INTRODUCTION TO THE RESEARCH}

My program of research focuses on identifying resource-minimal interventions that apply evidence-based principles targeting mental health in under-served communities while demanding little money, time, or frontline staff training. My work seeks to identify broadly meaningful and effective targets for intervention, and to use an implementation and services research lens to identify how best to reach those targets in ways that are sustainable in community-based settings where children and adolescents spend their time.

\section{Rationale for Research}

Among predictors of future positive outcomes for adolescents, academic success—-specifically, graduating from high school—ranks amongst the most meaningful. Youths who graduate from high school show improved outcomes across a wide range of indicators, from better career outcomes and earning potential to better physical and mental health, than those who fail to graduate (Freudenberg \& Ruglis, 2007b).

Adolescents who grow up in environments of concentrated urban poverty face significant challenges to their academic outcomes, as evidenced by a drop-out rate nearly four times higher than children who have never been poor (Hernandez, 2011a). These challenges require solutions specific to the problems these teens face, but these solutions must also be viable in environments where resources are often lacking. Interventions that can reach children in naturalistic settings and leverage existing resources efficiently will offer a higher chance of effecting meaningful change than those requiring additional resources.

Self-concept offers a potential lever for change that is well-suited to intervention in under-resourced environments. It is universal, shows strong bidirectional relationships with academic outcomes (H. W. Marsh \& Seaton, 2013), and shows meaningful 
relationships to mental health symptoms (Sowislo \& Orth, 2013); further, interventions that utilize the self to foster change in children and teens have shown powerful results with relatively minimal intervention (Cohen, Garcia, Apfel, \& Master, 2006). However, while research on self-concept has been going on for decades, debate still exists about the nature of its structure and the relation of different parts of the self to one another. Gaining a better understanding of these relationships than what is currently available will help to improve the ability of self-concept based interventions to foster change.

If self-concept offers a meaningful target for intervention to promote academic success, then schools offer an important setting in which to deliver those interventions. Teens spend a significant portion of their day in an academic setting, and given the significant barriers to accessing mental health treatment for low-income familiesincluding financial resources, access to transportation, the time off of work and school often required to make it to appointments - the reliable access to children in their schools makes delivering interventions there invaluable, particularly when targeting academic success. However, intervention in schools is not without challenges. Teachers in lowincome schools consistently report feeling overwhelmed (Atkins et al., 2006) and are hired to teach, not to deliver mental health intervention. Thus, to leverage the opportunities that a school environment offers with regards to intervention, the tools offered must fit seamlessly within the school's existing work.

\section{Presentation of Research Findings}

This dissertation examines the nature of self-concept in children and adolescents and the promise of an intervention designed to leverage self-concept to foster improved academic outcomes while remaining inexpensive and easy to deliver with fidelity in a 
school setting. Three separate manuscripts describe the work. Chapter Two analyzes the relationship between non-academic self-concept and academic outcomes utilizing structural equation modeling to test the moderating effect of academic self-concept and symptoms of mental health disorders. Chapter Three extends these findings to an adolescent population and examines and discusses the impact that the transition to adolescence has on students' sense of themselves and the relationship of the self to academic outcomes. Chapter Four culminates in the examination of a randomized controlled trial testing a self-concept intervention designed to be broadly effective and deliverable in routine classroom settings. Five 9 th grade World History teachers from a large urban public high school delivered a self-guided journal writing intervention to their students as part of their regular curriculum. Eighty-nine students agreed to allow access to their academic data, and 75 of the 89 agreed to provide self-report data on mental health symptoms and self-concept in addition to their grades. We hypothesized that 1) Students in the control condition would show improved grade point average at the end of the academic year relative to those in the control condition, and that 2) these changes would be mediated by improvement in academic self-concept and reduction in mental health symptoms. Findings point to some validation of the theoretical model; implications for future research and for self-concept intervention are discussed in Chapter Five. 


\section{NON-ACADEMIC SELF-CONCEPT FOR URBAN YOUTH: ASSOCIATIONS WITH ACADEMIC SUCCESS}

This manuscript has been published in School Mental Health, Volume 8, Issue 2, pages 278 to 291 .

Ogle, R. R., Frazier, S. L., Nichols-Lopez, K., \& Cappella, E. (2016). Non-academic selfconcept among urban youth: Associations with academic success. School Mental Health, 8(2), 278-291.

Authors' note: Primary support for this manuscript was provided by NIMH research grant P20MH078458 (PI: Marc S. Atkins). 


\begin{abstract}
An extensive literature demonstrates the relationship between academic self-concept and academic achievement, but the relationship between non-academic subdomains of the self and academic success in children and adolescents remains less clear. The current study examined longitudinal associations between social and behavioral self-concept, mental health symptoms, and indicators of academic achievement. Children $(n=364)$ from 36 classrooms across five elementary schools participated in the study. Children reported attitudes about the self, and teachers assessed children's mental health symptoms and academic functioning at two time points. Structural equation models indicated that behavioral self-concept predicts subsequent academic engagement and study skills in low-income urban youth through improvement in academic self-concept and reduction in mental health symptoms. Findings point toward the potential promise of non-academic self-concept as a target for intervention to improve youth academic outcomes.
\end{abstract}

Keywords: Self-concept, self-aspect, academic success, urban youth, mental health

Non-Academic Self-Concept for Urban Youth: Associations with Academic Success

\title{
Introduction
}

Children who experience poverty, especially African-American and Latino children, are at far higher risk for failing to graduate from high school than children who have never been poor, and the difference in academic trajectory between these students often can be identified as early as third grade (Hernandez, 2011). Therefore, children in urban poverty are at heightened risk for development of negative self-concept around school 
performance; further, minority children are more likely to be vulnerable to stereotype threat in academic settings, which can further hinder learning and academic performance (Taylor and Walton, 2011). Because the majority of children in the U.S. public school system are now low income, as defined by free \& reduced lunch status (Suitts, 2015), the need to better understand the risk and protective factors that operate on children living in poverty with regards to academic success has become even more urgent and critical.

Self-concept may be one such factor that plays a key role in academic success. Self-concept refers to an individual's beliefs, perceptions and attitudes about themselves. These beliefs may be global, assessing an individual's beliefs about themselves as generally good or worthy (often referred to as self-esteem or self-worth), or specific to a particular domain, such as academic self-concept (attitudes about oneself as a student), social self-concept (attitudes about him/herself as a friend), and so on (Marsh \& Shavelson, 1985). Several decades of research in child self-concept have generated a robust literature demonstrating that more positive self-concept predicts school success, higher quality of life, and improved mental health (Mann, Hosman, Schaalma, \& de Vries, 2004). Conversely, negative self-concept predicts poor academic functioning and higher risk for multiple mental health disorders (Mann, Hosman, Schaalma, \& de Vries, 2004). Together, these findings suggest that self-concept contributes meaningfully to youth adjustment and outcomes and warrants further examination as a possible lever for change. However, the precise structure of self-concept, the relationship of various subdomains of self-concept, and the relationship of those subdomains to indicators of academic success, requires additional attention and clarification. 


\section{Multidimensional Models of Self-Concept}

Characteristic of the earliest multidimensional models, Shavelson et al. (1976) proposed only two subdomains of self: academic self-concept, and non-academic selfconcept (comprising social, emotional and physical aspects). While these subdomains possess high face validity, and evidence supporting the model is sound (Marsh et al., 1985), we know little about how change in one may influence the other, as they are considered independent and distinct, with change happening vertically (e.g., from global self-concept to academic) but not horizontally (e.g., from academic self-concept to social). Under this hierarchical framework, changes in one subdomain (e.g., social selfconcept) would not influence changes in another (e.g., academic self-concept) and, as a result, intervention to improve social self-concept, for instance, would hold limited ability to affect a child's academic self-concept.

More recently, McConnell (2011) presented an alternative model that conceptualizes the subdomains of self-concept differently. Specifically, McConnell describes self-concept not as a hierarchical framework, but rather as a distributed network of multiple self-aspects (e.g., husband, father, church member, lawyer), each one associated with a variety of different attributions (e.g., caring, nurturing, faithful, intelligent). A self-aspect can be associated with multiple attributions, and the same attribution also can be tied to multiple different self-aspects; as a result, multiple selfaspects may share a relationship, in terms of frequency of association or effect on each other, through their shared attribute connections. Figure 1 presents an example of the aspect-attribute distribution for a fictional college student, Rachel (McConnell, 2011). In 
this example, the female attribute is related to, and can activate, or be activated by, the sorority sister, girlfriend, and daughter aspects, and changes in self-evaluation on any of these domains can in turn affect the perception of other associated aspects (McConnell, 2011). McConnell's model thus suggests that a change in self-evaluation on a particular subdomain, such as social self-concept, can influence other subdomains, such as academic self-concept, by bolstering attributes shared between them. By this framework, non-academic self-concept could meaningfully influence academic self-concept and, by extension, academic achievement.

\section{Children's Academic Self-Concept Predicts Academic Success}

Extensive research demonstrates a strong relationship between self-concept, specifically academic self-concept, academic motivation, and academic achievement (Marsh, Byrne, \& Shavelson, 1988; Valentine, DuBois, \& Cooper, 2004). Early examinations of self-concept often focused on global self-concept's contribution to academic outcomes, and tests of early models (Shavelson, Hubner, \& Stanton, 1976) suggested significant but modest correlations between global self-concept and grades for both children and adolescents (Marsh, 1990b). However, more rigorous examinations have revealed that when both global and academic self-concept are included simultaneously in one model, the effect of global self-concept on academic success becomes negligible (Marsh \& O’Mara, 2008). Specifically, Marsh and colleagues examined longitudinal associations among self-reported global and academic self-concept and academic attainment in a sample of 2,213 10th grade boys at 5 time points (early $10_{\text {th }}$ grade, late $11_{\text {th }}$ grade, high school graduation, 1 year post-graduation, and 5 years post- 
graduation). Findings revealed that global self-concept in $11_{\text {th }}$ grade had little to no effect on educational attainment by $12^{\text {th }}$ grade. On the other hand, academic self-concept in $10_{\text {th }}$ and 11th grades, achievement as measured by school performance, and educational attainment as measured 1 year after graduation, all showed significant reciprocal effects, and 1 year post-high school academic self-concept predicted educational attainment 5 years after graduation (Marsh \& O'Mara, 2008).

Multiple studies testing causal and temporal hypotheses suggest that their relationship is bidirectional: academic success predicts positive academic self-concept (Filozof et al., 1998; Marsh and Yeung, 1997), and positive academic self-concept predicts subsequent academic success (Marsh, 1990a). For example, Marsh \& Yeung (1997) examined self-reported academic self-concept, teacher-reported academic performance, and student grades among Australian adolescents in grades 7 to $10(\mathrm{n}=$ $603 ; 100 \%$ male; mean age by grade, $12.7,13.6,14.6$ and 15.5 years, respectively) at the end of each academic semester over a three year period. They found that academic success positively impacted academic self-concept, but academic self-concept also predicted academic success, even after controlling for past academic outcomes (Guay, Marsh, \& Boivin, 2003; Marsh \& Yeung, 1997). The relationship between academic selfconcept and academic achievement exists both in children (Helmke \& van Aken, 1995) and adolescents (Marsh \& O'Mara, 2008), and across ethnic groups (Marsh, 1990). Children naturally develop an academic self-concept as they progress through their school years; thus, academic self-concept represents a meaningful predictor of school success for a large percentage of youth. 


\section{Children's Mental Health Predicts Academic Success}

As with academic self-concept, mental health symptoms and disorders in children also can impact children's academic functioning as early as preschool (Arnold, 1997) and as late as college (Eisenberg, Golberstein, \& Hunt, 2009); also similar to academic selfconcept, early studies of self-concept and psychopathology relied on measures of global rather than specific self-concept and revealed associations between low global selfconcept and internalizing disorders, particularly depression and suicidal ideation, in children and adolescents (Dumont \& Provost, 1999; Harter, 1993; Rosenberg, Schooler, Schoenbach, \& Rosenberg, 1995). However, comprehensive review of the self-esteem literature (Baumeister, Campbell, Krueger, \& Vohs, 2003) suggests that while low global self-concept correlates with depression, the direction of causality remains unclear, findings regarding influence of environment are mixed, and confounding variables are not always adequately controlled, together bringing into question the utility of global self-concept as a predictor or target for intervention. Further, mirroring findings summarized above, multiple studies show specific subdomains of self-concept correlating more strongly than global self-concept with mental health symptoms. A study by Bidell and Deacon (2010) with high school students $(n=92$, mean age 16.26 years, 55\% Caucasian, 36\% Hispanic) showed negative evaluations of the self in specific domains (e.g., academic, social) more strongly correlated with both school-counselor reported and youth self-report externalizing psychopathology, even when global self-worth was retained as a predictor (Bidell and Deacon, 2010). 
In another study, Marsh and colleagues (Marsh, Parada, \& Ayotte, 2004) examined $9037_{\text {th }} \& 8$ th grade students (mean age 12.6 years, $49 \%$ male) of multiple ethnicities from economically disadvantaged neighborhood schools in Montreal, Canada. Students completed the Youth Self-Report (a widely used measure of psychopathology) and the Self-Description Questionnaire II (a measure of global and specific self-concept) at the beginning of the academic year. Findings revealed that student-reported self-esteem (measured using the Self Description Questionnaire II) meaningfully correlated with every index of internalizing and externalizing symptomatology on the Youth Self Report; however, for every index of the scale, there were multiple subdomain items (e.g., honesty, relationship to parents, etc.) that correlated even more strongly (Marsh, Parada, $\&$ Ayotte, 2004). Taken together, these studies suggest that more specific views of the self demonstrate a stronger relationship than global self-concept to both academic and mental health outcomes. Hence, subsequent research has tested multidimensional models of self-concept, and each subdomain's unique relationship to youth outcomes. Children experiencing externalizing disorders (attention-deficit/hyperactivity disorder, oppositional defiant disorder, and conduct disorder) have lower GPAs and standardized test scores than their peers, as well as higher rates of grade repetition, aggression, and school dropout. Hinshaw (1992) completed a review of multiple longitudinal studies demonstrating that early childhood teacher ratings of externalizing behavior correlated strongly with delinquency in high school, controlling for SES and family history; that aggressive or aggressive-withdrawn children more likely to be in special education programs or behind grade level three years later; and that 2 nd grade assessment of 
aggression, immaturity, depression and dependency predicted test scores and GPA at 9 th and 12th grades, controlling for IQ (Hinshaw, 1992).

Children suffering from internalizing disorders (anxiety disorders, major depressive disorder, and dysthymia) also have lower GPAs and standardized test scores. A longitudinal study of 424 children identified as having depression and/or anxiety at ages six to eight based on a version of the Achenbach Child Behavior Checklist, were significantly less likely to graduate high school, even when controlling for race, gender, SES, and maternal factors (e.g., age of delivery, mother's achievement, marital status) (McLeod \& Kaiser, 2004). A retrospective study of a large, nationally representative sample $(n=5,692)$, controlling for familial stressors (e.g., childhood trauma, parental neglect, parental educational attainment) as well as age, sex and ethnicity, found that children with any internalizing disorder showed a highly significant increase in the odds ratios for failing to complete high school (any anxiety disorder $=$ OR 1.3; any mood disorder $=$ OR 1.5) $($ Breslau, Lane, Sampson, \& Kessler, 2008). In addition, Cole and colleagues (Cole, Martin, Peeke, Seroczynski, \& Fier, 1999) showed in a longitudinal study of 3 rd and 6th grade students $(n=807)$ over three years that anxiety and depression predict subsequent changes in academic self-concept; as children's symptoms of depression and anxiety increase, they believe themselves less competent academically than objective measures would indicate. This suggests that self-concept may show a meaningful relationship with mental health disorders, though the nature of that relationship requires closer examination. 


\section{Self-Concept Interventions: Why Subdomains Matter}

Growing experimental evidence suggests that subdomains of self-concept can influence one another and can be leveraged to impact academic outcomes. A 2006 study published in Science demonstrated that strengthening a personally relevant self-aspect can have a meaningful impact on academic success (Cohen, Garcia, Apfel, \& Master, 2006). At the start of a new school year, Cohen and colleagues asked youth $(n=243$, grade 7, 48\% African American) to select an aspect of the self (e.g., sense of humor, being a good friend, being a good athlete, etc.) that was most important to them, and to complete a brief writing exercise in which they explained why it was important. After completion, researchers collected the intervention packets, and this completed the intervention. Teachers were not permitted to read the student responses, and students were not informed about the purpose of the writing exercise. At the end of the academic year, African American students' cumulative GPA had increased significantly, by an average of one-half point on a 4-point scale, relative to peers in a demographically matched control group. The authors concluded that an increase in self-integrity (another single-variable proxy for positive self-concept) and corresponding reduction in stereotype threat (threat that arises during an opportunity to confirm a negative stereotype about oneself), led to better academic performance. The same intervention, with slight modification, has shown similar effects for women in math and science education (Miyake, Kost-Smith, Finkelstein, Pollock, Cohen \& Ito, 2010), on academic performance and physical health outcomes in college students (Walton \& Cohen, 2011), on sympathetic nervous system responses to naturalistic stressors (Sherman, Bunyan, 
Creswell, \& Jaremka, 2009), on reducing narcissistic aggression in adolescents (Thomaes, Bushman, Orobio de Castro, Cohen, \& Denissen, 2009), and in promoting prosocial attitudes and behaviors in adolescents (Thomaes, Bushman, de Castro, \& Reijntjes, 2012).

The studies described above also highlight an important consideration around the effect of children's self-concept on academic outcomes: namely, the increased risk to low-income and minority students as a result of stereotype threat. Cohen and colleagues argue that the intervention works for minority students by mitigating the effects of stereotype threat for those students.

\section{What We Know and What We Need to Know}

In summary, previous research demonstrates the following: A. Low academic self-concept predicts poor academic achievement, B. Mental health disorders also predict poor academic achievement, C. Global self-concept relates to both academic self-concept and mental health symptoms, but D. Subdomains of self-concept show stronger associations than global self-concept to academic outcomes, and 5. The associations between subdomains of the self-concept may not be as limited as earlier research suggested. Cohen's research and related studies suggest that even brief interventions that target non-academic subdomains of self-concept can improve academic and mental health outcomes for adolescents and adults, effectively leveraging prior findings regarding the reciprocal influence of self-concept on functional outcomes, and suggesting that different subdomains may influence each other more than previously believed. To our knowledge, associations among these constructs have not been explored or leveraged in children. 
Therefore, based on the literature cited above, we tested a theoretical model (Figure 2) of the relationship between non-academic self-concept, academic self-concept, mental health symptoms, and academic functioning (engagement and study skills) for elementary school children.

\section{Current Study}

The current study examines the relationship between non-academic self-concept, academic self-concept, mental health symptoms, and academic functioning. We hypothesized that non-academic self-concept, specifically social and behavioral selfconcept, would correlate positively with academic self-concept and academic motivation, and correlate negatively with mental health symptoms. We also hypothesized that academic self-concept and academic motivation would positively predict, and mental health symptoms would negatively predict, subsequent academic engagement and study skills. Thus, we propose that non-academic self-concept can impact academic success via its influence on mental health symptoms and academic self-concept.

\section{Method}

All intervention and data collection procedures were conducted in accordance with APA Ethical Guidelines and with approval from the university's Institutional Review Board and the partnering urban northeastern school district's Research Review Board. 


\section{Participants}

Data for the current study comes from a classroom-randomized school mental health services study focused on supporting teachers around classroom environment and instruction to improve academic and social outcomes for children referred for disruptive behaviors (Cappella et al., 2012). The total baseline sample included 364 children in 36 K-5 classrooms across 5 public schools in low-income neighborhoods in a large urban area in the eastern U.S. (43\% female, 87\% Latino, 11\% African American, 89-99\% free and reduced lunch). Schools were selected based on the following criteria: they maintained existing relationships with community agencies that provide school-based mental health services, and they served a high percentage of low-income students as determined by percentage of children eligible for free or reduced lunch programs. All teachers were invited to participate in the study, and sufficient community mental health staff were available to accept all teachers expressing interest into the study. A total of $27 \%$ of teachers (42 of 154 ) agreed to participate and subsequently were randomized into consultation or control conditions. All children within consented classrooms were eligible to participate, including children with and without referrals for disruptive behavior; $43.9 \%$ of children (364 of 828 ) received parent permission and provided written assent.

A subset of the overall sample was included in the current study. First, the research questions required youth self-report; thus, the sample was restricted to grades 3 to 5 and, in turn, reduced to 22 classrooms (11 intervention, 11 comparison) and 148 students ( 74 referred by their teacher for behavioral problems, and 74 randomly selected comparison peers, 2 each per classroom). Eligibility for inclusion in the current study 
additionally required that students provided data on all measures used in the current study at both Time 1 and Time 2. Eligibility criteria produced a final sample of 110 children (44\% female, 80\% Latino, 8\% African American, 89\% free and reduced lunch), including children in grades $3(20 \%), 4(34.5 \%)$, and $5(45.5 \%)$ and children in both intervention (44\%) and control (56\%) conditions.

\section{Measures}

Harter Self-Perception Profile for Children. The Harter SPPC (Harter, 1985) measures children's self-concept ratings across five sub-domains, and presents a global index of self-esteem (that is distinct from subdomain scores). The measure presents 36 items (six for each subscale). Each consists of two competing statements characterizing two groups of children, one performing well and one performing poorly in a particular domain of functioning (e.g., "Some kids do well at their school work BUT other kids don't do well at their work"). Students select the statement with which they most agree (in this example, either "Some kids do well" or "Other kids don't do well"), and then also rate whether the statement they selected is "Sort of true for me" or "Really true for me". Items are scored 1 to 4 , with positive statements (e.g., "Some kids do well”) receiving higher scores, and strong agreement (e.g. "Really true for me") at the endpoints. Thus, for example, a child who selects "Others don't do well" and "Really true for me" would receive a score of 1 for that item ("Somewhat true for me" would score a 2), while a child who selects "Some kids do well" and "Really true for me" would receive a score of 4 for that item ("Somewhat true for me" would score a 3). Higher scores indicate higher selfconcept within that domain. 
Academic (6 items, $\alpha=.580$, e.g., "Some kids feel they are very good at their school work BUT other kids worry about whether they can do the school work assigned to them"), Social (6 items, $\alpha=.396$, e.g., "Some kids know how to make classmates like them BUT other kids don't know how to make classmates like them") and Behavioral (6 items, $\alpha=.701$, e.g., "Some kids behave themselves very well BUT other kids often find it hard to behave themselves") scales were administered at Time 1 and included in analyses to represent self-concept within those subdomains. The parent study excluded the Physical Appearance and Athletic subdomains from administration in order to minimize burden on participants, making it unavailable for analysis here. Research examining the factor structure and concurrent validity with other measures of personality shows high convergent and internal validity, as well as strong test-retest reliability (Muris, Meesters, \& Fijen, 2003). Use of the measure with similar samples in other studies (Cardemil, Reivich, Beevers, Seligman, \& James, 2007) showed high reliability and validity in low income, Latino and African-American children in grades 5-8.

Academic Motivation Inventory. The AMI (Ginsburg-Block \& Fantuzzo, 1998) is a 13-item, 3-point Likert-style self-report measure adapted from the 39-item Young Children's Academic Intrinsic Motivation Inventory (Gottfried, 1990), designed to assess children's motivation to learn and willingness to persist when challenged academically. The AMI was intended for use in urban low-income communities (modifications focused on improving clarity and reducing unnecessarily complex question structure) and normed on an ethnic minority sample (Ginsburg-Block \& Fantuzzo, 1998). Four subdomains include reading, math, and general academic motivation, each with 12 items, and a 3-item 
scale measuring how a child responds when presented with difficult material (e.g., "I like to do easy reading work"). We included the AMI at Time 1 Total Score (sum of the four subscales; $\alpha=.812$ ) in this analysis. As academic self-concept and academic motivation are closely related, we included the academic motivation score to further explore how non-academic self-concept can influence academic related attitudes; hence, the AMI corresponds with the academic self-concept construct in the theoretical model.

Strengths \& Difficulties Questionnaire. The SDQ (Goodman, 1997) is a widely used, 25-item, 0 to 2 (Not true, somewhat true, certainly true) Likert-style scale, teacherreport measure of psychopathology that screens for mental health symptoms and impairment in five domains: Emotional Difficulties (corresponding to internalizing symptoms), Conduct Problems, Hyperactivity, Peer Problems, and Prosocial Behavior. Three subscales were administered at Time 1: Emotional Difficulties ( 5 items, $\alpha=.778$ ), Conduct Problems (5 items, $\alpha=.805$ ), and Hyperactivity (5 items, $\alpha=.909$ ), which were combined using structural equation modeling to represent a single Mental Health Symptoms latent factor at Time 1. The Hyperactivity measure was used as the marker variable for the latent factor as it had the highest reliability of the three subscales. Examination of the validity of the measure in a multiethnic sample showed no difference between minority and majority children and strong fit of the model in a factor analysis on the teacher report version of the SDQ (Hill \& Hughes, 2007). The SDQ score corresponds to the Mental Health Symptomatology construct in the theoretical model.

Academic Competence Evaluation Scales. The ACES (DiPerna \& Elliott, 1999) is a 60-item, 5-point Likert-style teacher rating scale designed to evaluate students on five 
subdomains of academic ability: Academic Skills, Academic Motivation, Engagement, Study Skills, and Interpersonal Skills. Only Engagement (8 items, $\alpha=.963$ ) and Study Skills (11 items, $\alpha=$.974) subscales were administered at Time 2 and included in the current analyses. The ACES shows high test-retest reliability and internal consistency across samples, and shows high validity through confirmatory factor analysis and strong correlations with other indicators of academic success and competency, including standardized testing and grade performance (DiPerna \& Elliott, 1999) and examination of the ACES in a nationally representative sample including several hundred Latino children demonstrated similar evidence of reliability and validity with that population (Elliott, DiPerna, Mroch, \& Lang, 2004), making it a strong indicator of academic success as described in the theoretical model.

\section{Procedures}

Recruitment was completed during early fall of the academic year. Teachers received letters explaining the study; consented teachers were randomized to intervention or control conditions. All students from consented classrooms were invited to participate. Research staff presented information about the study to each class, and informed consent packets were sent home to parents. All children in grades 3 to 5 who returned a parental consent form with permission to participate were subsequently assented with a written form.

Data were collected at two time points, late fall and late spring. Between time points, teachers in the intervention condition received regular support from a school- or community-based mental health professional around improving classroom climate 
(emotional support and organization) and increasing positive and productive interactions with students with disruptive behaviors. Participating schools received modest compensation for participation; teachers were not individually compensated due to school district regulations. Students completed measures during teacher-selected noninstructional times during the school day and received small prizes.

\section{Intervention}

The intervention in the parent study paired community mental health providers with classroom teachers in a consultation and coaching model to assist teachers around minimizing and managing disruptive behavior. Mental health providers were either employed by the school district or by local agencies. Teachers and providers received training together from research staff on the use of effective, evidence-based tools for classroom behavior management (Cappella et al., 2012). Research staff supervised mental health providers who in turn coached teachers to implement recommended strategies (e.g., Good Behavior Game, Random Positive Attention, Positive Peer

Reporting). Neither the research staff nor the mental health providers intervened directly with students, as the research aimed to examine the extent to which consultation would lead to increased use by teachers of evidence-based strategies and subsequent improvements in children's classroom functioning.

\section{Data Analysis}

Data analysis was conducted using MPlus 6.0 (Muthén \& Muthén, 2010). The model in Figure 4 was estimated using a complex sampling feature involving a maximum 
likelihood estimator with robust standard errors and sandwich estimators for computations, in order to account for the clustering of students within classrooms (Muthén \& Satorra, 1995). As missing data are present due to planned missingness using a two-method measurement design, Full Information Maximum Likelihood procedures were used in order to estimate parameters and standard errors following recommendations by Graham et al. (Graham, Taylor, Olchowski, \& Cumsille, 2006). Finally, as children were grouped by condition in the parent study, we controlled for possible intervention effects by regressing condition on Time 2 outcome variables of academic engagement and study skills.

\section{Results}

\section{Outliers and Normality}

Prior to analysis, data were evaluated for both model-based and non-model based multivariate outliers using a mean leverage score cutoff of four times the mean centered leverage value and standardized df beta values greater than an absolute value of 1.0 respectively (Jaccard \& Wan, 1993; Bollen \& Long, 1993). No significant outliers were found. Normality was evaluated using univariate indices of skewness and kurtosis and Mardia's index for multivariate normality (Mardia, 1970). No skewness and kurtosis values were found above 1.96 and Mardia's test was non-significant.

\section{Structural Equation Modeling}

The model in Figure 4 was evaluated using fit statistics following recommendations of Bollen and Long (1993). Examination of fit indices uniformly 
suggest a good fit for the model; chi-square value was not significant, $\mathrm{X}_{2}(24)=22.50$, $\mathrm{p}=.55$; the root mean square error of approximation was less than .001, the $\mathrm{p}$-close test was .95 , and the comparative fit index was 1.00 . The loadings for our latent construct of mental health all exceeded the minimum cutoff value of .3; however, conduct and hyperactivity loaded more highly than did emotional difficulties and thus accounted for more of the variance in the latent construct, which makes sense given that the conduct and hyperactivity scales both describe symptoms of externalizing disorders, while the emotional difficulties scale reflects internalizing symptoms. Because we expect both externalizing and internalizing symptoms to be affected by, and to affect, the other measures of interest in the model in similar ways, and because formal diagnoses are typically not available when working in a classroom setting, we chose to model these symptoms as a single latent factor.

Analysis of the path coefficients revealed several significant pathways. Table 1 presents the unstandardized and standardized path coefficients, and significance values for the model. Seven of the twelve proposed pathways were found to be significant. Selfconcept (social, behavioral, academic), academic motivation, and mental health symptoms were measured at T1. Engagement and study skills were measured at T2. Social self-concept and behavioral self-concept related positively and significantly to academic self-concept, such that higher ratings of social and behavioral self-concept predicted higher academic self-concept scores. The model accounted for $19 \%$ of the variance in academic self-concept scores. Behavioral self-concept also related to both academic motivation and mental health symptoms, with higher ratings of behavioral self- 
concept correlated with increased motivation and decreased mental health symptomatology. The model accounted for $8 \%$ and $16 \%$ of the variance in academic motivation and mental health symptoms, respectively. Mental health symptoms at Time 1 predicted study skills at Time 2, with higher mental health symptoms correlating with lower study skills. Finally, academic motivation and self-concept at Time 1 predicted engagement at Time 2, with higher ratings of motivation and self-concept correlating with increased engagement. The model accounted for $13 \%$ and $46 \%$ of the variance in academic engagement and study skills, respectively.

The joint significance test paradigm was used to test indirect effects of social and behavioral self-concept on academic engagement and study skills. The joint significance method for testing mediation is recommended over other methods as it offers low Type I error rates while maximizing statistical power (MacKinnon, Lockwood, Hoffman, West, \& Sheets, 2002). This method simultaneously examines the significance of paths from the focal independent variable to the intervening variable and from the intervening variable to the dependent variable. Results indicated that behavioral self-concept predicted both academic engagement and study skills. Higher ratings of behavioral self-concept predicted higher ratings of engagement through academic self-concept and academic motivation. Higher ratings of behavioral self-concept also predicted higher ratings of study skills mediated by lower mental health symptoms.

\section{Discussion}

The current study examined longitudinal associations among self-concept, mental health symptoms, and indicators of academic achievement. Consistent with predictions, 
children's non-academic self-concepts was meaningfully related to academic functioning, mediated both by academic self-concept and mental health symptoms, offering support for the proposed theoretical framework and the first evidence, to our knowledge, of these mediated relationships in elementary school children. More specifically, children's behavioral self-concept related positively to academic self-concept and academic motivation, and negatively to mental health symptoms. Children who endorsed positive behavioral self-concept also endorsed high academic motivation, and their teachers reported fewer mental health symptoms compared to children who endorsed a negative behavioral self-concept. Behavioral self-concept also predicted both academic engagement and study skills. Thus, children who believe they behave well also believe they are competent in school, and have fewer symptoms of anxiety, depression, and disruptive behavior disorders; they also subsequently display more engagement in school, and better study skills. The current study offers initial evidence to support a flexible model of non-academic self-concept in children and its connection to important indicators of academic achievement. The results also suggest, perhaps most critically, that non-academic self-concept earlier in the school year has meaningful implications for student performance later in the school year.

The idea that children's views of themselves and their capabilities in a specific domain (e.g., academic) affect their subsequent performance in that domain is not a new one, and is consistent with findings of previous research. The current study expands on this by showing that a child's positive view of oneself in one subdomain predicts improvement over time in another subdomain. If a child views herself as being 
competent in behavior, that belief can affect their engagement in schoolwork and their ability to study, both meaningful components of academic success, through higher academic self-concept and fewer mental health symptoms, both of which also predict academic outcomes. This suggests that a change in the way a child views herself in one area may lead to subsequent improvement in other areas-once a child believes they can behave well, they may start to believe they can learn well.

Five of the proposed pathways were non-significant. Social self-concept, in particular, was significant only in one of three proposed pathways in the original model. However, it is noteworthy that McConnell's (2011) model would suggest a closer relationship between subdomains as attributes are shared between them. For younger children, though, attributes that commonly correspond to the self in a social context may be farther removed from the academic self than the behavioral self-aspect would be, as behavior and academic success are both monitored and reinforced directly by the teacher in a classroom setting. Further study is needed to more fully assess the self-aspects of central importance to children and their relationship to academic and other functional outcomes.

Previous research often has viewed academic self-concept as discrete from nonacademic self-concept (Marsh \& Shavelson, 1985), with each having a limited effect on the other. Findings here suggest the connection between non-academic and academic self-concept can be both significant and predictive for elementary school children, lending additional support to McConnell's (2011) self-aspect model. In particular, behavioral self-concept, which is a subdomain in which we would expect children to have 
a high perception of internal control, relative to others, is related to academic motivation, mental health, academic self-concept, engagement, and study skills. This suggests that behavioral self-concept may be a meaningful target for direct intervention.

Examinations of self-concept from a clinical psychology perspective typically focus on self-esteem or self-worth, as vulnerabilities in these global indices often correlate with depression and other disorders in children (Dumont \& Provost, 1999; Harter, 1993; Marsh et al., 2004). However, these indices are often less useful in predicting functional outcomes, such as academic success (Baumeister et al., 2003). The results of the current study demonstrate a meaningful relationship between non-academic self-concept and academic success through mental health symptoms, and the correlation between the two may hint both at the additive power of intervening on mental health needs together with academic ones to improve outcomes, as well as the potential utility of non-academic self-concept as a direct target for intervention to address both academic and mental health concerns concurrently. Our results help bridge the gap between social, personality and clinical literatures, such that suggestions from the former about the utility of a multidimensional model of the self (O'Mara, Marsh, Craven, \& Debus, 2006) may help increase the power and reach of self-concept as a lever for change in mental health and educational interventions.

\section{Implications for Intervention}

Targeting non-academic self-concept as a lever for change may hold several potential advantages for prevention and intervention. We earlier described Cohen's (2006) original intervention for 7 th grade students, in which a brief self-concept 
intervention targeting non-academic self-concepts identified as important by each student led to improved academic performance as measured by GPA at the end of the school year. Follow-up data suggest that benefits extended beyond end of the academic year and may be self-reinforcing over time, reflecting a positive feedback loop that helps to sustain intervention effects (Cohen, Garcia, Purdie-Vaughns, Apfel, \& Brzustoski, 2009). Several others have adapted this intervention paradigm and replicated these findings with junior high, high school and college students. Preventative interventions that target selfconcept to improve academic functioning are especially appealing because they offer high impact while remaining low-cost in terms of money, materials, time, and training.

Academic success is a significant protective factor for a host of negative outcomes (Bureau of Labor Statistics, May 22, 2013; Thornberry, 1985) and has a reciprocal relationship with academic self-concept (Filozof et al., 1998; Marsh \& Yeung, 1997); therefore, a low-cost, high-reach intervention tool that leverages self-concept and improves academic outcomes may offer a new direction for serving children whose mental health needs otherwise interfere with learning and related outcomes. This may be especially meaningful for low-income communities where, historically, mental health needs are high and resources available are low. In fact, children in poverty receive fewer services despite greater mental health need (Kataoka, Zhang, \& Wells, 2002) and teachers frequently lack sufficient training or resources to minimize the extent to which students' mental health symptoms interfere with teaching and learning. As such, a universal level prevention tool that teachers can deliver in a classroom setting without additional training may help to serve many children who would benefit from increases to 
their non-academic self-concept. We do not suggest that self-concept intervention, especially brief intervention, by itself will suffice to treat mental health disorders in children and adolescents; however, the potential addition of supplemental intervention tools like those we are proposing here may offer high appeal for teachers for their ease of use and high return on investment. The current study highlights the meaningful role mental health symptoms play in mediating the relationship between behavioral selfconcept and academic outcomes for children and suggests that similar opportunities for brief self-concept interventions may hold utility in elementary school classrooms, as part of a more comprehensive and multi-level mental health framework for schools. This may be particularly true for underserved children; in Cohen's original study (2006), the effects showed for minority students, but did not reach significance for the Caucasian children, and the children at highest risk - those who had previously experienced greater difficulty in school, and who the authors conceptualized as having the highest risk levels for failure - showed the greatest amount of improvement. In other words, the children who were most vulnerable had the most to gain from this type of intervention. The results of the current study suggest that relationships between subdomains of the self-concept are operating even in older children, not just adolescents; as such, this type of intervention may be efficacious with younger groups than previously thought.

Self-concept interventions also can be tailored to fit each child as an individual, utilizing their existing strengths and interests, even when delivered to large groups in natural settings (e.g., schools). Moreover, if brief intervention targeting behavioral selfconcept can bolster academic self-concept and influence academic improvement, then we 
may want to consider a wider variety of settings (e.g., after school programs) and activities (e.g., sports, music, theatre) where opportunities to leverage specific selfaspects may be even more salient, presenting other untapped opportunities to improve self-concept and, in turn, academic trajectories. For example, children who join a school sports team and perform well would likely show a high athletic self-concept; reinforcing this self-concept via brief intervention may subsequently bolster academic self-concept (via traits associated with both subdomains) and help the child to feel more efficacious and capable in school, helping to contribute to future success. As another example, given the strong connection between behavioral self-concept, mental health symptoms and academic outcomes in the current model, a brief opportunity for children at the beginning of the year, or during the school week, to succeed in a behavioral task and receive specific reinforcement for that success, might help to improve behavioral self-concept (again via traits associated with both subdomains) and subsequent academic functioning.

Previous research on self-concept intervention suggests that self-concept itself is difficult to change. Both self-affirmation theory (Steele, 1988), on which Cohen's original intervention relies (Cohen et al., 2006), and cognitive behavioral therapy, acknowledge that efforts to challenge negative thoughts about oneself in a particular domain show less chance of success when the new thoughts being introduced conflict with reality. As echoed by self-affirmation theory, however, bolstering self-concept in an area where children do show real strengths or success may help to subsequently improve their outlook and functioning in other areas, which the results of the current study would support. Thus, intervening on non-academic self-concept, rather than academic self- 
concept directly, may offer some additional utility toward modifying academic selfconcept and subsequent academic achievement.

\section{Limitations}

The results of the current study should be interpreted with caution, given certain limitations of its design. First, reflecting effort to minimize interference with instructional time and response burden for students and teachers, only certain subscales from the Harter Self-Perception Scales and the ACES were selected for administration in the parent study. In addition, GPA or objective academic performance data were not available at any time point; therefore, the variables included in the current analyses do not fully describe the multiple self-aspects commonly present in children, nor do they provide a complete picture of their relationship to academic success. However, this is balanced by the relative psychometric strength of these measures, and their wide acceptance within the respective disciplines of each. We believe the measures used herein offer a sufficient approximation of the constructs of interest, and allow for a reasonable claim as to the appropriateness of further examination of the model and its practical implications for future research.

Second, the reliability scores for the Self Perception Profile for Children items were low, particularly for the Social subscale. Even though these items have been normed for the age group examined here, other studies have shown children in this age range to have difficulty with these scales (Bureau of Labor Statistics, 2014), and for these children, many of whom are reading below grade level, the scale may have been overly complex. Nevertheless, we found significant results tied to all of the Harter subscales, 
though further research with other samples and/or with other measures of self-concept is warranted.

Third, data were collected as part of an intervention study, which introduced a potential confound. Treatment and control groups were collapsed, though most measures were collected at Time 1 and we controlled for intervention effects in the analyses. Further, reliance on only two time points of data limits conclusions that can be drawn regarding mediation. Though two time points are sufficient, three time points are considered preferable (Cole \& Maxwell, 2003); thus, further examination of longitudinal relationships among social and behavioral self-concept, mental health symptoms, and indicators of academic achievement is warranted. Still, we are encouraged by findings that point to potential new opportunities for self-concept interventions.

Finally, the challenges associated with obtaining student and parent consent in struggling schools coupled with our eligibility restrictions produced a relatively small sample that represented $30 \%$ of eligible students and to some extent minimizes generalizability of the findings. Though the sample was adequately powered, and while we made every attempt to remain as inclusive as possible given data available from the parent study, nevertheless, results here should be interpreted with caution until they can be replicated with a larger and more complete sample.

\section{Directions for Future Research}

These results suggest several directions for future research. Further examinations of these relationships in clinical samples, both with internalizing and externalizing 
disorders, would be highly useful, and may offer further insight into how these relationships interact when psychopathology is particularly severe. Additionally, analysis of these relationships using additional time points, to fully explore the mediating effect of academic self-concept and mental health symptoms on non-academic self-concept's relationship with academic functioning, will help to reinforce and to better understand the connections identified here. Given the changes in self-concept over time and across major life changes, tracking these variables and their impact longitudinally as children move into early and lade adolescence would also be highly useful, and may help to identify when and where to best use these relationships from an intervention perspective. Lastly, connections with other subdomains of self-concept—-such as filial self-concept (the belief about one's self as a son or daughter) or athletic self-concept—should also be explored, toward ultimately identifying and prioritizing which subdomains may be particularly useful, relevant, or accessible as targets for intervention.

Every learning opportunity offers children information not only about the outside world, but about themselves and their relationship to it - just as they assimilate new information into existing knowledge, so too do new experiences change their views on, and expectations of, themselves. Thus, to foster academic achievement in children, they must acquire the skills and develop attitudes and processes to build resilience, overcome challenges, and continue to grow in the face of adversity. The current study suggests that these lessons need not be learned solely through prior success in school, but rather can happen anywhere a child is given an opportunity to succeed, and learn they can do so. 


\section{Tables and Figures}

Table A1. Correlations Among and Descriptive Statistics for Key Study Variables

\begin{tabular}{|c|c|c|c|}
\hline Parameter Estimates & Unstandardized & Standardized & $p$ \\
\hline $\begin{array}{l}\text { T1 Social Self-Concept } \rightarrow \text { T1 Academic } \\
\text { Motivation }\end{array}$ & .12 & .015 & .831 \\
\hline $\begin{array}{l}\text { T1 Behavioral Self-Concept } \rightarrow \text { T1 Academic } \\
\text { Motivation }\end{array}$ & 1.941 & .284 & $.001 * * *$ \\
\hline T1 Social Self-Concept $\rightarrow$ T1 ASC & .209 & .192 & $0.004 * *$ \\
\hline T1 Behavioral Self-Concept $\rightarrow$ T1 ASC & .324 & .343 & $<.001 * * *$ \\
\hline $\begin{array}{l}\text { T1 Social Self-Concept } \rightarrow \text { T1 Mental Health } \\
\text { Symptoms }\end{array}$ & -.567 & -.123 & .323 \\
\hline $\begin{array}{l}\text { T1 Behavioral Self-Concept } \rightarrow \text { T1 Mental } \\
\text { Health Symptoms }\end{array}$ & -1.41 & -.352 & $<.001 * * *$ \\
\hline T1 Academic Motivation $\rightarrow$ T2 Study Skills & .217 & .1 & 0.216 \\
\hline $\begin{array}{l}\text { T1 Academic Self-Concept } \rightarrow \text { T2 Study } \\
\text { Skills }\end{array}$ & .79 & .05 & 0.471 \\
\hline $\begin{array}{l}\text { T1 Academic Motivation } \rightarrow \text { T2 Academic } \\
\text { Engagement }\end{array}$ & .377 & .257 & $.005^{* *}$ \\
\hline $\begin{array}{l}\text { T1 Academic Self-Concept } \rightarrow \text { T2 Academic } \\
\text { Engagement }\end{array}$ & 1.376 & .13 & $.04 *$ \\
\hline $\begin{array}{l}\text { T1 Mental Health Symptoms } \rightarrow \text { T2 Study } \\
\text { Skills }\end{array}$ & -2.246 & -.608 & $<.001 * * *$ \\
\hline $\begin{array}{l}\text { T1 Mental Health Symptoms } \rightarrow \text { T2 Academic } \\
\text { Engagement }\end{array}$ & -.378 & -.151 & .209 \\
\hline Measurement Model & & & \\
\hline $\begin{array}{l}\text { Conduct Problems } \rightarrow \text { Mental Health } \\
\text { Symptoms }\end{array}$ & -- & .685 & $<.001 * * *$ \\
\hline $\begin{array}{l}\text { Emotional Disturbance } \rightarrow \text { Mental Health } \\
\text { Symptoms }\end{array}$ & -- & .318 & $<.001 * * *$ \\
\hline Hyperactivity $\rightarrow$ Mental Health Symptoms & -- & .871 & $<.001 * * *$ \\
\hline
\end{tabular}

Notes. $* p<.05 ., * * p<.01, * * * p<.001$. ASC $=$ Academic Self-Concept 


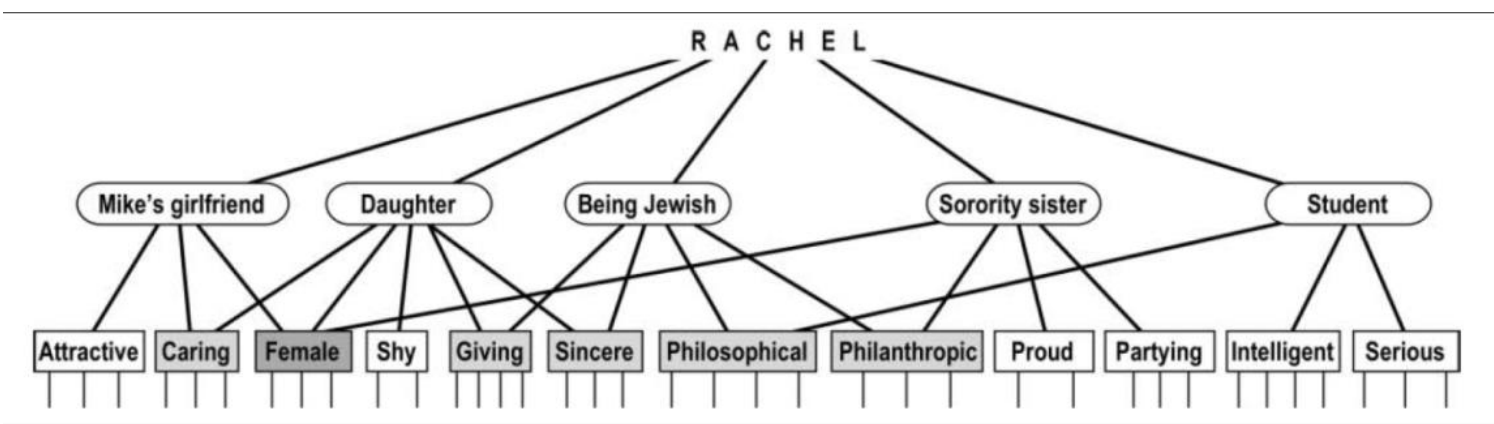

Figure A1. Example self-aspect map for a hypothetical student, Rachel (McConnell, 2011). 


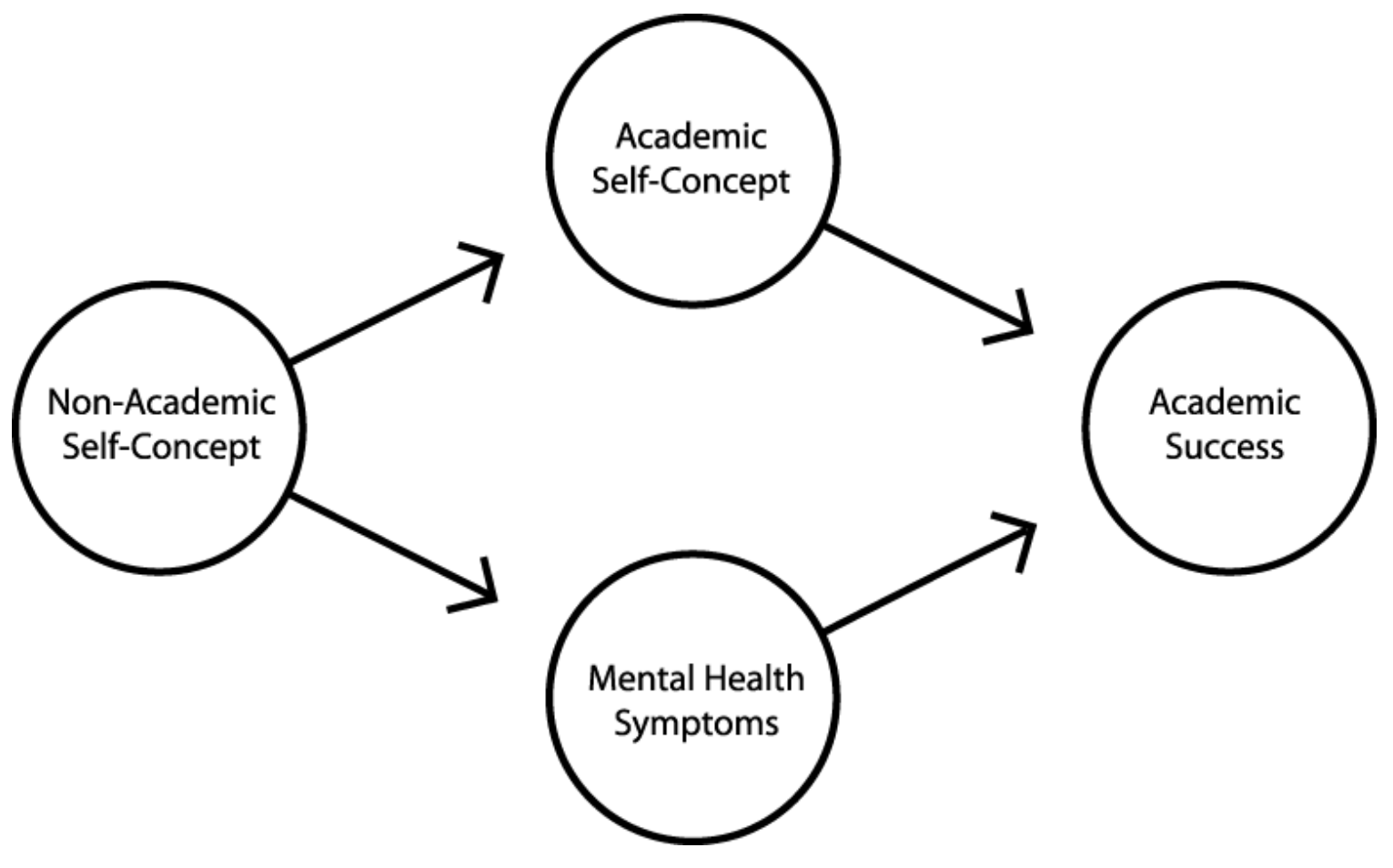

Figure A2. Theoretical model. 


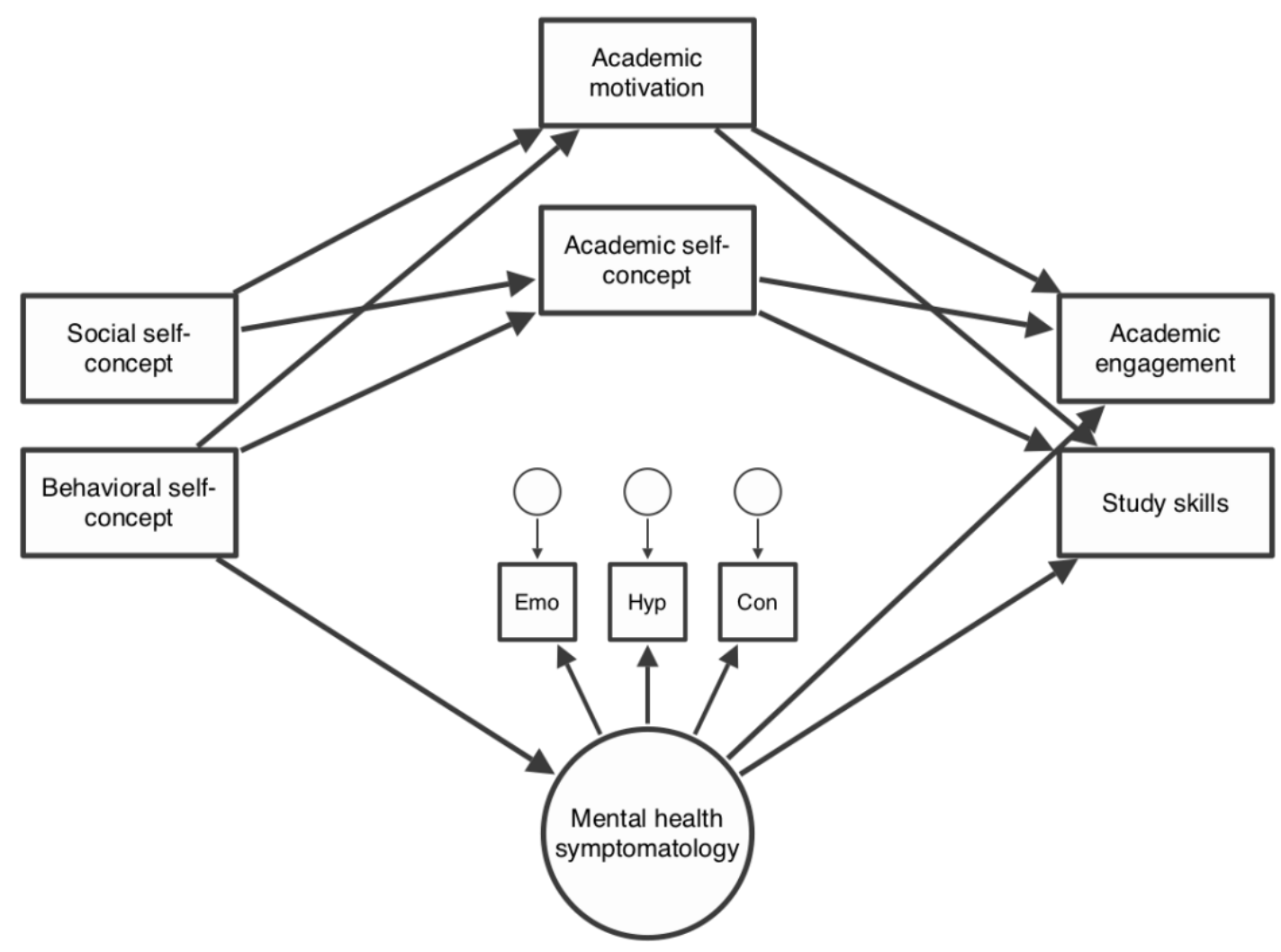

Figure A3. Predicted associations among social and behavioral self-concept, academic self-concept and motivation, mental health symptomatology, and academic functioning. 


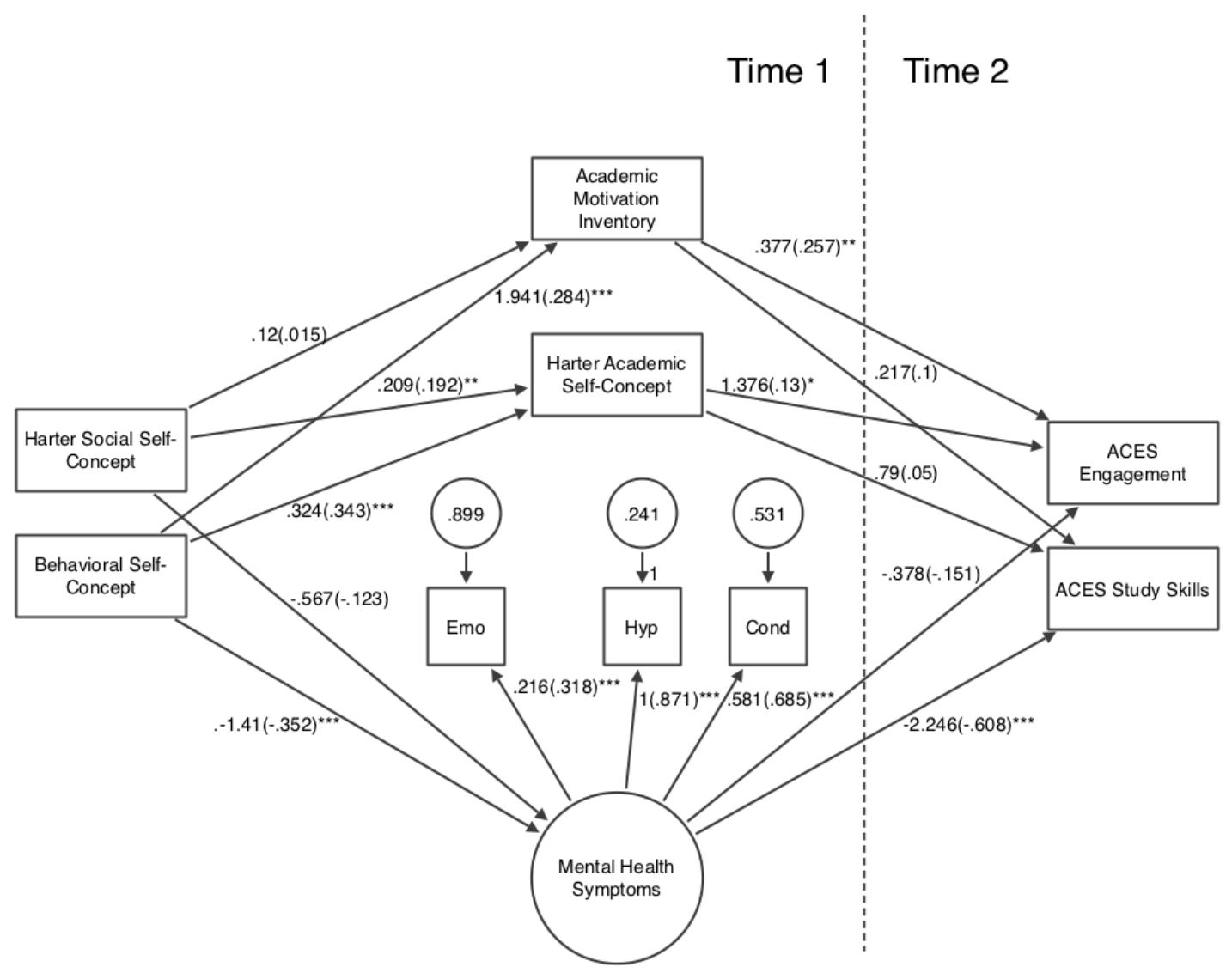

Figure A4. Measurement model with results (standardized in parentheses). Covariate of intervention not pictured. 


\section{NON-ACADEMIC SELF-CONCEPT IN ADOLESCENCE: ASSOCIATIONS WITH ACADEMIC SUCCESS}

This manuscript will be submitted to School Mental Health, and thus adheres to its use of APA 6th Edition formatting guidelines.

Ogle, R.R., Frazier, S. L., \& Prinstein, M. (in preparation). Non-Academic Self-Concept in Adolescence: Associations with Academic Success.

Authors' note: This research was supported in part by a National Institute of Child Health and Development National Research Service Award (F31 HD087066) awarded to Robert Ogle. 


\begin{abstract}
Academic self-concept shows meaningful relationships to academic success in children and adolescents, but the nature of the relationship between non-academic self-concept and academic outcomes in adolescence is less clear. We examined the effect of nonacademic self-concept on academic success as measured by GPA through two mediating pathways: reduction in mental health symptoms, and improvement in academic selfconcept. Two hundred thirty-eight students from a middle-class suburban middle school answered questionnaires on their self-concept and mental health at two time points, as well as academic data from school records. Results indicate that non-academic selfconcept may affect academic self-concept, though evidence for effect on GPA did not emerge. Implication of these results as they relate to adolescent development are discussed.
\end{abstract}

Keywords: Self-Concept, Adolescence, Structural Equation Modeling, Academic Success

Non-Academic Self-Concept in Adolescence: Associations with Academic Success

\title{
Introduction
}

Graduating from high school remains one of the most important milestones for an adolescent to achieve. Compared to those who graduate from high school, teens who drop out of school experience increased risk across multiple domains: they are more likely to be underemployed, unemployed, or receiving government assistance (Bridgeland, DiIulio Jr, \& Morison, 2006; Sum, Khatiwada, McLaughlin, \& Palma, 2009); they are more likely to be involved in the justice system (Bridgeland et al., 2006; Sum et al., 2009); and are more likely to engage in risky health behaviors and to have a lower life expectancy 
(Freudenberg \& Ruglis, 2007b). Teens who fail to complete high school also experience increases in negative mental health symptoms (Kaplan, Damphousse, \& Kaplan, 1994). Identifying factors that can increase academic success and reduce high school dropout, therefore, may offer broad-reaching and powerful levers for change to improve the lives of adolescent high school students.

\section{Self-Concept and Academic Success}

Self-concept, or the mental representation that a person has of him or herself, demonstrates strong bidirectional relationships with academic outcomes (H. W. Marsh \& Seaton, 2013). For instance, investigators found in a large sample of fifth grade students in Germany ( $\mathrm{n}=1508$ ) strong support both for effects of reading self-concept on reading achievement, as well as reading achievement on reading self-concept (Retelsdorf, Köller, \& Möller, 2014). A meta-analysis of the effect of self-belief on subsequent achievement showed a small effect size at the global level, with effect sizes increasing as more specific self-beliefs were measured (e.g., math self-concept more strongly predicts math performance than does overall academic self-concept) (Valentine, DuBois, \& Cooper, 2004a).

In these examples, as in much of the recent research on self-concept, the relationships demonstrated are between academic self-concept, or how a person evaluates themselves with regard to academic ability, and academic achievement. Associations between academic self-concept and academic achievement reflect the notion that more specific areas of self-concept more strongly and closely correlate with related areas of functioning (Valentine et al., 2004a). Theories modeling differentiated areas of the self

have been well supported over several decades of research (H. W. Marsh \& Seaton, 2013; 
H. W. Marsh \& Shavelson, 1985; H. W. Marsh \& Yeung, 1997; Shavelson, Hubner, \& Stanton, 1976a), and from the earliest demonstrations of the differentiated model (Shavelson et al., 1976a), it has been widely accepted that academic self-concept remains separate from other areas of the self (e.g., social, behavioral, athletic). General academic self-concept, then, might relate to reading or math self-concept, but not to a student's perception of themselves as a soccer player or a romantic partner.

However, recent work challenges this assumption. In particular, McConnell (2011) suggests that two interconnected layers compose the self: the aspect layer, containing roles or identities (e.g., student, athlete, actor, woman) and the trait layer, containing personal characteristics (e.g., intelligent, caring, strong). In McConnell's model, aspects do not directly relate to other aspects, nor do traits to other traits, but instead, aspects and traits relate to one another. Strong, determined, and competitive traits might be connected to the athlete aspect, or caring, wise and loving traits to the mother aspect. Critically, an aspect can be related to multiple traits, and a trait may connect to several different aspects. McConnell (2011) in a large emerging adult sample found that when a person's appraisal of themselves in a given aspect improves, their perception of their associated traits also improves, and the reverse was also true.

Importantly, these findings challenge assumptions of prior models by allowing for changes in areas of self-concept to influence other areas of the self through shared traits. For example, if a person's sense of self as a student and as an athlete both connect to the determined trait, then improving a person's sense of themselves as an athlete may also bolster their sense of determination, which in turn would reinforce their self-aspect of student. Given the relationship between academic self-concept and academic success, 
these findings may suggest that improving non-academic self-concept may offer a pathway for improving academic outcomes.

\section{Mental Health, Academic Success and the Self}

Mental health disorders also rank amongst the most powerful influencers of academic outcomes. A nationally representative sample of 5,691 adults found that emotional and behavioral disorders predicted school dropout at every level of educational attainment, from primary school through completion of undergraduate education (Breslau, Lane, Sampson, \& Kessler, 2008). In that study, students with an identified psychological disorder were seven times more likely to fail to complete a given educational milestone than their non-disordered peers. Nearly half of all high school students will experience a mental health disorder by age 18 , with $22 \%$ experiencing a disorder with severe impairment and over $40 \%$ experiencing comorbid disorders (Merikangas et al., 2010); hence, tools that help to reduce or prevent mental health symptoms may also be useful in promoting academic success.

Self-concept relates not only to academic success through the relationship with academic self-concept, but also to mental health symptomatology. A large body of evidence examines the relationship between global self-esteem, or a person's feeling of self-worth as a "good" or "bad" person, and mental health symptoms. A meta-analysis of longitudinal studies showed low self-esteem strongly predicts depressive symptoms, while low self-esteem and anxiety show a reciprocal relationship where each influences the other (Sowislo \& Orth, 2013). Consistent with the literature around academic selfconcept and achievement, evidence from a Canadian study of 903 junior high students also suggests from self-report that the predictive power of self-concept on mental health 
increases as more specific parts of the self are considered, even when controlling for global self-esteem (Marsh, Parada, \& Ayotte, 2004).

These associations inform the theoretical model presented in Figure 1. Given the potential for non-academic areas of self-concept to influence both mental health symptomatology and academic self-concept, and for mental health symptoms and academic self-concept to influence academic success, we suggest that non-academic selfconcept can affect academic outcomes through pathways mediated by academic selfconcept and mental health symptoms. Indeed, among a public school sample of 364 ethnically diverse K-5th grade children (Ogle, Frazier, Nichols-Lopez, Cappella, \& LINKS, 2016), both social and behavioral self-concept showed significant relationships with indicators of academic success. Social self-concept predicted academic engagement through an indirect relationship with academic self-concept, and behavioral self-concept predicted improvement in engagement through an indirect relationship with academic self-concept and in study skills through an indirect relationship with mental health symptomatology. The question remains as to whether similar relationships hold for the critical window of adolescence, or impact academic trajectories for high school students.

\section{Self-Concept in Adolescence}

Adolescence is a period of significant change in self-concept, driven by significant ongoing hormonal, neurological and cognitive development and their interaction with environmental factors. These changes may in turn modify the relationship between self-concept and academic success. As teens continue to develop cognitively, they become more capable than younger children of differentiating between parts of themselves and evaluating those areas of the self independently (e.g., feeling that 
a person is a great athlete but poor student) (Steinberg \& Morris, 2001). A large longitudinal cohort study of two waves ( $\mathrm{n}=936$ and 984 respectively) revealed that academic, social, physical appearance and sports self-concept structures all became less stable as children entered adolescence, with a general trend downward as they begin to evaluate themselves with increasing cognitive capacity (Cole et al., 2001). They also begin to preferentially select areas of focus that align with their perceived competency, in order to maintain positive self-concept in domains where they perform well (Cole et al., 2001). As such, areas that traditionally appeal to younger children, or areas that demonstrate overlap in young children, may not demonstrate the same relationships in adolescence.

The social context also becomes increasingly important as children enter adolescence and begin to give more importance to the opinions of peers (Somerville, 2013). As romantic partnerships form and behavioral pressures (e.g., risky behavior, substance use, sexual activity) increasingly influence social acceptability within the peer group, the relative importance of different areas of the self also begins to change (Cole et al., 2001). Social desirability of different aspects of the self may further change or complicate relationships between different areas of self-concept. As such, understanding the connections between various self-aspects in adolescence may help to elucidate the utility of those connections as potentially meaningful levers for change.

\section{Current Study}

The current study examined the direct relationships between non-academic selfconcept in adolescents on academic self-concept and both internalizing and externalizing mental health symptoms, and the indirect relationships of non-academic self-concept on 
academic performance as measured by grade point average. We hypothesized that nonacademic areas of self-concept would influence academic success through two pathways: through protection against mental health symptomatology as indicated by lower selfreported depression and externalizing behaviors, and through higher academic selfconcept that would in turn related to higher academic success as measured by GPA.

\section{Methods}

All data collection procedures were conducted in accordance with APA Ethical Guidelines and under supervision of both the university's institutional review board and school district's research review board (\#IRB-16-0290-CR01).

\section{Participants}

Participants were 478 students at one middle class suburban middle school who enrolled in a larger study of relationships between negative feedback seeking and depressive symptoms in adolescents (Borelli \& Prinstein, 2006). The sample was 51\% female, $87 \%$ Caucasian, $4 \%$ Asian-American, 2\% African-American, 2\% Latino, and 6\% identifying as multi-ethnic, and $11 \%$ of students received free or reduced lunch. All students in grades 6,7 and $8(n=831)$ were invited to participate in the original study; of these, 784 students (92\% of all eligible students) returned completed consent forms. Of these, 652 (83\% of returned consents) agreed to participate. Of these, 44 students (7\%) withdrew or failed to complete data collection at Time 1, resulting in a final Time 1 sample of 583 students. Time 2 data collection took place 11 months later; of the 583 students with complete data at Time 1, 95 were missing data at Time 2; specifically, 5 withdrew, 36 relocated prior to Time 2 data collection, and 54 provided incomplete data, leaving a Time 2 sample of 478 students with complete data on all variables utilized in 
the original study analyses. The current study retained all consented students for a final sample of 652 .

\section{Measures}

Self-Perception Profile for Adolescents. The Harter Self-Perception Profile for Adolescents (SPPA) (Susan Harter, 2012) is a 45-item self-report scale adapted from the Self-Perception Profile for Children. The scale assesses the student's own perspective of themselves across eight specific domains of particular importance during adolescence, as well as the student's global self-worth. Each item contains a statement that describes two groups of teens and asks the student to identify which group is more like them, and how much (whether the defining characteristic of that group is "Really True" or "Sort of true" for the student). For example, an item assessing academic self-perception reads "Some teenagers feel that they are just as smart as others their age BUT other teenagers aren't so sure and wonder if they are as smart." The items are then coded from 1 to 4 , with 1 representing lower levels of positive self-perception and 4 representing a higher selfperception. Eight subscales include Scholastic, Social, Athletic, Job Competence, Physical Appearance, Romantic Appeal, Behavioral Conduct and Close Friendship. Subscale scores are derived by averaging responses from individual items. Harter and colleagues (2012) reported acceptable reliability, with Cronbach's $\alpha$ scores ranging from .74 to .92 in large, nationally representative samples, as well as factor analysis showing strong evidence for internal validity. The original study used a 21 -item modified version that captured the Scholastic Competence $(\alpha=.983)$, Social Competence $(\alpha$ $=.985)$, and Physical Attractiveness $(\alpha=.978)$ subscales, as well as the Global scale of self-esteem $(\alpha=.984)$. 
Child Depression Inventory. The Beck Child Depression Inventory (CDI)

(Kovacs, 1992) is a 27-item self-report measure adapted from the original Beck

Depression Inventory for adults. The CDI assesses symptoms and common sequelae of Major Depressive Disorder and Dysthymia across five factors: Negative Mood, Ineffectiveness, Negative Self-Esteem, Interpersonal Problems, and Anhedonia. Students are asked to rate responses to questions on a 0 to 2 scale (e.g., "I am sad once in a while", "I am sad many times", and "I am sad all the time" corresponding to 0,1 and 2 respectively). The test generates both individual factor subscores (derived by summing the individual items) and a total score of depressive symptoms (via summing all items from the questionnaire). The CDI has been tested extensively with youth across age groups and demographics and has strong evidence to suggest its utility not only as a screener for mental health issues, but as a diagnostic tool, when symptoms rise above a total symptom cutoff score. Kovacs and colleagues reported strong evidence of validity and reliability in their original work; $\alpha=.88$ for the current sample. Total Score was used in the model.

Disruptive Behavior Questionnaire. The original authors adapted the SelfReported Delinquency questionnaire (Elliott \& Ageton, 1980) to create the Disruptive Behavior Questionnaire (DBQ; Borelli \& Prinstein, 2006). The DBQ is a 15-item selfreport measure that asks students about their frequency (e.g., never, once, more than three time) of participation in a variety of risky behaviors typical of youth presenting with externalizing disorders over the course of the previous year (e.g., lying, stealing, illegal drug use, alcohol use, risky sexual behavior). The measure yields a sum score of risk behavior and captures severity of externalizing behavior. Psychometrics have been 
reported previously (Elliot \& Ageton, 1980); reliability for the current sample was high $(\alpha=.998$ at Time 2$)$.

Academic Records. Cumulative Grade Point Averages (GPA) were obtained directly from students' hard copy school records at Time 2.

\section{Procedure}

All students in a middle-class suburban middle school were invited to participate in the original study. The self-report measures were delivered to students during late Fall of the academic year (Time 1) and during the Fall of the following academic year (Time 2). Self-report measures were completed by students either in their classrooms during regular instructional time or during a school assembly at both time points; research staff were available for assistance as needed. GPA data was collected from electronic records by research staff. Students who participated received a lanyard as compensation.

\section{Data Analysis}

Data analysis was conducted using the Latent Variable Analysis (Lavaan) package within the statistical program R. Missing data was handled using Full Estimation Maximum Likelihood (FIML). The model in Figure B2 was estimated using a maximum likelihood estimator and robust standard errors. Bootstrapping of standard errors was used with 1000 draws to minimize the effect of sampling error.

\section{Results}

The model in Figure 2 was evaluated using fit statistics consistent with the recommendations of Bollen and Long (Bollen \& Long, 1993). Both absolute indices of fit indicate poor fit: the standardized root mean square residual was .082, and the chi-square test was highly significant, $\mathrm{X}_{2}(24)=47.27, \mathrm{p}<.000$. The root mean square error of 
approximation was $.250,90 \%$ CI .191-.215, and the comparative fit index was .497 , well below the suggested threshold of .9 (Bollen \& Long, 1993). However, given that the current analysis is a path model, poor model fit does not preclude the analysis of individual paths (as non-significant relationships will negatively affect fit while remaining interpretable); thus, analysis of the model is presented below.

Path coefficient analysis results are presented in Table B1. The analysis revealed significant pathways between several points in the model. Social self-concept at Time 1 predicted academic self-concept at Time $2(B=.334,95 \%$ confidence interval: .234, .449). Physical attractiveness self-concept at Time 1 predicted academic self-concept at Time $2(B=.283,95 \%$ confidence interval: $.209, .356)$ and depressive symptoms at Time $2(B=-2.463,95 \%$ confidence interval: $-3.753,-.926)$. Global selfconcept at Time 1 predicted academic self-concept at Time $2(B==.308,95 \%$ confidence interval: .205, .408), externalizing symptoms at Time $2(B=.334,95 \%$ confidence interval .187, .489), depressive symptoms at Time $2(B=3.266,95 \%$ confidence interval $1.658,4.974)$, and GPA at Time $2(B=.974,95 \%$ confidence interval .380, 2.016). Depressive symptoms at Time 2 correlated with GPA at Time 2 ( $B$ $=-.15,95 \%$ confidence interval $-.486,-.020)$. None of the other tested relationships were significant; complete results are available in Table B1. The final measurement model with unstandardized coefficients and 95\% confidence intervals is available in Figure B3.

The joint significance test paradigm was used to test indirect effects of nonacademic self-concept domains on GPA through mental health symptom scores and academic self-concept. Because indirect effects are not normally distributed, confidence interval interpretation was used to determine results. Two of the proposed indirect effects 
displayed $95 \%$ confidence intervals that did not include zero, suggesting meaningful relationships. Physical attractiveness self-concept at Time 1 predicted Time 2 GPA through depressive symptoms at Time $2(B=.370,95 \%$ confidence interval: $.039,1.199)$, such that higher attractiveness concept at Time 1 displays a positive association with GPA at Time 2 through a negative association between Time 1 attractiveness self-concept and Time 2 depressive symptoms, and a negative correlation between Time 2 depressive symptoms and Time 2 GPA. Global self-concept at Time 1 predicted Time 2 GPA through depressive symptoms at Time $2(B=-.491,95 \%$ confidence interval: -1.781 , -.047), such that higher global self-concept at Time 1 predicts lower GPA at Time 2 via a positive association between Time 1 global self-concept and Time 2 depressive symptoms, and a negative association between Time 2 depressive symptoms and Time 2 GPA.

\section{Discussion}

The current study examined direct and indirect associations among non-academic subdomains of self-concept, academic self-concept, internalizing and externalizing mental health symptoms, and academic success as measured by grade point average in middle school students at two time points. Our findings present mixed support for the model. Consistent with predictions, non-academic self-concept meaningfully related to academic self-concept and to mental health symptoms, and mental health symptoms related meaningfully to academic outcomes. Contrary to our predictions, academic selfconcept did not show significant correlation with GPA. Further, the nature of the relationships presented here overlap somewhat, but not completely, with those observed in elementary aged youth in our previous work. 


\section{Non-Academic Self-Concept and Academic Self-Concept}

Non-academic self-concept was assessed early in the school year and comprised of three domains: social, physical, and global. All of them related to academic selfconcept later in the year. Social, physical and global self-concept at Time 1 related to academic self-concept at Time 2, such that youth who endorsed themselves as socially skilled, physically attractive, or overall good people early in the academic year also reported feeling they were good students in spring. This is consistent with previous findings for elementary school students, suggesting that meaningful associations between non-academic self-concept and academic self-concept may be equally relevant across developmental stages and including adolescence. These findings also highlight differences in theoretical models presented earlier. Recall that Shavelson's model (Shavelson et al., 1976) predicts that global self-concept should relate to academic selfconcept, reflecting that all specific self-concept descends from global self-esteem. The relationship between physical and social self-concept at Time 1 and academic selfconcept at Time 2, however, lends support to a more interconnected framework as presented by McConnell (2011), as these domains would be considered distinct and unrelated in Shavelson's model. This offers support for the potential of non-academic self-concept to become a target for intervention aimed at improving academic selfconcept in adolescence.

\section{Non-Academic Self-Concept: Relationship with Mental Health Symptoms}

Both global self-concept and physical attractiveness self-concept at Time 1 predicted depressive symptoms at Time 2. Youth who reported viewing themselves as more physically attractive subsequently reported lower symptoms of depression, while 
youth who reported viewing themselves as intrinsically good reported higher symptoms of depression the following year. The relationship between physical self-concept and depression is consistent both with our hypotheses and with recent research suggesting lower physical attractiveness predicts distress and depression across the life span (Gupta, Etcoff, \& Jaeger, 2016). While physical attractiveness may not be an ideal target for intervention in schools (much as some adolescents might like school-sponsored makeovers), a recent study on emerging adults ( $\mathrm{n}=4882$, mean age 22 years) in the U.S. demonstrated that the self-reported belief in attractiveness, rather than objective indicators of physical beauty, show a relationship to depressive symptoms. Given that this data captures attitudes, and that physical attractiveness self-concept also predicted academic self-concept in the following academic year, it may be that targeting factors such as acceptance of oneself, body image, or other similar factors for adolescents may have broad-reaching effects, even potentially for academic outcomes. This finding is an important extension of previous work examining the model in younger children, as physical attractiveness self-concept emerges during older childhood and early adolescence in a way not observed in younger children (Harter, 2000).

The positive relationship between global self-concept and depressive symptoms nearly a year later is surprising, especially given the robust literature around self-esteem and depression that suggests youth who report viewing themselves as good or worthy later report lower levels of depression (Rieger, Göllner, Trautwein, \& Roberts, 2016; Sowislo \& Orth, 2013). Several potential factors may help to explain the current results. First, as self-concept is known to vary over time in adolescence (Shapka \& Keating, 2005), it may be that time points were far enough apart for meaningful changes to occur 
in students' lives and self-appraisals, such that global self-concept assessed in one academic year did not relate meaningfully to their mental health functioning in the following academic year. Further, more specific subdomains of self-concept often better predict mental health symptoms (Marsh et al., 2004), as discussed above; it may be that changes in more specific domains may be contributing to changes in mental health symptoms in a way that a global measure of self-worth may not be accurately capturing here. Finally, the instrument used to assess depressive symptoms asks youth to consider their mood and related behavior over only the prior two week period; as such, it does not allow for easy differentiation between transient and persistent symptoms; in tandem with the intensity and variability of emotions in early adolescence (Larson, Moneta, Richards, \& Wilson, 2002), it may be that what is captured here represents variability not tied to the presence of a true disorder, thereby explaining in part why the resulting correlations do not replicate patterns of findings reported in previous studies.

Global self-concept also showed an unexpected relationship with self-reported externalizing symptoms, such that youth who endorsed feeling good or worthy were more likely to report more severe symptoms of externalizing disorders eleven months later. Given that we do not have other reporters to corroborate this data, it should be interpreted with some caution given the tendency of youth with ADHD to under-report symptoms and problems in related functioning (Owens, Goldfine, Evangelista, Hoza, \& Kaiser, 2007; Sibley et al., 2010). Further, risky behavior is often seen as valuable in a social context, making it subjectively important to young adolescents (Knoll, Magis-Weinberg, Speekenbrink, \& Blakemore, 2015). Thus, it may be that risky behavior does not correlate with low self-esteem for young teens, but rather the opposite. For both findings, 
however, it is important to stress that the nature of the prospective model, and absence of repeated measures for all variables, limits our ability to make inferences about change between time points on these factors; further research with a model controlling for more factors is certainly warranted here.

Finally, consistent with our expectations, social self-concept did not predict externalizing or internalizing symptoms.

\section{Non-Academic Self-Concept, Mental Health and Academic Self-Concept: Relationship to Academic Outcomes}

Both direct relationships between mental health symptoms, academic selfconcept, and non-academic self-concept, as well as indirect relationships of nonacademic self-concept through mental health and academic self-concept, were examined here. Several interesting findings emerged. First, and of most surprise, there was not a significant correlation between academic self-concept and GPA. This finding is inconsistent with a large body of previous research demonstrating that connection $(\mathrm{H}$. W. Marsh \& Seaton, 2013). Again, unobserved variables which attenuate the relationship may be at play here, and further work would be warranted to identify what these factors might be. Further, given the reciprocal relationship between academic self-concept and academic outcomes (Marsh \& O’Mara, 2008), it may be that changes in one have not had sufficient time to propagate to the other. Nevertheless, these findings are surprising and deserving of further examination.

Finally, depressive symptoms at Time 2 negatively correlated with GPA at Time 2, such that youth who endorsed depressive symptoms also, concurrently, performed less well in school. These results extend our understanding of the robust relationship between 
internalizing symptoms and academic outcomes for middle school students. Given that symptoms of depression and diagnoses of mood disorders begin to markedly increase during early adolescence (Kessler, Avenevoli, \& Merikangas, 2001), it remains important to recognize the influence these disorders can exert on academic engagement and progress, and to identify ways to mitigate those risks and limit those impacts. The fact that social self-concept did not relate to depressive symptoms is also important. Marsh and colleagues (Marsh et al., 2004) demonstrated that specific areas of the self compared to global self-concept - are better predictors of mental health symptoms. This may mean that a broader set of self-concept data may help to identify which areas most meaningfully influence internalizing symptoms for young teens. However, given that social self-concept did not show any relationship, and that only physical attractiveness predicted externalizing symptoms, the utility of particular areas of the self may be more unique and specific to each individual than previously thought. If this is true, a meaningful way to assess which areas of a teen's self are most important to them could help to guide intervention efficiently around both mental health and academic outcomes and would be an important opportunity for future research. Previous interventions using the self as a lever for change allow students to identify and use what's important to them (Cohen et al., 2006); hence, as the self becomes even more complex and distinct in adolescence, perhaps such personalized interventions become even more critical.

Interestingly, while academic self-concept did not show a meaningful relationship with GPA, global predicted academic self-concept at Time 2, such that youth who report higher perception of self-worth perform better in school nearly a year later. This suggests that the predictive power of global self-concept was not due to an indirect effect through 
academic self-concept. Perhaps, there may be even more reason to consider intervention in ways that promote non-academic self-concept when attempting to improve academic outcomes for adolescents. If academic self-concept is the part of the self that most relates to academic success, then intervention should target it directly. However, the current data suggest that improving non-academic self-concept in youth may have both direct and indirect associations with academic success, which could allow for a more flexible and versatile set of intervention tools to be developed for this population.

\section{Limitations}

Several limitations warrant mention. First, the availability of data representative of the constructs in question, particularly the predictors in question, is limited by the archival nature of the study. Common to secondary data analysis, we were restricted to only two non-global domains of self-concept. While they meaningfully related to academic success, and to a large extent also to mental health symptoms, the current study offered limited opportunity to explore other aspects of self-concept that may be even more influential (e.g., romantic, athletic) during adolescence. Replication with additional predictors may reveal a broader or more nuanced picture.

Second, the prospective model analyzed here does not allow for inferences about change over time, and the lack of academic data from a third time point prevents true testing of mediation, resulting in limited ability to interpret the observed indirect effects. While the model is consistent with much previous work and helps to extend and reinforce previous findings, additional examination with data collected specifically for this purpose, controlling for variables of interest across time points and to test mediation at multiple time points, is an important and worthwhile direction for future work. 
Third, the measure for externalizing symptomatology captured self-reported risky behavior. While many of these behaviors do qualify as symptoms for externalizing disorders (particularly Oppositional Defiant Disorder and Conduct Disorder), and these types of behaviors frequently present in children and adolescents with externalizing disorders, the DBQ used in the original study is not a traditional screening or diagnostic tool for externalizing symptoms. Critically, it does not capture many of the symptoms of Attention Deficit/Hyperactivity Disorder that relate most closely to academic functioning and achievement, and which we would expect to most strongly demonstrate the expected relationships with grade point averages.

Additionally, the measures consist almost entirely of self-report data, which also introduces shared method variance as a potential concern. This is particularly concerning with regards to symptoms of mental health disorders, as previous work has demonstrated that multiple sources of report on symptoms in youth lead to better diagnostic outcomes (Sibley et al., 2012; Silverman \& Ollendick, 2005; Steiner \& Remsing, 2007). Validation of the model with more comprehensive and varied sources of reporting, especially around mental health symptoms, would provide valuable additional information and likely strengthen the overall model.

Finally, the available data do not contain information on trait level ratings or changes. According to McConnell's model (2011), any effect of non-academic selfconcept domains on academic self-concept, and subsequent academic success, would happen through bolstering associated traits such as perseverance, determination, or intelligence. A primary study that collects more of this information, in tandem with accurately capturing more predictors, may help to disentangle some of the complexity 
and point to a more nuanced pattern of meaningful relationships between self-concept, mental health and academic outcomes in middle school students.

\section{Future Research and Concluding Remarks}

The results of the current study suggest several potential pathways for future work. First, an expansion to include additional areas of non-academic self-concept as predictors in the model, particularly ones that may carry more weight in adolescence, would allow us more understanding of which areas of non-academic self-concept matter for teens. Second, adding a measure or set of measures to capture traits, as suggested by McConnell (2011), may help to reveal specific pathways through which areas of selfconcept influence each other. Third, additional measures of mental health symptoms, including teacher and parent as well as self-report, and measures that capture a broader range of symptoms, including anxious symptoms, may provide an opportunity to better understand the relationships between self-concept and mental health. Finally, research with additional time points and repeated measures would allow for true mediation analysis and testing of indirect effects, and would better help to validate the causal effects (if any) on academic outcomes of non-academic areas of the self in adolescence, and how these effects change, maintain or attenuate between childhood and adolescence.

Beyond these tests, a more detailed analysis incorporating importance ratings for areas of non-academic self-concept, as potential moderators of relationships, may help to guide subsequent research and intervention. As teens seek to differentiate themselves from their peers and to establish their identities, their evaluation of which parts of themselves are important, meaningful or valuable to them will likely change. Understanding which parts of themselves teens value more or less could provide 
meaningful moderator data that would allow expansion beyond the current model. Selfidentification of meaningful attributes is a hallmark of self-affirmation intervention tools (Walton, 2014), and understanding how subjective importance of self-concept domains relate to other areas of the self would significantly deepen our understanding of these complex relationships. For example, a youth who values social self-concept as an area of primary importance, but who endorses low social self-concept, might develop symptoms of depression as a result, whereas another youth with similar ratings of social self-concept but low ratings of importance may not. Gathering importance ratings would allow for that sort of analysis, meaningfully advance our understanding, and perhaps help to guide intervention tools or efforts.

Adolescence represents a period of dramatic change in the cognitive, physical, social, academic and environmental domains, and youth perceptions of themselves similarly undergo meaningful change as children mature into teenagers. The results of the current study both help to further illuminate those changes and their implications for students' academic lives, and suggest that further research to better understand those changes and their relationships to student functioning remains warranted. 


\section{Tables and Figures}

Table B1. Path model results

\begin{tabular}{|c|c|c|c|c|c|c|c|c|}
\hline & & & & & & & \multicolumn{2}{|c|}{$\begin{array}{c}95 \% \\
\text { Confidence } \\
\text { Interval }\end{array}$} \\
\hline & & & $\begin{array}{l}\text { Unstandardized } \\
\text { Estimate }\end{array}$ & $\begin{array}{l}\text { Std. } \\
\text { Error }\end{array}$ & Z-value & p-value & Lower & Upper \\
\hline Academic SC & $\sim$ & Social SC & 0.334 & 0.052 & 6.372 & 0.000 & 0.234 & 0.449 \\
\hline Academic SC & $\sim$ & Physical SC & 0.283 & 0.037 & 7.589 & 0.000 & 0.209 & 0.356 \\
\hline Academic SC & $\sim$ & Global SC & 0.308 & 0.05 & 6.125 & 0.000 & 0.205 & 0.408 \\
\hline DBQ & $\sim$ & Social SC & 0.109 & 0.076 & 1.431 & 0.152 & -0.034 & 0.262 \\
\hline T2.DBQ.Total & $\sim$ & Physical SC & 0.13 & 0.074 & 1.763 & 0.078 & -0.027 & 0.266 \\
\hline T2.DBQ.Total & $\sim$ & Global SC & 0.334 & 0.077 & 4.367 & 0.000 & 0.187 & 0.489 \\
\hline CDI.T2.Total & $\sim$ & Social SC & 2.028 & 1.024 & 1.981 & 0.048 & -0.095 & 3.906 \\
\hline CDI.T2.Total & $\sim$ & Physical SC & -2.463 & 0.718 & -3.43 & 0.001 & -3.753 & -0.926 \\
\hline CDI.T2.Total & & Global SC & 3.266 & 0.864 & 3.781 & 0.000 & 1.658 & 4.974 \\
\hline GPA & & $\begin{array}{l}\text { Academic } \\
\text { SC }\end{array}$ & 0.575 & 0.555 & 1.035 & 0.301 & -0.32 & 1.879 \\
\hline GPA & $\sim$ & DBQ & 0.021 & 0.641 & 0.032 & 0.974 & -0.51 & 1.616 \\
\hline GPA & & CDI & -0.15 & 0.152 & -0.986 & 0.324 & -0.486 & -0.02 \\
\hline GPA & & Social SC & 0.242 & 0.747 & 0.324 & 0.746 & -1.256 & 1.704 \\
\hline GPA & & Physical SC & -0.01 & 0.54 & -0.019 & 0.985 & -1.223 & 0.612 \\
\hline GPA & $\sim$ & Global SC & 0.974 & 0.446 & 2.184 & 0.029 & 0.38 & 2.016 \\
\hline
\end{tabular}

Note: $\mathrm{SC}=$ self-concept. CDI $=$ Child Depression Inventory. DBQ = Disruptive Behavior Questionnaire. T2 = Time 2 . 


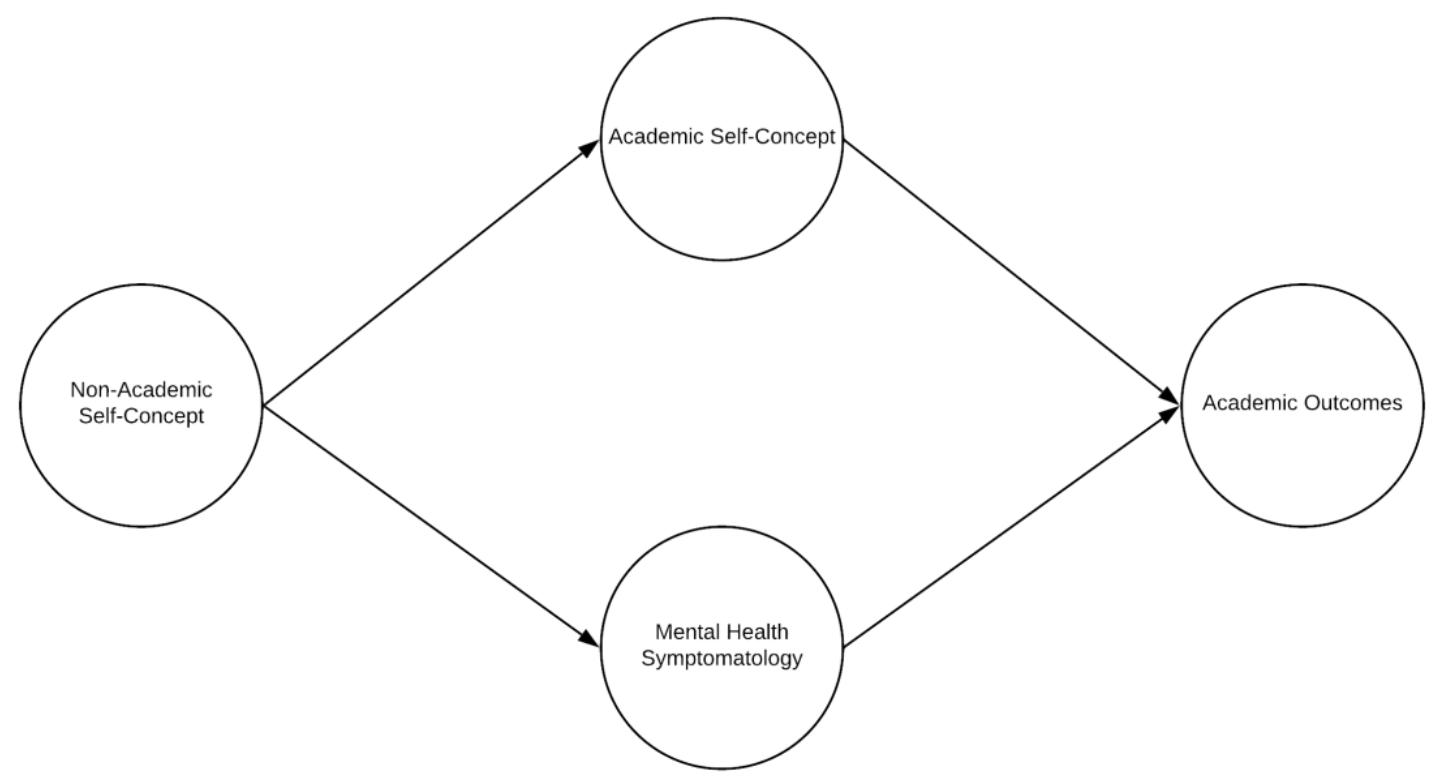

Figure B1. Theoretical Model 


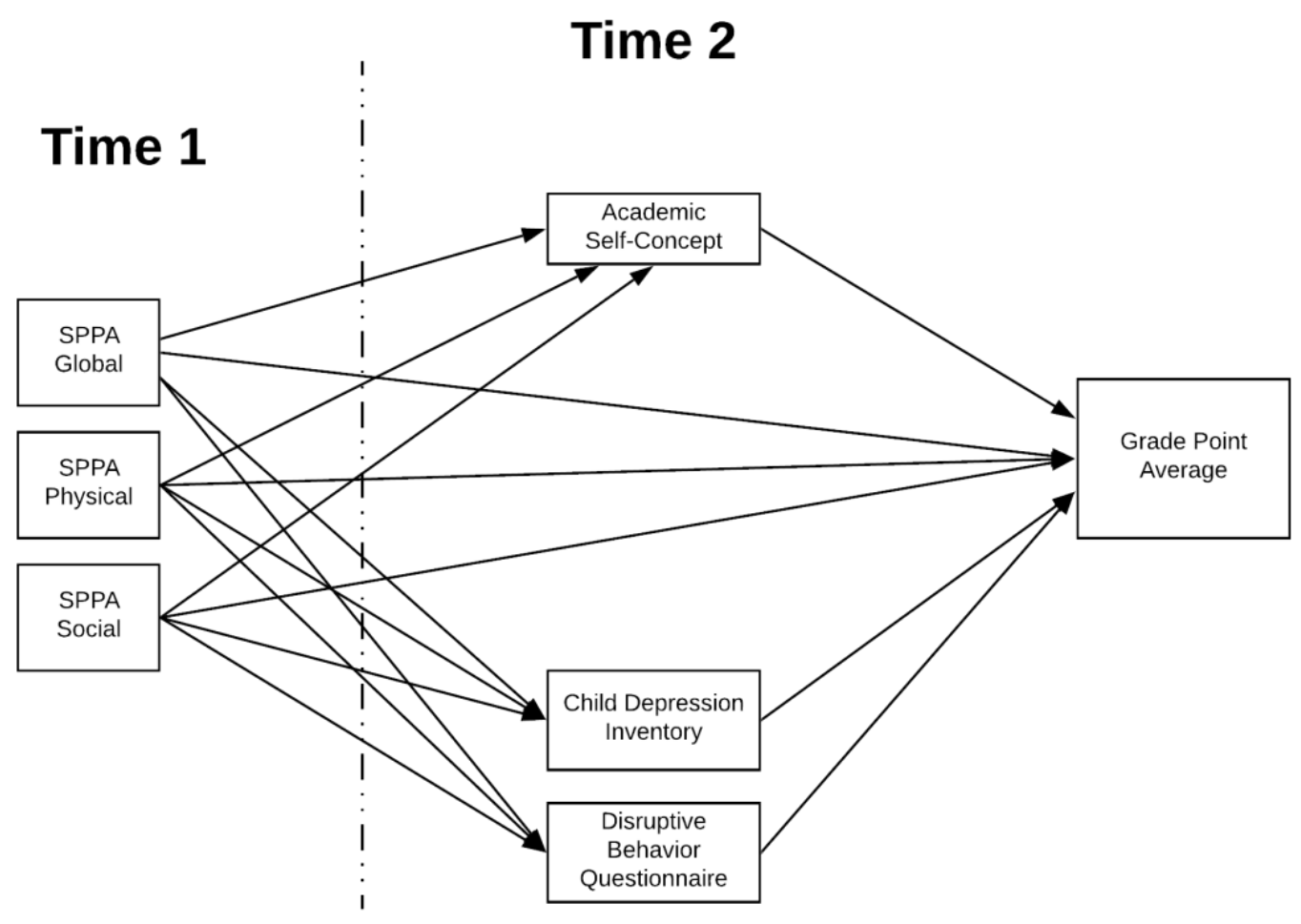

Figure B2. Path model 


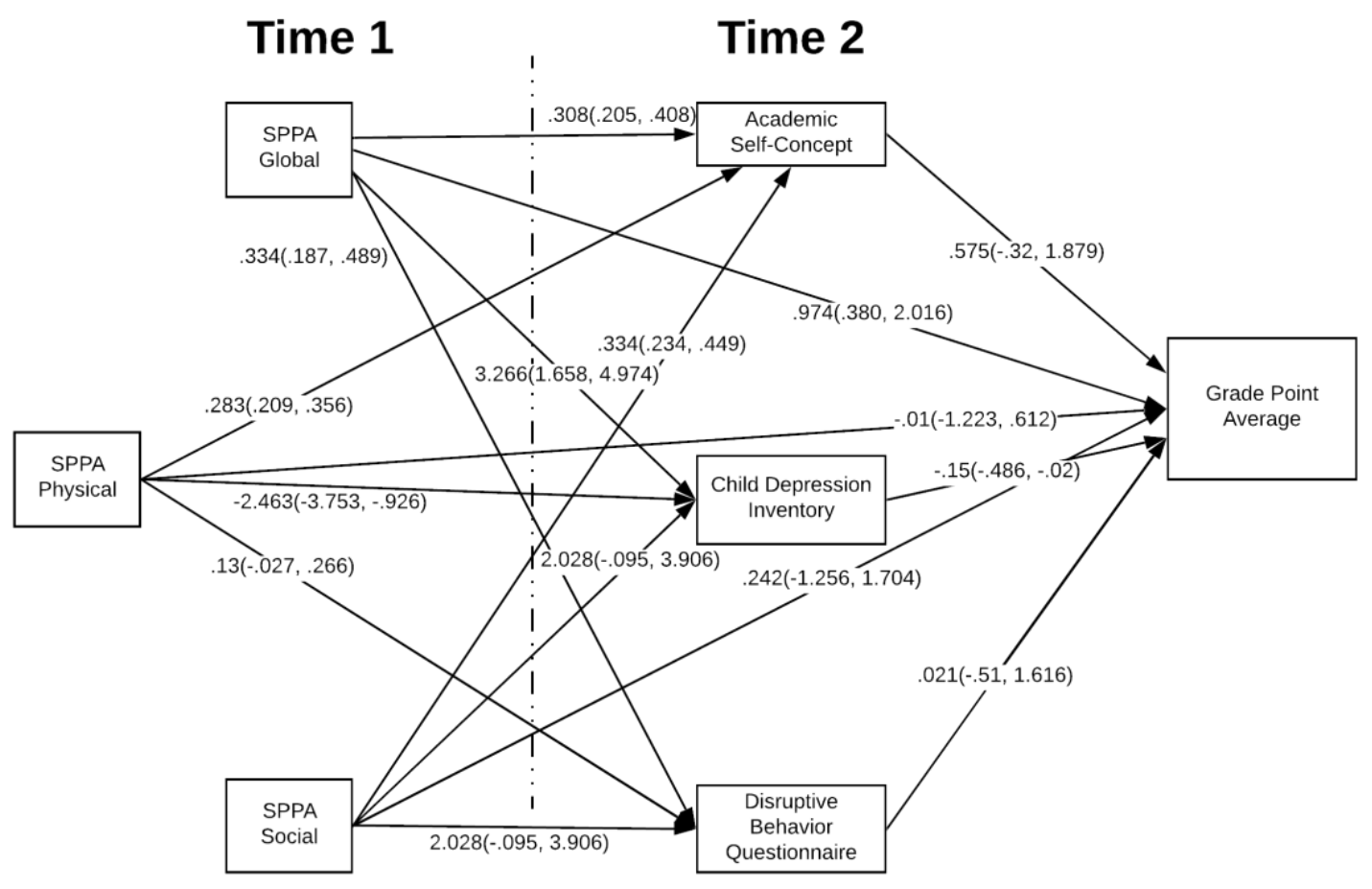

Figure B3. Path model with unstandardized path coefficients 


\section{RANDOMIZED CONTROLLED TRIAL OF A SELF-GUIDED SELF-CONCEPT WRITING INTERVENTION TO PROMOTE ACADEMIC SUCCESS IN URBAN UNDER-RESOURCED PUBLIC HIGH SCHOOLS}

This manuscript will be submitted to the Journal of Child Psychology and Psychiatry, and thus adheres to its use of APA 6th Edition formatting guidelines.

Ogle, R.R., \& Frazier, S. L. (in preparation). Randomized Controlled Trial of a SelfGuided Self-Concept Writing Intervention to Promote Academic Success in Urban Under-Resourced Public High Schools.

Authors' note: This research was supported in part by a National Institute of Child Health and Development National Research Service Award (F31 HD087066) awarded to Robert Ogle. 


\begin{abstract}
Students who successfully complete high school show positive life outcomes in many domains relative to those who not. However, many students in under-resourced urban high schools face significant challenges that reduce their chances of graduation, compounded by frequent lack of resources available to the schools themselves. We describe a randomized controlled trial that examined the promise of a self-guided, resource-minimal journal writing intervention targeting self-concept to improve academic outcomes. The 9th grade class of a diverse, low-income urban high school was invited to participate. Teachers delivered the intervention as part of their normal classroom activity over the course of five weeks. Results did not indicate a main effect of intervention on GPA; however, some evidence validating the underlying theoretical model emerged. We discuss the implications of the current findings for intervention in under-served schools and self-concept as a potential lever for change.

Keywords: Randomized Controlled Trial, Self-Concept, Academic Success, Mental Health, Adolescent.
\end{abstract}

Randomized Controlled Trial of a Self-Guided Self-Concept Writing Intervention to Promote Academic Success in Urban Under-Resourced Public High Schools

\title{
Introduction
}

Failing to complete high school negatively impacts a student's trajectory across career, family, economic, physical and mental health trajectories (Freudenberg \& Ruglis, 2007a), making successful completion of high school a critical goal for adolescents. Students in diverse, low-income communities, however, show significant risk for 
dropping out before high school graduation (Suh, Suh, \& Houston, 2007). A longitudinal study of over 3,900 students revealed that children who experience some period of poverty while growing up fail to complete high school nearly four times as often as those who have never been poor ( $22 \%$ vs. $6 \%$ ), and those who spend more than half of their childhood in poverty are over five times as likely to drop out of high school (32\% vs. 6\%) (Hernandez, 2011). Youth who attend school in a high-income community are $68 \%$ more likely to enroll in a 4 year university than those from lower-income communities (Palardy, 2013). The gap in academic outcomes for low-income students has existed for decades, and has widened over the last 40 years despite efforts to narrow it (Reardon, 2013). Identifying factors that contribute to this disparity, and ways to address it, therefore, is a critical public health issue.

\section{Effects of Poverty on Children's Health and Future Outcomes}

Children from lower-income households often face internal and external stressors that may negatively impact their academic functioning and likelihood of graduation. In a seminal review, Brooks-Gunn \& Duncan (1997) summarized a variety of challenges

which can be broadly grouped into unmet needs and risk factors. Unmet needs (e.g., poor shelter, insufficient nutrition, lack of enrichment and educational opportunities) refer to developmentally meaningful or necessary factors that children in low-income communities have long been known to lack, while risk factors (e.g., caregiver neglect, emotional or physical abuse, mental and physical illness, community violence) conversely, suggest a heightened potential to experience or witness negative or damaging events (Brooks-Gunn \& Duncan, 1997). These deprivations and exposures to stressful or traumatic stimuli correlate with observable changes in brain structure and neurological 
activity, particularly in areas responsible for language, learning and memory, and emotional regulation (S. B. Johnson, Riis, \& Noble, 2016).

Among these factors, an increased risk for mental health disorders leaves children in low-income families particularly vulnerable to negative outcomes with regards to academic functioning. We have known this for some time: nearly one in two children classified as Seriously Emotionally Disturbed, or SED, drop out of high school, according to a nationally representative sample of 664 youth (Rylance, 1997), and youth with emotional and behavioral disorders show higher rates of grade retention, dropout, lower academic performance as measured by GPA, and higher rates of course failures than youth with other identified disorders that impact academics, including learning disorders and intellectual disability (Wood \& Cronin, 1999). Youth who demonstrate higher levels of risk for behavioral disorders in school have lower standardized test scores, increased service utilization, and higher rates of disciplinary action (Baker, Kamphaus, \& Horne, 2006). Despite improved academic and social outcomes (e.g., high school graduation rates, reading performance at grade level, school dropout) for students with other identified disabilities (e.g., learning disabilities, autism spectrum disorder) in recent years, the trend toward poor outcomes remains steep for children with severe emotional disturbance (Bradley, Doolittle, \& Bartolotta, 2008). Those students with mental health disorders who do from graduate high school are less likely than nondisordered students to enter college and more likely than non-disordered students to drop out before completion, at a rate of $86 \%$ dropout in a population with psychiatric diagnoses as compared to the $30-40 \%$ dropout rate for the general population (Hartley, 2010). Thus, mental health disorders may contribute significantly to academic difficulty, 
and children in low-income communities face both higher rates of disorders and more difficulty seeking and receiving treatment. A nationally representative sample $(n=3082$ children ages 8 to 15 ) revealed that low income children were more likely (Adjusted Odds Ratio (AOR) 2.3) to have ADHD than higher income peers, but higher income peers were far more likely to receive treatment (AOR 3.4) (Froehlich et al., 2007). Children in low-income families also face significant barriers to seeking treatment, including access to reliable transportation, childcare for families to support attendance, conflict with work schedules, and insufficient ability to pay or lack of health insurance with sufficient coverage (Santiago, Kaltman, \& Miranda, 2013).

Taken together, this literature suggests that: children from low-income families experience higher rates of academic difficulty and higher rates of school dropout; mental health disorders represent a significant source of academic difficulty and failure to achieve educational outcomes; low-income children have disproportionately high rates of mental health disorders; and children in low-income communities face significant barriers to accessing mental health treatment that result in lower rates of service utilization. Thus, low income children have a higher need and heightened risk while at the same time the lowest access to care. In turn, developing and validating treatment tools that mitigate or overcome these challenges remains critically important to improving overall academic outcomes and lifetime trajectories for these vulnerable youth.

\section{Opportunities in School-Based Intervention}

One way to address these concerns is to deliver services in naturalistic settings during routine activities for families and children, thereby increasing accessibility and removing many of the barriers to care associated with traditional clinic or office-based 
therapy (Atkins et al., 2006). An extensive body of literature documents the benefits of intervention in schools for reaching a significant portion of youth by using a wide variety of approaches at the universal (targeting all children within the school), selected (targeting children at risk of developing more serious mental health concerns) and indicated (targeting children currently experiencing meaningful or severe symptoms or functional impairment) levels (Fazel, Hoagwood, Stephan, \& Ford, 2014). Amongst settings where children routinely present, none offer more consistent access to a large number of children than schools, which makes them, from one perspective, an ideal location for service delivery. In fact, past studies have estimated that as much as $80 \%$ of services delivered to children in the U.S. are delivered in schools (Rones \& Hoagwood, 2000).

Stakeholders and researchers have utilized a wide variety of both prevention and intervention methods to promote mental health in schools, with ample evidence of effects. A recent review including 63 studies of cognitive-behavioral prevention and intervention programs with anxious and depressed youth in schools $(n=15,211)$ at elementary, middle and high school levels (both prevention and treatment, including classroom based as well as pull-out services) identified effect sizes of .50 (medium) and .30 (small to medium) for anxiety and depression programs, respectively (Mychailyszyn, Brodman, Read, \& Kendall, 2012). A systematic review of nonmedication interventions for attention-deficit/hyperactivity disorder in school settings identified a wide range of studies demonstrating significant effects of school-based treatments (including classroom based techniques such as a daily report card as well as pull-out services), though the authors noted that the wide range of interventions used, 
rigor of studies, and variability in methods of symptom assessment and reporting make drawing wide ranging conclusions difficult (Richardson et al., 2015). Another review identified 19 studies of school-based interventions for trauma and post-traumatic stress disorder (primarily using pull-out individual or group services) $(n=4,655)$ with overall effect size estimates in the medium to large range (Cohen's $d=.68$ ) (Rolfsnes $\&$ Idsoe, 2011).

In addition to directly targeting mental disorders and common mental health symptoms, many programs also focus on building skills useful for mitigating or avoiding more serious mental health concerns, often in the context of universal programs. Durlak and colleagues' (Durlak, Weissberg, Dymnicki, Taylor, \& Schellinger, 2011) recent review included K-12 student outcomes $(\mathrm{n}=270,034)$ for 213 school-based social and emotional learning programs, combined effect size estimates yielded a medium to large effect size for skills development (Hedge's $g=.57$ ) and small effect sizes on conduct ( $g$ $=.22)$ and emotional $(g=.24)$ symptoms.

Still others leverage school-based services within a community service model approach, seeking to influence mental health outcomes indirectly by targeting predictors of learning. The Links 2 Learning Program (Atkins et al., 2015), for example, aligns with teachers' competencies and goals by leveraging classroom-based intervention tools (e.g., peer assisted learning, Good Behavior Game) that target academic performance to improve academic outcomes and, indirectly, on-task behavior for teacher-referred children diagnosed with disruptive behavior disorders. Thus, ample evidence suggests that opportunity for successful mental health intervention in schools exists, across the 
public health triangle, and that schools represent a valid setting for reaching large numbers of youth who may benefit from universal, targeted, and intensive services.

\section{Challenges in School-Based Intervention}

Despite their high promise and utility, however, successful school-based mental health intervention must overcome significant challenges. Schools deliver the majority of mental health services for youth in the United States (Farmer, Burns, Phillips, Angold, \& Costello, 2003), but attention and resources devoted to mental health treatment vary widely between schools and districts, with many not positioned to provide evidencebased services (Evans \& Weist, 2004). Even when attempting to address mental health concerns, schools often lack the personnel, finances, and time required to implement interventions with fidelity. For instance, in a study evaluating reasons for successful implementation of a well validated school based intervention, $100 \%$ of the sites without external grant funding supporting the work were unable to implement successfully (Langley, Nadeem, Kataoka, Stein, \& Jaycox, 2010). Further, many programs that target mental health do not also sufficiently examine academic outcomes, despite schools' preference for both (Hoagwood et al., 2007). Instead, they focus on mental health symptoms as outcome variables, which fails to answer the primary question of interest for schools: Does the work being tested help our students learn?

One potential pathway to addressing many of these issues lies in ensuring that interventions closely align with the goals and priorities of the school staff, particularly with regard to academic and classroom functioning (Atkins, Hoagwood, Kutash, \& Seidman, 2010). Teachers are frequently called on to deliver less intensive services as part of their classroom work (Franklin, Kim, Ryan, Kelly, \& Montgomery, 2012), but 
view mental health work as the role of the school psychologist or other support staff

rather than their own responsibility (Reinke, Stormont, Herman, Puri, \& Goel, 2011), and when teachers (or other school personnel) experience the intervention material as competing with their other instructional demands, successful implementation over time decreases (Langley et al., 2010).

\section{Barriers to Successful Intervention in Low-Income Schools}

In many ways, schools in under-resourced communities look similar to the students they serve. Schools in traditionally under-served neighborhoods face conditions of heightened student needs while also lacking sufficient resources to address them. Staffing challenges, particularly around teacher recruitment and retention (Hanushek, Kain, \& Rivkin, 2004), mean that students who most need educators with strong command of material and classroom behavior management are instead served by faculty who are often recent graduates, without a teaching license, formal education training or certification to teach the classes they offer (Tatet, 1999). Teachers in low-income neighborhoods also receive less support upon hiring, fewer opportunities for mentoring from colleagues, and curriculum materials that may not align with state standards and are sometimes ill-suited to their classrooms (S. M. Johnson, Kardos, Kauffman, Liu, \& Donaldson, 2004). As a result, schools in low-income communities also experience a much higher rate of teacher attrition and turnover (Ingersoll, 2001), making successful implementation over time more difficult.

While low-income schools serve a high percentage of children suffering from mental health conditions, their capacity to adopt and deliver complex interventions is limited. Teachers and staff in low-income communities already feel overwhelmed 
(Atkins et al., 2006), leading to high rates of depersonalization and burnout (Hoglund, Klingle, \& Hosan, 2015), and thus learning new tools for identifying or responding to mental health need may be perceived as burdensome resulting in more skepticism than enthusiasm (Graczyk et al., 2005). Additionally, schools in underserved communities typically receive less funding than schools in more affluent neighborhoods (Heuer \& Stullich, 2011), leaving them less equipped to pay for additional mental health services or resources.

Schools in low-income neighborhoods, therefore, are both in desperate need of intervention services and face multiple barriers to delivering them effectively, and evidence suggests services are frequently less efficacious as a result: A meta-analysis using the same selection and review criteria from Rones and Hoagwood (2000) but focusing on low-income schools found fewer programs with significant effects and lower pooled effect sizes $(g=.08)$ than for school-based programs as a whole (Farahmand, Grant, Polo, \& Duffy, 2011). In order to promote delivery of services within the school context, therefore, interventions designed to be delivered in schools must be feasible and effective within the school context (Atkins, Hoagwood, Kutash, \& Seidman, 2010); require few resources in terms of staff time and training, financial cost, and time for delivery; and align with schools' primary instructional goals and achievement outcomes.

\section{Wise Interventions: Low-Resource, High-Impact}

Over the last two decades, enthusiasm has continued to build around interventions that move beyond traditional individual psychotherapy to address mental health concerns. Several promising lines of research have emerged, including positive psychology, which utilizes a strengths-based approach to promoting behavioral and emotional change (Bolier 
et al., 2013), mobile or online interventions either as adjunct to or replacement for traditional therapy (Firth, Torous, Nicholas, Carney, Pratap, et al., 2017; Firth, Torous, Nicholas, Carney, Rosenbaum, et al., 2017; Lindhiem, Bennett, Rosen, \& Silk, 2015), brief intervention frameworks such as the Family Check Up (Dishion, Nelson, \& Kavanagh, 2003), and single-session interventions for youth mental health (Schleider \& Weisz, 2017). While these paradigms vary widely in target and method of service delivery, they share a focus on identifying methods for treatment that go beyond the deficit-based approach of traditional face-to-face individual therapy.

One such approach may offer particular utility in effecting change that aligns with teachers' and schools' existing goals while imposing minimal additional burden. "Wise" interventions rely on identifying and targeting a specific psychological process that may negatively impact functioning (Walton, 2014). A variety of different methods and targets for intervention exist, but they tend to share a few key features: they are relatively brief, they operate to remove psychological barriers to success, and they tend to display effects over time (Yeager \& Walton, 2011). Walton and Wilson further "define "wise interventions" as ones that focus on (are "wise to") the meanings and inferences people draw about themselves, other people, or a situation they are in and use precise, theoryand research-based techniques to alter these meanings" (Walton \& Wilson, 2018). In order to be effective, these interventions must meaningfully affect some aspect of a person's subjective self-perception, in a way that matters in their contextual environment and that leads to a recursive change (Yeager, Walton, \& Cohen, 2013). As a person's self-appraisal changes and leads to subsequent change in outcome (e.g., believing themselves to be a good student and subsequently performing better on a test), their self- 
appraisal continues to improve, leading to further improvement and performance, creating a positive feedback loop that is believed to drive many of the observed effects of wise intervention (Cohen, Garcia, Purdie-Vaughns, Apfel, \& Brzustoski, 2009).

Wise interventions have a strong history of effecting change in academic settings. An intervention by Eskreis-Winkler and colleagues showed changes in deliberate practice and subsequent math performance in 7 th grade students and end of semester grades for middle school ( $n=427$ th graders) and undergraduates ( $n=120$ students) after one 45 minute computerized intervention (Eskreis-Winkler et al., 2016). In that study, students who completed an electronic Deliberate Practice Task subsequently showed improvement in their utilization of deliberate practice and performance on post-test math problems as well as improved grades. Similarly, Blackwell and colleagues (Blackwell, Trzesniewski, \& Dweck, 2007) showed improvement in grade trajectory relative to a control group after an 8 week workshop on perception of intelligence. Their intervention, tested with a primarily minority, low-income urban sample $(\mathrm{n}=99,52 \%$ African-American, $45 \%$ Latino, $79 \%$ free lunch), used eight 25 -minute workshops to promote the idea of malleable intelligence and led to a significant difference in post-intervention math achievement.

One of the most promising and widely cited paradigms, developed by Cohen and colleagues (Cohen et al., 2006), demonstrated improvements in academic achievement as measured by cumulative GPA across the school year through a single 15 minute journal writing intervention in which children identify and write about the most important part of themselves. In the original study ( $\mathrm{n}=243$, grade 7, $48 \%$ African American), students completed the exercise at the beginning of the academic year, and the African American 
students improved by as much as half a point in their cumulative 4-point GPA score by the end of the year. The intervention requires no staff training or time beyond distributing the packet in a routine classroom setting. Cohen's paradigm has been replicated with several different populations (e.g., women in STEM fields, 1 st generation college students) and target problems (e.g., stereotype threat, social belonging, body image \& weight loss) (see Walton 2014 for a more detailed review) with similarly promising results.

Cohen's intervention, in particular, requires minimal resources to implement with fidelity, and aligns well with schools' existing priorities by targeting academic outcomes. Notably, their work targets stereotype threat (defined as distress caused by a situation in which negative performance would confirm a negative stereotype about oneself) via selfaffirmation, which would not be contextually relevant for children who do not experience a negative stereotype. Further, while some of the authors have hypothesized that selfaffirmation may be at play in existing mental health interventions (e.g., as a cognitive reframing tool when treating depression) (Cohen \& Sherman, 2014) they have demonstrated effects for academic outcomes, but have not examined the utility of the paradigm on mental health. Identifying a psychological process that can apply more universally and mitigate mental health symptoms while supporting academic success (which may further reinforce recursive cycles believed necessary to effect change via wise intervention) (Cohen et al., 2009) may help to broaden the efficiency and utility of the paradigm in under-resourced schools. 


\section{Self-Concept: A Universal Lever for Change}

Self-concept may be an especially salient target for wise intervention targeting both mental health and academic success for several reasons. First, self-concept is intrinsic to all students; by the time adolescents enter high school in the United States, they typically have reached (or are approaching) a developmental stage in which their self-concept is becoming more varied and sophisticated (Shapka \& Keating, 2005) and identity formation becomes particularly important and meaningful to youth during that time (Shapka \& Keating, 2005). Second, self-concept relates meaningfully to mental health outcomes (Marsh et al., 2004), such that higher ratings of self-concept across both global and specific (e.g., social, academic, or athletic self-concept) domains predict lower levels of mental health symptoms, and to academic achievement, such that higher academic self-concept both predicts and is predicted by academic achievement in a reciprocal relationship (Guay, Marsh, \& Boivin, 2003a).

Third, self-concept and exploration of self matters to adolescents, making it intrinsically motivating (Deci \& Ryan, 1985) in a way that helps with engagement from youth who may otherwise be uninterested in intervention tools; this is especially important regarding interventions delivered without support from adults who can monitor and assist with motivation. Fourth, prior research suggests that different areas of selfconcept can influence one another even when seemingly discrete or unrelated; hence, self-concept interventions may tap into existing strengths and resources to foster change in other areas. A recent study (McConnell, 2011) demonstrated that different aspects of self-concept can meaningfully impact other discrete aspects through traits connected to both aspects; for example, a person who improves their athletic self-concept may 
subsequently improve their academic self-concept through a mediating improvement in the hard-working trait shared both by the athlete and student parts of the person's selfconcept. Recent research (Ogle et al., 2016) suggests these sorts of connections may predict academic success, as non-academic self-concepts engender positive change in academic self-concept and subsequently in achievement outcomes. Thus, for intervention in schools, self-concept offers potential for a naturally motivating tool broad enough to yield improvement to students regardless of their particular challenges and useful both with regards to mental health symptoms - critical to academic success, as discussed above - as well as academic achievement directly.

Evidence exists to suggest activity that promotes non-academic self-concept shows a positive relationship with academic self-concept. For instance, one study of extracurricular programs in Australia across 1504 students from 26 diverse high schools showed a positive relationship between high quality non-academic extracurricular experiences and general, social and academic self-concept (Blomfield \& Barber, 2011). A review of the link between extracurricular activity and educational achievement found an overall pattern of positive associations between extracurricular participation and educational attainment in adolescence (though the authors note significant heterogeneity and nuance to these findings) (Farb \& Matjasko, 2012).

Together, these findings suggest a method for intervention to improve academic outcomes via targeting what we refer to as the Positive Primary Self-Aspect (PPSA). The PPSA is a youth's self-identified most important part of themselves. PPSA is operationalized as the part of a youth that has high importance (as rated by the adolescent), a high degree of ability to positively influence other aspects of the child's 
life, or utility, and in which the youth has a high degree of self-perceived ability or competence. These three factors - competence, utility, and importance - make up the defining features of the PPSA. If the PPSA strengthens, then associated traits should also strengthen, and other aspects of the self would then improve as a result. Figure C1 illustrates a theoretical model by which PPSA may influence academic outcomes, through improvement in academic self-concept and protection against negative mental health symptoms. We expect that, as an adolescent receives feedback or experiences success in a way that improves their appraisal of their PPSA, they will then experience a reduction in (or protection from) symptoms of negative mental health concerns, and their academic self-concept will increase. Together, these changes would then lead to improvement in academic performance.

\section{Current Study}

The current study extends previous intervention science examining broadly effective, resource-minimal tools for academic improvement. The study had two main aims. Aim 1 tested via randomized controlled design the impact of a self-guided, selfconcept writing intervention delivered during routine instruction to ninth grade students in a diverse and low-income high school. We expected intervention to improve PPSA, which would lead to improved academic outcomes relative to students in the control group. Aim 2 examined the proposed theoretical model and the relationship between PPSA and academic success. Specifically, students were randomized into intervention and control conditions. We predicted that students in the intervention condition would show better academic outcomes as measured by cumulative GPA at the end of the academic year relative to students in the control condition (Aim 1). We further 
hypothesized that improvement in PPSA would yield improvement in GPA through two mediators: improved academic self-concept and reduced mental health symptoms (Aim 2).

\section{Method}

All data collection procedures were conducted in accordance with APA Ethical Guidelines and under supervision of both the university's institutional review board and school district's research review council.

\section{Participants}

Participants were recruited from the 9 th grade class of a large urban high school in a major city in the southeastern United States. All students currently taking World History and Honors World History were invited to participate, including students above $9_{\text {th }}$ grade who were repeating the course, in order to minimize burden on teaching staff (who would otherwise need to provide alternative instructional materials during intervention administration). Because the intervention is designed to be universally applicable, there were no exclusion criteria. Of the roughly 425 students invited to participate, 93 returned consent forms with parental permission to participate in data collection. Several students subsequently left the school prior to administration of the intervention, yielding a final total of 89 participants (58\% Female, 78\% Hispanic, 19\% Black, 3\% White) for Aim 1. Of these, 75 (84\%) agreed to complete online questionnaires for Aim 2, yielding data at three time points: pre-test (January), post-test (March), and end of the academic year (May). Significant attrition occurred between recruitment and Aim 2 pre-test, as well as between pre-test, post-test and follow-up, leaving final samples of 37 participants at Time 1, 14 participants at Time 2 and 6 
participants at Time 3 , due primarily to failure of students to complete voluntary measures during extracurricular time.

\section{Intervention}

Show Our Strengths is a six-week, self-guided writing intervention, designed to be delivered in classrooms during the first six weeks of the academic year. Each week, students receive a packet of instructions and exercises that are designed to guide them through identifying and strengthening a highly salient positive self-aspect, and to help them understand how to use those self-aspects to improve functioning across various life domains, with a particular focus on academic self-concept and selection of academicdirected behavior (e.g., studying, seeking help on difficult material). Exercises and worksheets are sequential and build upon answers and work completed in prior weeks. The intervention is completely self-contained; all required instructions, worksheets, and paper are provided to each student, and are designed to be completed without any assistance from teachers or research staff. Once the student completed the week's writing assignment, they returned all materials to their envelopes and returned the envelopes to their teacher. Complete intervention packets were supplied to teachers pre-assembled, with envelopes labeled for each student. The intervention thus required no additional training or time for existing school staff; teachers were asked only to distribute and collect envelopes once per week. The writing exercise required no more than 10 minutes of classroom time each week. Students who missed a week due to absence were instructed to begin where they left off and attempt to catch up to the current week as time permitted. 
Day 1: Identifying PPSAs. The first week's component is based largely upon the self-integrity intervention originally designed by Cohen and colleagues (Cohen et al., 2006). Students receive a list of roles (e.g., athlete, artist, student, family member) and identify which one is most important to them. Students write, in their own words, why that particular role is important to them. The Primary Positive Self-Aspect (PPSA) the student selects then is used as the basis for subsequent strength and skill building writing exercises in the following weeks. Students are informed that their weekly writing will not be graded or read by teachers, but will be read by the research team, and are encouraged to be honest. As a check to ensure students accurately identify their most important aspect (or least in the control condition), students first rank order the list in order of importance.

Day 2: Identifying strengths. In week 2, students receive a packet designed specifically for their PPSA (e.g., athlete, friend, student) according to their prior week's selection, pre-assembled by the research team. Each week's stopping point is clearly marked to prevent students from moving to the next exercise prematurely. The first week's materials are attached to the packet in case a student has forgotten which PPSA they selected. Students select all of the strengths and positive values (e.g., perseverance, creativity) that characterize their PPSA from an included list. Additional space permits students to present other strengths or values that are not already on the list but they believe are important. The strengths and values list was developed from previous work on self-aspect/value associations by McConnell (McConnell, 2011a) and character strengths by Seligman (Seligman, Steen, Park, \& Peterson, 2005). 
Day 3: Connecting strengths to other aspects. Youth review the strengths they associated with their PPSA during the prior week, and select from among them the particular ones they believe can help in other areas of their lives: as student, friend, and family member. If their PPSA is already one of these aspects (e.g., friend), they are instructed to focus on the other two, describing how and why those strengths are useful in each role.

Day 4: Leveraging PPSA for Goal Attainment. Week 4 ties a student's PPSA to personal goals, and asks how that role, and strengths and values that characterize it, can help them to achieve their goals. Examples are provided (e.g., graduate high school, go to college, get a job), but youth are instructed to select any goal.

The last two weeks shift focus from describing the student's PPSA, to helping younger students with the same PPSA to succeed. This is intended to minimize students' awareness of our effort to influence their academic outcomes, as research shows awareness of the purpose behind intervention can reduce its effect in this paradigm (A. Silverman, Logel, \& Cohen, 2013).

Day 5: Reinforcing PPSA. Finding opportunities to further strengthen PPSAs over the course of their academic career should provide additional reinforcement of PPSA activation on other aspects of the self. Hence, students are asked to identify places where people with their PPSA can find others like them (e.g., where can artists go to be with other artists?), or find additional opportunities to enjoy activities associated with that role, particularly at their school. This is designed to increase students' voluntary engagement in activities relating to their PPSA, to continue activating and reinforcing positive effects in other areas beyond the immediate effect of intervention. 
Day 6: Helping others overcome. The final week asks students to use their own PPSA to help middle school students with the same PPSA to solve a problem. The student reads a brief description of a problem (e.g., a student is struggling academically and worrying about an upcoming test), and uses the strengths and values associated with their PPSA to offer and describe potential solutions. This provides another opportunity to engage in helping behavior, and facilitates problem solving related to common challenges they may face during high school, without asking the student to imagine themselves in the potentially threatening situation. After completing the final prompt, students are asked if they would like their answers to be used to help others.

\section{Control Intervention}

Students in the comparison condition completed a self-guided writing exercise mirroring the intervention condition, with one difference: youth in the control condition selected the least important aspect, rather than the most important, and wrote about why it may be important to someone else. Comparison students completed packets at the same time as their classmates in the intervention condition and followed identical procedures in all other respects. This procedure follows that originally used by Cohen and colleagues (Cohen et al., 2006), and while stringent, offers meaningful benefits: it minimizes differences between conditions, increasing internal validity; protects masking (for teachers and students) by limiting differences between conditions, and minimizes burden for teachers. 


\section{Measures}

With the exception of Demographic and Academic Outcomes data, which were collected for all participants, the below measures were collected only for students who consented to complete questionnaires for Aim 2.

Strengths \& Difficulties Questionnaire. (SDQ): The SDQ (Goodman, 1997) is a widely used, 25-item, 0 to 2 (Not true, somewhat true, certainly true) Likert-style, selfreport measure of psychopathology that screens for mental health symptoms and impairment in five domains, each with five items: Emotional Difficulties (corresponding to internalizing symptoms), Conduct Problems, Hyperactivity, Peer Problems, and Prosocial Behavior. The SDQ is a well-validated (Goodman, 2001) and widely used measure of child and adolescent mental health symptoms. The Emotional Difficulties subscale was used in the Aim 2 analyses; reliability in the current sample was borderline $(\alpha=.689)$ and represents the mental health structure in the theoretical model (Figure 1).

Harter Self Perception Profile for Adolescents (SPPA). The SPPA (S. Harter, 1985 ) is a widely used, well-validated measure of both general and specific child and adolescent self-concept. The measure consists of 48 items split evenly across eight scales that capture general self-concept and specific self-concept in scholastic, social, athletic, appearance, behavior, close friendship, relationship appeal and job competence domains. Respondents indicate whether they are "really" or "sort of" like one of two types of teens. Tests of the psychometric properties show high validity and reliability ranging from acceptable to excellent ( $\alpha=.74$ to .92$)$ in nationally representative samples. All subscale scores were collected. Scholastic Competence was used in the current analyses; reliability in the current sample was low $(\alpha=.61)$. Analyses suggested one of the items may have 
been difficult for the current population, when removed, reliability reached acceptable levels $(\alpha=.70)$.

Where I Do Well Questionnaire. The Where I Do Well Questionnaire (WIDW) was adapted from a measure by Eccles (Eccles, Wigfield, Harold, \& Blumenfeld, 1993)that examines PPSA as selected by youth. The WIDW contains 15 self-report Likert-style items (0-7, anchors vary by question) that assess subjective importance, enjoyment and centrality to their life of one's PPSA. The WIDW produces three subscale scores, each with five items: Competence (i.e., how capable or skilled a youth is in the given domain, $\alpha=.764$ ), Importance (i.e., how important that domain is to the youth, $\alpha=.662$ ) and Utility (i.e., how useful the skills and traits of the PPSA are in other areas of the youth's life, $\alpha=.898$ ) corresponding to those domains.

Demographic Data: Student demographic data (age, sex, ethnicity, and Free and Reduced Lunch Status) was collected directly from electronic school records.

Academic Outcomes: Global GPA data were collected from school administrators via electronic school records after final grades had been entered for the academic year.

\section{Procedures}

Recruitment was originally slated to begin in Spring of 2016. However, resubmission of the grant supporting the dissertation necessitated a delay into the Summer. Additional delays occurred due to a change in principal one week prior to the start of the academic year. Recruitment thus began in Fall 2016 with brief presentations within each World History classroom describing the nature of the study, an overview of procedures, brief discussion of potential risks and benefits, and consent and assent 
procedure information. Students had three options: no data collected, academic data collected only, or academic data and questionnaires collected. All students who agreed to have data collected comprised the Aim 1 sample. Of these, students who also agreed to complete questionnaires comprised the Aim 2 sample. At the end of each presentation, permission and assent packets were distributed for students to bring home and return signed (indicating permission or no permission) to their history teachers within a twoweek period. After this period, we determined that the number of eligible students (with written parental permission) would not yield sufficient power for data analysis, so intervention was delayed to allow time for additional recruitment strategies that included additional classroom presentations and consent forms in Spanish, as well as incentives (pizza lunch at the end of the semester) for returning signed consent and assent packets (students could mark that they did not wish to participate). These efforts yielded a better return, though still fewer than one-third of eligible students. Consented students were randomized via random number generator into two groups, and those groups were randomly assigned to intervention $(\mathrm{N}=47)$ and control $(\mathrm{N}=46)$ conditions.

The intervention and control journal writing prompts were delivered in World History classrooms once per week for six weeks during the third academic quarter of the 2016-2017 school year. Each teacher selected two days per week that ensured minimal disruption to their lesson plans and delivered the intervention on those days. Each week, during the first ten minutes of class, students received a manila envelope containing their journal packet and completed the prompt for the current week. Students who had missed a week prior were instructed to complete the missed assignment first and then to continue on if time permitted. At the end of the allotted time, students returned their journals to the 
manila envelopes and returned the envelopes to their teacher. Research staff delivered and collected envelopes on the corresponding day each week, and kept them in a locked cabinet in the school offices between administrations.

\section{Data Analysis}

Effects of the intervention on global GPA were estimated using multi-group latent growth curve modeling to understand the effect of the intervention controlling for academic performance from the first half of the year at the end of the third academic quarter (post-test) and the end of the calendar year. Full Information Maximum Likelihood (FIML) estimation was used to account for potential missing data. Mediator and moderator effects were analyzed using a structural equation modeling (SEM) approach, also using FIML and robust standard errors to mitigate the effect of missing data. A priori power analysis suggested the number of recruited students was sufficient to detect a medium to large effect on GPA, and a small to medium mediator effect within the supplemental SEM analysis. However, significant attrition between pre-, post-, and end of school year data collections resulted in a sample too small to conduct the SEM analysis as planned. Instead, we examined correlations between variables at pre-test, and conducted multiple regression analyses of Time 1 variables on Quarter 4 GPA, to begin exploring relationships proposed in the theoretical model with the information available.

\section{Results}

\section{Demographics}

Sample demographics for both Aim 1 and Aim 2 are summarized in Tables C1 and C2. We utilized T-tests to check for possible differences between treatment and 
control groups for the entire Aim 1 sample and for the Aim 2 sample. We also tested for differences between the Aim 1 and Aim 2 samples as a whole. No significant differences with regards to race, ethnicity, sex, or Free \& Reduced Lunch (FRL) status were indicated between the experimental and control groups (all $p>.05$ ) for Aim 1. Those who consented to both Aim 1 and Aim 2 analyses (and thus agreed to complete additional measures electronically at the three time points) did not differ from the overall Aim 1 sample (all $p>.05$ ). However, one significant difference - GPA at the end of Quarter 1 emerged between treatment and control groups for Aim 2, with the treatment group achieving a higher mean GPA at pre-experimental baseline (GPA $=3.38$ for treatment, 2.97 for control; $p=.028)$.

\section{Aim 1 Analyses}

The model in Figure 2 was evaluated using fit statistics following recommendations of Bollen and Long (Bollen \& Long, 1993). Indices of fit suggest an adequate to good fit for the model. The chi-square value was non-significant $(\square 2=(88)=$ 12.827, $p=.118)$, the comparative fit index was above $.95(\mathrm{CFI}=.987)$, and the standardized root mean square residual (SRMR) was .054. Both the intercept (variance $=.32, \mathrm{p}<.001)$ and the slope $($ variance $=.009, \mathrm{p}=.027)$ showed significant variability. Analysis of the model yielded no significant difference in trajectory of GPA over time by treatment group. The unstandardized estimate of slope on GPA across time points was $.003, p=.956$. 


\section{Aim 2 Analyses}

While initial recruitment of students for Aim 2 suggested sufficient power, high attrition between time points left a Time 2 sample of 14 and a Time 3 sample of 6 students, which was insufficient to conduct the analyses as planned.

Instead, we conducted a series of multiple regressions on Time 1 data to examine the correlations between indicators of PPSA, academic self-concept and emotional symptoms, and the relationship of each of these to Q4 grades. Correlations between Time 1 variables and end of year GPA are presented in Table C3. Multiple regression results are reported in Tables C4, C5 and C6. Multiple regression revealed a significant relationship for Competence $(B=.35, p=.011)$, a marginally significant relationship for Importance $(B=-.31, p=.054)$, and a nonsignificant relationship for Utility $(B=.037, p$ $=.58$ ) with Scholastic Competence (which captures academic self-concept) at Time 1 (see Table C4). To ensure variance was not being masked by non-significant results, we ran individual regressions as well as an additional multiple regression with utility removed. Competence $(B=.0338, p=.011)$ and Importance $(B=-.26, p=.046)$ showed significant relationships with Scholastic Competence when regressed together; however, none of the individual regressions reached significance. None of the subscales showed a significant relationship to Emotional Difficulties on the SDQ at Time 1; non-significant results are reported in Table $\mathrm{C} 5$.

Scholastic Competence at Time 1 predicted GPA at the end of the academic year $(B=.7735, p<.000)$. Emotional difficulties did not reach significance $(B=-.45, p$ $=.101)$ in predicting GPA. Competence $(B=.44, p=.101)$ and Importance $(B=-.41, p$ $=.101)$ predicted GPA when regressed together without Utility, but none of the 
individual subscales reached significance alone. Complete regression results are available in Table C6.

\section{Discussion}

The current study examined the promise of a universal, self-guided journal writing intervention for underserved high school students, designed to leverage nonacademic self-concept to improve academic outcomes via reducing negative mental health symptomatology and improving academic self-concept. Contrary to predictions, the intervention did not improve or influence GPA, academic self-concept or mental health symptoms; interpretations and implications are discussed below.

\section{Aim 1: Results and Implications}

Both the slope and intercept showed significant variability in the Aim 1 analyses, which suggests that individual students varied meaningfully in their degree of change and in their starting GPA. We expect a normal distribution of grades, which makes the latter expected; the variability in slope, however, suggests that other factors may be influencing the response to intervention. This suggests that moderator analyses may shine additional light on the results; while the current dataset lacks sufficient power to answer these questions, a replication with a larger sample and with the intervention delivered as intended at the beginning of the school year may offer valuable insight about who improves in response to the intervention and under what conditions.

No change in trajectory of growth curves was observed between the treatment and control groups. This outcome contradicts our hypotheses and a rich body of literature that has demonstrated impact of similar interventions across settings and samples (Yeager \& Walton, 2011), as discussed in the introduction. In particular, the intervention was 
designed to mirror Cohen's previous work (Cohen et al., 2006), which demonstrated strong effects on GPA for minority students in that study, and has shown effects on academic outcomes using similar paradigms in for women in STEM classes in college (a traditionally vulnerable group) (Miyake et al., 2010). Other similarly brief paradigms by Cohen, Walton and others have also shown meaningful effect on GPA for minority college students (Walton \& Cohen, 2011) and low-income Black and Latino 8th grade students (Oyserman, Bybee, \& Terry, 2006).

Nevertheless, while it is certainly possible that the intervention as designed does not foster sufficient change in a student's self-concept to influence grades, several alternative explanations for the discrepant findings warrant consideration. First, the delayed timing of the intervention — beginning halfway through the school year rather than at the beginning - warrants consideration. As suggested by the robust literature from Cohen and colleagues (Cohen et al., 2006), the original intervention demonstrated differences in GPA after a full academic year, attributed to a recursive cycle in which positive performance improved self-concept and thus subsequent performance (or the opposite) (Cohen et al., 2009). As such, it may be that the intervention requires a longer period of time to manifest differences in GPA. Cohen and colleagues did not report midyear data from their original study, so we do not know whether they observed effects prior to end of the school year. Given the frequent repetition of the paradigm with similar timeframes, however (Walton, 2014), it is reasonable to assume that were rapid effects a frequent occurrence, they would likely have been reported during one of those repetitions. While two end of quarter GPA points (at the end of the $3 \mathrm{rd}$ and 4 th academic quarters) were available for the model, the 3rd quarter finished only 20 days after the 
intervention completed, leaving little time for a recursive process as described above to take place.

Also related to timing, whereas in Cohen's original study the intervention was implemented before any major work had been assigned, in the current study any effects would have had to combat an already established grade point average. Starting late in the academic year meant the intervention had less time to influence self-concept, but also that opportunity to influence GPA was lowered as a function of all the academic work already submitted and graded before the intervention was administered. Even with a full year to work, the difficulty in overcoming those established grades meant that a significantly higher effect on students would have been necessary to achieve the same outcomes as in previous studies, due to the effect of the pre-intervention schoolwork on overall GPA. Taken together, the lack of significant difference between conditions on GPA is not surprising, even if the intervention were equally effective as the version already wellvalidated by Cohen and colleagues.

Second, the delayed start and abbreviated time may have interfered as well with hypothesized mechanisms of action. Cohen and colleagues' (2009) two-year follow-up of their original study revealed a gradually increasing effect over time, as students continually re-evaluate and update their sense of self and competency as they progress throughout their academic career. Transition periods — as when students enter high school for the first time - appear to have particular relevance and offer a unique opportunity to intervene in that process (Cohen et al., 2009). When students don't have prior evidence of their ability within a particular setting, they are more sensitive to indicators of performance and ability; as those indicators continue to accumulate, each individual 
evaluation will have less of an overall impact. The current study not only had less time for intervention effects to take hold, but also had to combat a large body of pre-existing evidence that students had gathered about their capability as high school students during Quarters 1 and 2. It may be that the intervention could have eventually caught up in terms of effects, if sufficient time were allowed. Alternatively, the first few weeks of high school may represent a critical period, in which this sort of intervention can plant seeds that lead to the major changes reported in previous studies. Had the intervention produced similar effects in this context, it would have offered a great deal of added utility to the paradigm, as teachers and administrators would have had more flexibility to integrate it throughout the school year; as such, findings from the unplanned mid-year testing of the intervention reinforce the importance of not just how, but when these types of interventions are delivered, and suggest that a replication adhering to the original timeline may yield different results.

Third, the active control condition utilized in the current study sets a particularly conservative comparison for demonstrating intervention effects. While a similar control design has been used previously (Cohen et al., 2006), the enhancement in the present study from a single prompt to six prompts over six weeks led to more time spent by the students in the control condition thinking about and reflecting on the material presented, which may offer more benefit than expected irrespective of students' own personal connections to it. Although the first prompt relies on direct reinforcement of self-concept (which we would expect to vary strongly between conditions based on students' personal connections to the material), the later prompts in both conditions encourage goal-setting, problem-solving, and offer opportunity for prosocial action. The longer time required for 
the current intervention also distanced students in the control condition from the original instruction to identify the least important part of themselves. While the instruction was repeated each week, it is not impossible that students may, consciously or unconsciously, begin considering themselves as time goes on, further closing the already narrow gap between the intervention and control conditions. Cohen's original study was lauded in part because of the strength of the active control condition used, and the strong results

displayed even with such an active control group. However, the changes in paradigm here may have made the control condition in the current study even more stringent than that in the original study, which could very well mask any effect of the intervention relative to a potentially beneficial control.

Any one of the factors discussed above could meaningfully have influenced the results of the current study in a way that would produce a null finding. Further, none of these factors are mutually exclusive, and in fact all three may have been at play. As such, while the potential certainly exists that the current intervention does not meaningfully engage its targets for change, the combination of previous work with similar interventions, a strong theoretical model and significant deviations from the original paradigm due to external factors also offers reason to consider that further study of the intervention remains warranted.

\section{Aim 2: Results and Implications}

Aim 2 represents an initial step toward examining the theoretical model underlying the design of the intervention, albeit in a highly exploratory fashion. While the lack of response data from students on Time 2 and 3 surveys did not allow for the 
planned mediation analyses using structural equation modeling, several interesting findings did emerge.

First, the Where I Do Well questionnaire, representing PPSA, showed several significant correlations with other data. Competence and Importance together correlated with Academic Self-Concept at Time 1, and they also predicted end of year GPA. Competence showed the expected positive relationship, such that academic self-concept and GPA are higher as competence increases. Surprisingly, importance showed a negative correlation in the same relationships. It may be that the importance subscale (used for the first time here) is psychometrically weak, as reflected by its borderline reliability. It may also be that the importance data is pointing to something else - perhaps embracing a highly important part of oneself outside of academics may reduce one's focus on schoolwork or perception regarding the importance of academic success. If that's true, it offers meaningful data both for educators in general and for refinement of our intervention. For example, if students prioritize their PPSA over academics, then connecting academic success to their PPSA explicitly may help to increase adolescents' academic motivation. The intervention attempts to help students understand how their PPSA can benefit them as a student, but it may be that what's needed is for students to understand how being a good student can benefit their PPSA (or how the two can reinforce each other). Contrary to our original predictions, Competence and Importance also directly predicted grades at the end of the academic year. Although other variables may help to explain those associations, at minimum there is some evidence to support the idea that intervention to improve a student's sense of competence in an area of interest to them may benefit their academics. This also represents the first quantitative test of the 
proposed factors that comprise the PPSA; the relationships observed here offer further support for the theoretical model and suggest avenues for further study.

Contrary to predictions, there was no significant effect of condition on either academic self-concept or mental health symptoms at Time 2. On the other hand, consistent with prior research and our own hypotheses, academic self-concept strongly predicted GPA at the end of the year. Though this finding is not new, further data demonstrating this relationship with students in an under-resourced urban high school strengthens the case for targeting self-concept as a lever for change with this population.

The relationship between academic self-concept and academic outcomes is a complex and reciprocal one (Guay et al., 2003): students must have time to improve their view of themselves, perform better at academic tasks as a result, subsequently improve their view of themselves further, and so on. As such, the time required for non-academic self-concept to influence meaningful change on academic self-concept may be longer than the abbreviated post-intervention window allowed. Additionally, the nature of selfaspect itself suggests that changes in non-academic parts of the self will generalize to academic self-concept only after positive changes in associated traits have time to take hold, be recognized and internalized by the student. We would expect this process also to be recursive; as a particular aspect is reinforced, it will subsequently strengthen a person's associated traits, and then those improved traits would in turn strengthen other associated self-aspects. However, as with other indicators of the self and their relationship to self-concept, we would expect these processes to happen over time and to vary extensively in time required as a function of the number of opportunities available for reinforcement around a trait or aspect. For example, a student who identifies "actress" 
as her PPSA would likely improve the trait "good memory" and subsequently her academic self-concept much more quickly if she were in a play immediately following the intervention than if she were not, as the frequent practice of memorizing lines would give many more opportunities to change and reinforce her views of herself in that particular domain. It is therefore entirely possible that, similar to GPA, the relationship between academic and non-academic self-aspects requires more time to change in response to improvement on one area than the current design allowed.

The control condition also provided several opportunities for positive personal experiences that closely matched what students in the intervention condition received. The final prompt, for example, still invited students to "help" younger (less similar) students via assistance through solving a problem. As these components draw heavily from commonly used and well-validated tools for prevention and intervention, perhaps they offer equivalent benefit and mask the difference between the two groups, especially with the limited time and small sample size included here. Replication with a larger sample and longer period of time might allow more rigorous examination of the potential incremental value, within the intervention, of reinforcement of the PPSA framework.

\section{Limitations}

The results of the current study should be interpreted with a large degree of caution. Most notably, early delays in launching the work resulted in missed opportunities to recruit at grade-wide events for families (originally planned as a primary opportunity for recruitment and parent permission procedures), necessitating an extended recruitment period that lasted through fall and part of winter. While recruitment efforts ultimately reached the minimums necessary at baseline, attrition led to under-powered 
analyses for Aim 1 and less rigorous analytic approach for Aim 2 reflecting insufficient data to test the planned structural equation models.

Second, extended recruitment also delayed the intervention well beyond the beginning of the new academic year. Beginning the intervention in the middle of 9 th grade represented a major shift in the intervention paradigm and, as elaborated above, highlights the missed opportunity to intervene when self-concept as a high school student is arguably at its most malleable. Wise psychological interventions, while powerful, are particularly sensitive to timing (Walton, 2014), and it is difficult to infer from the current study how different the results might have been under the original paradigm.

Third, even within the scope of the original timeline, the lack of a waitlist control or other non-active control condition further limits our ability to draw conclusions from the current dataset. The active control replicated the previous research design by Cohen and colleagues, but the addition of other components that may rely less on specific connection to a child's PPSA may have muddied the difference between the two more than anticipated. The active control also sought to serve the needs of the partner school; by making the control and intervention conditions similar in timing and instructions, we minimized burden on already overwhelmed teachers and the risk for errors in intervention delivery, as well as the risk of unmasking the conditions for teachers or students. While those aims were achieved, the difficulty in parsing difference between the two suggests that an alternative structure may be warranted as a next step, even if an eventual return to a control condition as conservative as this one would be appropriate in further work. 


\section{Future Directions}

The results of the current study suggest several potential pathways for future research. The most straightforward would be a replication of the current study adhering to the original timeline with regards to intervention delivery, and with additional resources and time devoted to ensuring adequate recruitment, as well as a modification of the data collection procedures designed to reduce attrition for the Aim 2 analyses. However, while the active control condition presents a strong case for the intervention's power if the results reach significance in a replication, the added complexity of the intervention in the current study relative to previous research suggests that a more lenient control condition may be appropriate as a first step, either in lieu of, or in addition to, the active control condition utilized here. If sufficient students were available, the latter option, with a three-group design, would be particularly useful as a tool to begin parsing out which components are especially helpful, and the degree to which PPSA influences students' engagement with the material and the effect it has on their own self-concept.

\section{Concluding Remarks}

The difficulties experienced in conducting the current study speak to the challenge inherent in conducting school-partnered research. The enthusiasm from our school partners - including both the original principal who encouraged us to develop the intervention and the new principal that permitted us to implement and study it - and funding agencies, high feasibility and acceptability demonstrated during earlier pilot studies, and powerful effects demonstrated with similar paradigms in other studies speak to the potential benefit of overcoming those challenges. While the work is often far more complex when conducted in a natural or routine setting, the potential to reach and effect a 
traditionally underserved population in a way that has implications both for their short term functioning and long-term trajectory makes taking on this complexity an important and necessary step towards the ultimate goal of improving the lives of children and adolescents from diverse, low-income communities using the best that our field has to offer. The current study highlights those challenges and opportunities, and leads to more questions about the best and most effective ways to continue this work - questions that we hope will inform not only our own future projects, but those of others as well. 


\section{Tables and Figures}

Table C1. Aim 1 demographics

\begin{tabular}{lccc}
\hline & $\begin{array}{c}\text { Control } \\
(\mathbf{n = 4 3})\end{array}$ & $\begin{array}{c}\text { Treatment } \\
(\mathbf{n = 4 5})\end{array}$ & P-value \\
\hline Race & $1(2.3 \%)$ & $2(4.4 \%)$ & 0.841 \\
$\quad$ White & $8(18.6 \%)$ & $9(20.0 \%)$ & \\
$\quad$ Black or African American & $34(79.1 \%)$ & $34(75.6 \%)$ & \\
$\quad$ Hispanic & & & \\
Sex & $18(41.9 \%)$ & $18(40.0 \%)$ & 1 \\
$\quad$ Male & $25(58.1 \%)$ & $27(60.0 \%)$ & \\
$\quad$ Female & $34(79.1 \%)$ & $31(68.9 \%)$ & 0.551 \\
Free \& Reduced Lunch Status & $3(7.0 \%)$ & $5(11.1 \%)$ & \\
$\quad$ Free Lunch & $6(14.0 \%)$ & $9(20.0 \%)$ & \\
$\quad$ Reduced Lunch & & & \\
$\quad$ Full Price & $2.90(0.612)$ & $2.93(0.566)$ & 0.828 \\
Q1Grade & $2.88[1.38,3.86]$ & $3.00[1.75,4.00]$ & \\
$\quad$ Mean (SD) & & & \\
$\quad$ Median [Min, Max] &
\end{tabular}


Table C2. Aim 2 demographics

\begin{tabular}{lccc}
\hline & $\begin{array}{c}\text { Control } \\
(\mathbf{n = 2 3})\end{array}$ & $\begin{array}{c}\text { Treatment } \\
(\mathbf{n = 1 4})\end{array}$ & P-value \\
\hline Ethnicity & $19(82.6 \%)$ & $11(78.6 \%)$ & 1 \\
$\quad$ Hispanic & $4(17.4 \%)$ & $3(21.4 \%)$ & \\
$\quad$ Non-Hispanic & $16(69.6 \%)$ & $10(71.4 \%)$ & 0.976 \\
Race & $4(17.4 \%)$ & $2(14.3 \%)$ & \\
$\quad$ White & $2(8.7 \%)$ & $1(7.1 \%)$ & \\
$\quad$ Black or African American & $1(4.3 \%)$ & $1(7.1 \%)$ & \\
$\quad$ More than One & & & \\
$\quad$ Other & $7(30.4 \%)$ & $5(35.7 \%)$ & \\
Gender & $16(69.6 \%)$ & $9(64.3 \%)$ & \\
$\quad$ Male & & & \\
$\quad$ Female & $20(87.0 \%)$ & $9(64.3 \%)$ & \\
FRL & $1(4.3 \%)$ & $2(14.3 \%)$ & \\
$\quad$ Free & $2(8.7 \%)$ & $3(21.4 \%)$ & \\
$\quad$ Reduced & & & \\
$\quad$ Full Price & $2.97(0.613)$ & $3.38(0.466)$ & $0.0283 *$ \\
Q1Grade & $2.88[1.75$, & $3.44[2.25,4.00]$ & \\
$\quad$ Mean (SD) & $3.86]$ & \\
Median [Min, Max] & & \\
\hline
\end{tabular}

Note: $*=p<.05$ 
Table C3. Aim 1 means, standard deviations, and correlations with confidence intervals

\begin{tabular}{|c|c|c|c|c|c|c|c|}
\hline Variable & $M$ & $S D$ & 1 & 2 & 3 & 4 & 5 \\
\hline $\begin{array}{l}\text { 1. PPSA } \\
\text { Competence }\end{array}$ & 5.71 & 0.84 & & & & & \\
\hline $\begin{array}{l}\text { 2. PPSA } \\
\text { Importance }\end{array}$ & 5.22 & 0.82 & $\begin{array}{c}.61 * * \\
{[.36, .78]}\end{array}$ & & & & \\
\hline 3. PPSA Utility & 4.92 & 1.57 & $\begin{array}{c}.21 \\
{[-.12, .50]}\end{array}$ & $\begin{array}{c}.58 * * \\
{[.31, .76]}\end{array}$ & & & \\
\hline $\begin{array}{l}\text { 4. SDQ Emotional } \\
\text { Difficulties }\end{array}$ & 1.59 & 0.44 & $\begin{array}{c}-.16 \\
{[-.46, .18]}\end{array}$ & $\begin{array}{c}-.28 \\
{[-.55, .05]}\end{array}$ & $\begin{array}{c}-.20 \\
{[-.49, .13]}\end{array}$ & & \\
\hline $\begin{array}{l}\text { 5. Academic Self- } \\
\text { Concept }\end{array}$ & 2.86 & 0.54 & $\begin{array}{c}.28 \\
{[-.05, .55]}\end{array}$ & $\begin{array}{c}-.08 \\
{[-.40, .25]}\end{array}$ & $\begin{array}{c}-.05 \\
{[-.37, .28]}\end{array}$ & $\begin{array}{c}-.12 \\
{[-.43, .21]}\end{array}$ & \\
\hline 6. 4th Quarter GPA & 2.97 & 0.74 & $\begin{array}{c}.22 \\
{[-.11, .51]}\end{array}$ & $\begin{array}{c}-.16 \\
{[-.46, .18]}\end{array}$ & $\begin{array}{l}-.15 \\
{[-.45, .18]}\end{array}$ & $\begin{array}{c}-.27 \\
{[-.54, .06]}\end{array}$ & $\begin{array}{c}.57 * * \\
{[.30, .75]}\end{array}$ \\
\hline
\end{tabular}

Note. $M$ and $S D$ are used to represent mean and standard deviation, respectively. Values in square brackets indicate the $95 \%$ confidence interval for each correlation. The confidence interval is a plausible range of population correlations that could have caused the sample correlation (Cumming, 2014). * indicates $p<.05 . * *$ indicates $p<.01$. PPSA $=$ Positive Primary Self-Aspect. SDQ $=$ Strengths \& Difficulties Questionnaire. 
Table C4. Correlation of scholastic competence and PPSA at time 1

\begin{tabular}{|c|c|c|c|c|c|}
\hline & \multicolumn{5}{|c|}{ Dependent variable: } \\
\hline & \multicolumn{5}{|c|}{ SPPA Scholastic Competence } \\
\hline & $(1)$ & $(2)$ & $(3)$ & $(4)$ & $(5)$ \\
\hline WIDW Competence & $\begin{array}{l}0.353^{* *} \\
(0.131)\end{array}$ & $\begin{array}{l}0.338^{* *} \\
(0.126)\end{array}$ & $\begin{array}{l}0.178^{*} \\
(0.105)\end{array}$ & & \\
\hline WIDW Importance & $\begin{array}{c}-0.318^{*} \\
(0.160)\end{array}$ & $\begin{array}{c}-0.268^{* *} \\
(0.130)\end{array}$ & & $\begin{array}{l}-0.056 \\
(0.111)\end{array}$ & \\
\hline WIDW Utility & $\begin{array}{c}0.037 \\
(0.068)\end{array}$ & & & & $\begin{array}{l}-0.018 \\
(0.058)\end{array}$ \\
\hline Constant & $\begin{array}{c}2.326^{* * *} \\
(0.629)\end{array}$ & $\begin{array}{c}2.333^{* * *} \\
(0.623)\end{array}$ & $\begin{array}{c}1.848^{* * *} \\
(0.603)\end{array}$ & $\begin{array}{c}3.157^{* * *} \\
(0.587)\end{array}$ & $\begin{array}{c}2.954^{* * *} \\
(0.300)\end{array}$ \\
\hline Observations & 37 & 37 & 37 & 37 & 37 \\
\hline $\mathrm{R}^{2}$ & 0.187 & 0.180 & 0.077 & 0.007 & 0.003 \\
\hline Adjusted $\mathrm{R}^{2}$ & 0.113 & 0.132 & 0.050 & -0.021 & -0.026 \\
\hline Residual Std. Error & $0.510(\mathrm{df}=33)$ & $0.505(\mathrm{df}=34)$ & $0.528(\mathrm{df}=35)$ & $0.547(\mathrm{df}=35)$ & $0.549(\mathrm{df}=35)$ \\
\hline F Statistic & $2.533^{*}(\mathrm{df}=3 ; 33)$ & $3.726^{* *}(\mathrm{df}=2 ; 34)$ & $2.902^{*}(\mathrm{df}=1 ; 35)$ & $0.254(\mathrm{df}=1 ; 35)$ & $0.096(\mathrm{df}=1 ; 35)$ \\
\hline
\end{tabular}


Table C5. Correlation of emotional difficulties and PPSA at time 1

\begin{tabular}{|c|c|c|c|c|}
\hline & \multicolumn{4}{|c|}{ Dependent variable: } \\
\hline & \multicolumn{4}{|c|}{ SDQ Emotional Difficulties } \\
\hline & $(1)$ & $(2)$ & $(3)$ & $(4)$ \\
\hline WIDW Competence & $\begin{array}{c}0.008 \\
(0.112)\end{array}$ & $\begin{array}{l}-0.081 \\
(0.087)\end{array}$ & & \\
\hline WIDW Importance & $\begin{array}{l}-0.137 \\
(0.138)\end{array}$ & & $\begin{array}{c}-0.150^{*} \\
(0.087)\end{array}$ & \\
\hline WIDW Utility & $\begin{array}{l}-0.016 \\
(0.058)\end{array}$ & & & $\begin{array}{l}-0.056 \\
(0.046)\end{array}$ \\
\hline Constant & $\begin{array}{c}2.345^{* * *} \\
(0.541)\end{array}$ & $\begin{array}{c}2.056^{* * *} \\
(0.502)\end{array}$ & $\begin{array}{c}2.376^{* * *} \\
(0.457)\end{array}$ & $\begin{array}{c}1.870^{* * *} \\
(0.238)\end{array}$ \\
\hline Observations & 37 & 37 & 37 & 37 \\
\hline $\mathrm{R}^{2}$ & 0.081 & 0.024 & 0.079 & 0.040 \\
\hline Adjusted $\mathrm{R}^{2}$ & -0.002 & -0.004 & 0.052 & 0.013 \\
\hline Residual Std. Error & $0.439(\mathrm{df}=33)$ & $0.439(\mathrm{df}=35)$ & $0.427(\mathrm{df}=35)$ & $0.436(\mathrm{df}=35)$ \\
\hline F Statistic & $0.972(\mathrm{df}=3 ; 33)$ & $0.862(\mathrm{df}=1 ; 35)$ & $2.992^{*}(\mathrm{df}=1 ; 35)$ & $1.469(\mathrm{df}=1 ; 35)$ \\
\hline
\end{tabular}


Table C6. Prediction of end of year GPA by PPSA, emotional difficulties and SPPA scholastic competence

\begin{tabular}{|c|c|c|c|c|c|c|c|}
\hline & \multicolumn{7}{|c|}{ Dependent variable: } \\
\hline & \multicolumn{7}{|c|}{ Cumulative End of Year GPA } \\
\hline & (1) & (2) & (3) & (4) & (5) & (6) & (7) \\
\hline WIDW Competence & $\begin{array}{c}0.443^{* *} \\
(0.178)\end{array}$ & $\begin{array}{l}0.441^{* *} \\
(0.172)\end{array}$ & $\begin{array}{c}0.193 \\
(0.145)\end{array}$ & & & & \\
\hline WIDW Importance & $\begin{array}{c}-0.423^{*} \\
(0.218)\end{array}$ & $\begin{array}{c}-0.417^{* *} \\
(0.176)\end{array}$ & & $\begin{array}{l}-0.140 \\
(0.150)\end{array}$ & & & \\
\hline WIDW Utility & $\begin{array}{c}0.005 \\
(0.092)\end{array}$ & & & & $\begin{array}{l}-0.072 \\
(0.078)\end{array}$ & & \\
\hline SPPA Scholastic Competence & & & & & & $\begin{array}{c}0.774^{* * *} \\
(0.189)\end{array}$ & \\
\hline SDQ Emotional Difficulties & & & & & & & $\begin{array}{l}-0.450 \\
(0.274)\end{array}$ \\
\hline Constant & $\begin{array}{c}2.624^{* * *} \\
(0.859)\end{array}$ & $\begin{array}{c}2.625^{* * *} \\
(0.846)\end{array}$ & $\begin{array}{l}1.871^{* *} \\
(0.834)\end{array}$ & $\begin{array}{c}3.701^{* * *} \\
(0.792)\end{array}$ & $\begin{array}{c}3.323^{* * *} \\
(0.405)\end{array}$ & $\begin{array}{c}0.754 \\
(0.552)\end{array}$ & $\begin{array}{c}3.688^{* * *} \\
(0.453)\end{array}$ \\
\hline Observations & 37 & 37 & 37 & 37 & 37 & 37 & 37 \\
\hline & 0.183 & 0.183 & 0.048 & 0.024 & 0.023 & 0.323 & 0.072 \\
\hline Adjusted $\mathrm{R}^{2}$ & 0.109 & 0.135 & 0.021 & -0.004 & -0.005 & 0.303 & 0.045 \\
\hline
\end{tabular}




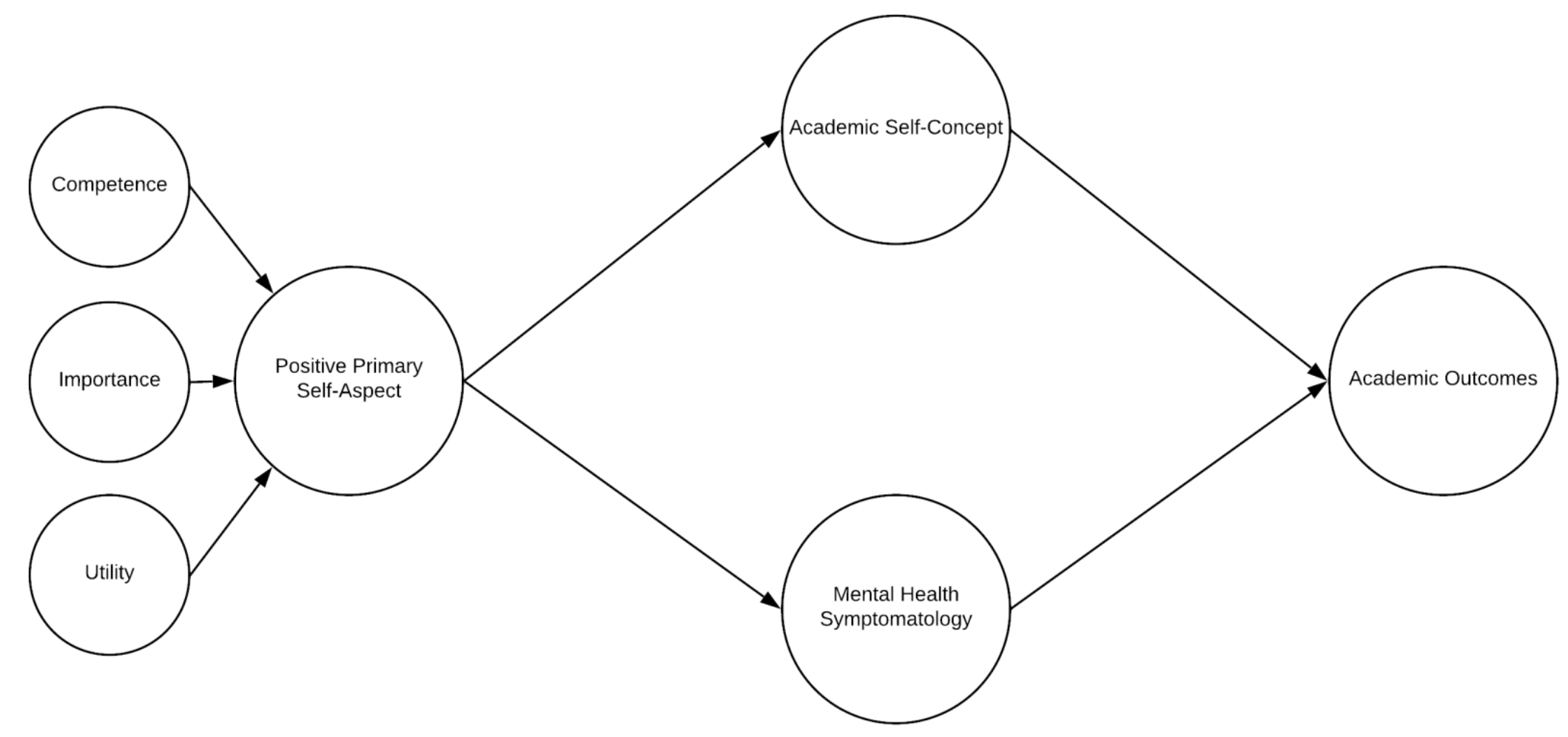

Figure C1. Theoretical model for aim 2 analyses 


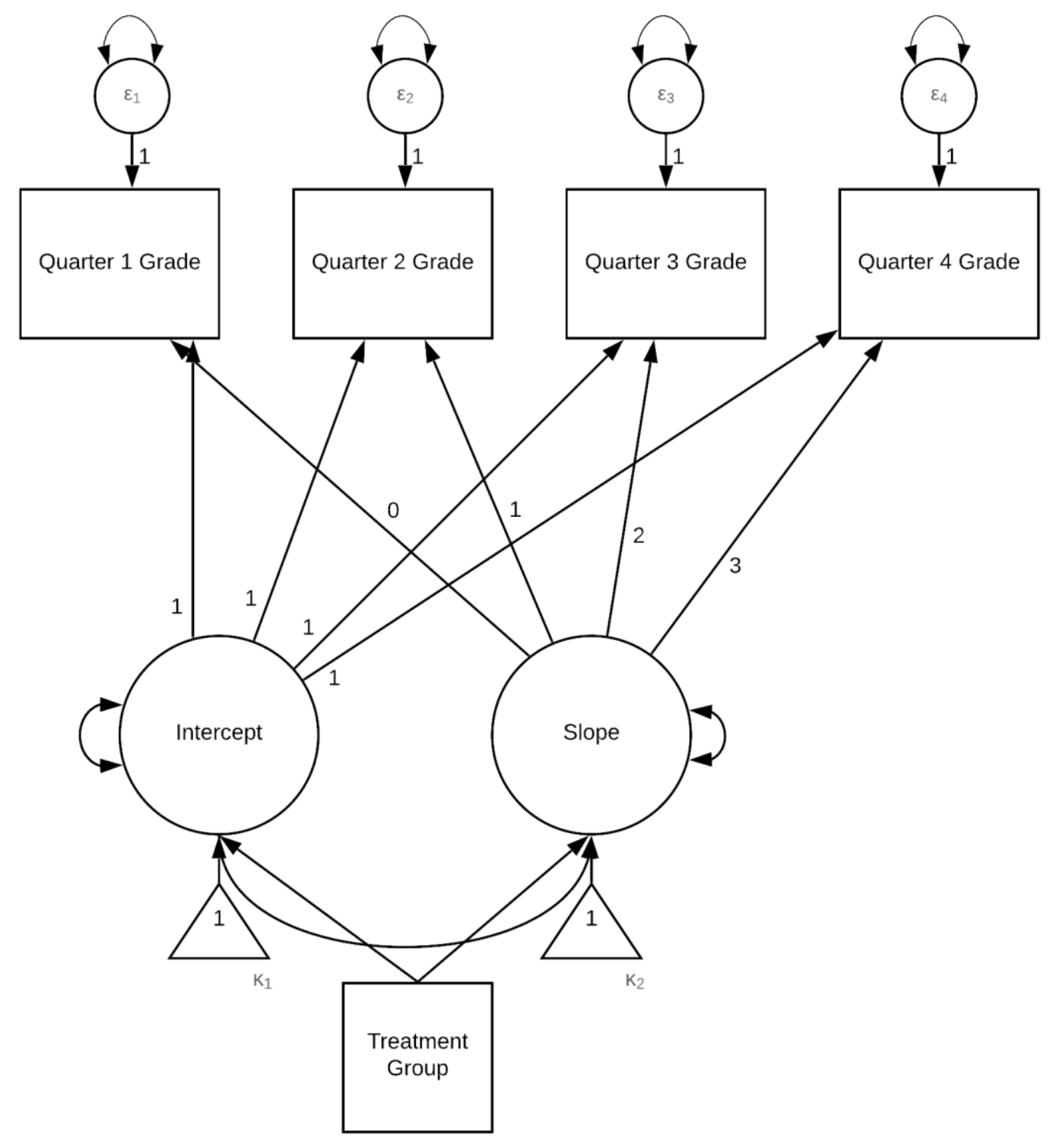

Figure C2. Measurement model for aim 1 growth curve analyses 


\section{FIELD STATEMENT}

The studies presented here expand upon what we know about challenges and opportunities associated with intervention in under-resourced schools. The degree to which self-concept delivers on its potential to change the trajectory of a student's academic career remains unclear, but evidence emerges across the three studies, and advances the literature by offering a more nuanced understanding of the structure of selfconcept in children and adolescents. Two main goals shaped the research presented here. First, we sought to better understand the relationship between non-academic self-concept, mental health, academic self-concept, and academic outcomes. Second, we examined the promise of a wise intervention designed to leverage non-academic self-concept to improve academic outcomes for underserved youth. In this Field Statement, we synthesize findings across studies to inform future directions for research on adolescent self-concept and school-based wise intervention toward improving mental health, academic success, and life trajectories for vulnerable youth.

\section{Self-Concept in Adolescence}

Together, results offer a more detailed and complex picture of the relationship between non-academic self-concept and academic outcomes in children and adolescents. In brief, the evidence for our proposed theoretical model is mixed, particularly as children reach the early adolescent stage of development. While each proposed pathway within the theoretical model showed a significant relationship in at least one analysis, none of the models tested showed significant relationships for all observed paths. This may be due in part to limitations present within the analyses; nevertheless, what's clear when examining the results as a whole is that self-concept in adolescence and its 
relationships to functioning in academic and mental health domains is variable and complicated.

This variability suggests a next step in understanding these relationships may be to examine adolescent self-concept more closely, with particular attention paid to identifying potential moderators. Findings reveal several possible directions. First, the self-concept journals offer a wealth of rich writing from underserved youth about their PPSAs and the relationship of their PPSA to other aspects of their lives. A qualitative examination of the content contained within students' journal entries may offer a great deal of additional information about participants' experience of themselves, beyond what can be captured in a standardized measure. The prompts also contain information about traits connected to students' self-aspects, which could help to understand and even begin to model the aspect/trait relationships proposed by McConnell (McConnell, 2011) in a diverse, low-income adolescent population. Given that effective wise intervention requires thorough understanding of the construct being targeted (Walton \& Wilson, 2018), mapping these connections between aspects and traits would not only deepen our understanding of adolescents' view of themselves, but also offer more insight into the results of the intervention and potential ways to modify or strengthen the journal prompts toward a higher degree of efficacy.

Another potential route for further study would be to further develop the Where I Do Well measure originally offered in Paper 3, and to collect additional data that allows testing of the theoretical model with a larger sample and a more complete set of data from which to work. The additional power offered from a larger sample, combined with data that may serve as moderators or mediators of the proposed relationships (derived from 
the qualitative work discussed above) would further our understanding of how selfconcept connects to mental health and academic outcomes, and how those relationships change based on other factors.

Finally, an examination of effects specific to individual PPSAs might also yield important additional information. We hypothesize here that any PPSA is valuable with regards to protecting against mental health symptoms and improving academic selfconcept and subsequent academic outcomes, but whether or not all PPSAs are equally beneficial to adolescents is an important question that requires further study. If a specific aspect or aspects show higher potential to effect positive changes in student outcomes relative to others, or if some aspects show stronger relationships to common traits that mediate the effect of PPSA on mental health or academic self-concept, then identifying those aspects with more influence could inform changes to the intervention or development of new intervention tools best positioned to improve outcomes using selfconcept as a lever for change.

\section{Wise Interventions}

The second goal, testing the promise of a wise intervention leveraging selfconcept to improve academic outcomes, did not show the effects we expected. Recall that Walton (Walton, 2014) proposed three keys to successful wise intervention: (1) the targeted psychological process matters in the context where the intervention is delivered, (2) the intervention changes the targeted process, and (3) the immediate effect of intervention also begins a recursive process of change over time. Walton's keys offer a helpful framework for examining the implications of the findings presented here. 
First, it may be that PPSA does matter enough in a school setting, or relate closely enough to academic self-concept, to serve as an effective lever for change in an academic context. If that is true, then a different psychological structure with a similar intervention paradigm might yield different results. Examining whether specific PPSAs offer differential effects on academic outcomes, as discussed above, might provide more specific or useful targets for intervention as opposed to students' self-selected PPSA.

Alternatively, PPSA may matter within a school context, but the intervention itself may have failed to meaningfully effect it. If that is the case, then reworking the intervention to better engender change in PPSA would be an appropriate next step. Again, further work to better understand the relationship between PPSA, associated traits, and academic self-concept would be a necessary step as part of this effort, in order to better identify which portions of the intervention may be more or less effective with regard to changing these components. Brief replications using individual prompts along with pre-post measurement of PPSA or self-concept structures could also help to determine which components, if any, might be more useful to keep or adapt before replicating the entire paradigm with another group of students.

Finally, the intervention may have achieved a change in PPSA, but that change may not have led to a change in trajectory over time, driven by the recursive processes believed to underlie the long-term effects of similar wise interventions (Cohen et al., 2009). Given the significant change in timeline of intervention delivery, it is difficult to tease apart whether this change failed to occur or whether insufficient time to observe change was available for the current study. An examination of the same students' grades 
during their subsequent academic year could potentially offer one place to begin, and yield additional data to determine whether effects emerged after a longer period. Each of these approaches to examining the intervention, alone or in tandem, can offer additional insight into why the intervention did not achieve the expected effects, especially when paired with deeper examination of self-concept in adolescence. Together with the results of the current work, they offer several meaningful and feasible pathways for continued study that can contribute to the body of literature around school-based intervention for underserved youth.

\section{Concluding Remarks}

The work presented here, in many ways, serves as a microcosm of the challenges and opportunities associated with intervention in under-resourced schools. I'm humbled and thankful for the opportunity to have learned so many lessons from this work about community-university collaboration, the realities of school-based research, and a detailed, first-hand understanding of the challenges that the men and women who spend every day serving this population face. It's one thing to read the research on the nature of underserved schools, and quite another to stand side by side with the one mental health professional available to a population of 1800 students, as she deals with gang violence, homelessness, substance abuse, and threats of active shooters - often in the same day.

Given the severity of need present within this population, it may be argued that wise intervention may not be sufficiently powerful to overcome the pre-existing disadvantages these adolescents experience. On its face, a one-hour intervention changing the academic trajectory of at-risk students may seem difficult to believe (Yeager \& 
Walton, 2011). However, it is precisely the minimal nature of the intervention that argues for continued work to refine it until the questions posed by the current results are answered. Schools who serve diverse, low-income populations lack the resources to reach the majority of students who need help with more traditional school-based intervention models (Baker et al., 2006), which certainly mirrored the experience of our community partner school, which served 1800 students with one mental health professional on staff. We would not argue that an intervention of this type would serve as a replacement for more intensive mental health services for adolescents meeting criteria for psychiatric illness. However, a resource-minimal tool that can be disseminated and implemented with fidelity, aligns with schools' primary mission, keeps burden to teachers to a minimum, and has potential to be broadly effective at the universal level, may represent a meaningful part of an overall intervention strategy designed to deliver the appropriate level of services to as many students as possible, consistent with current public health recommendations for school-based mental health (Fazel et al., 2014). Given the particular need to identify tools of this type for diverse, low-income adolescents, the current work offers sufficient justification for further exploration of the intervention framework presented here as one piece of a broader strategy to shift the landscape of school mental health services for underserved youth.

My hope is that these findings help to further understand the complex interplay of factors that influence self-concept in adolescence, and that they allow for refinement of tools used to offer an effective and useful self-concept based intervention that works within a broader framework of resource-minimal tools designed to maximize a school's ability to respond to the wide variety of challenges faced by its students within their 
existing budget of resources. If this work helps to better equip under-resourced schools to help the students who need it most, then the time and effort required to complete it were well spent. 


\section{REFERENCES}

Arnold, D. H. (1997). Co-occurrence of externalizing behavior problems and emergent academic difficulties in young high-risk boys: A preliminary evaluation of patterns and mechanisms. Journal of Applied Developmental Psychology, 18(3), 317-330. https://doi.org/10.1016/S0193-3973(97)80003-2

Atkins, M. S., Frazier, S. L., Birman, D., Adil, J. A., Jackson, M., Graczyk, P. A., ... McKay, M. M. (2006). School-Based Mental Health Services for Children Living in High Poverty Urban Communities. Administration and Policy in Mental Health and Mental Health Services Research, 33(2), 146-159. https://doi.org/10.1007/s10488-006-0031-9

Atkins, M. S., Hoagwood, K. E., Kutash, K., \& Seidman, E. (2010). Toward the Integration of Education and Mental Health in Schools. Administration and Policy in Mental Health, 37(1-2), 40-47. https://doi.org/10.1007/s10488-010-0299-7

Atkins, M. S., Shernoff, E. S., Frazier, S. L., Schoenwald, S. K., Cappella, E., MarinezLora, A., ... Bhaumik, R. (2015). Redesigning community mental health services for urban children: Supporting schooling to promote mental health. Journal of Consulting and Clinical Psychology, 83(5), 839.

Baker, J. A., Kamphaus, R. W., \& Horne, A. M. (2006). Evidence for Population-Based Perspectives on Children's Behavioral Adjustment and Needs for Service Delivery in Schools. School Psychology Review, 35(1), 31-46.

Baumeister, R. F., Campbell, J. D., Krueger, J. I., \& Vohs, K. D. (2003). Does High SelfEsteem Cause Better Performance, Interpersonal Success, Happiness, or Healthier Lifestyles? Psychological Science in the Public Interest, 4(1), 1-44. https://doi.org/10.1111/1529-1006.01431

Bidell, M. P., \& Deacon, R. E. (2010). School Counselors Connecting the Dots between Disruptive Classroom Behavior and Youth Self-Concept. Journal of School Counseling, 8(9). Retrieved from https://eric.ed.gov/?id=EJ885062

Blackwell, L. S., Trzesniewski, K. H., \& Dweck, C. S. (2007). Implicit theories of intelligence predict achievement across an adolescent transition: A longitudinal study and an intervention. Child Development, 78(1), 246-263. 
Blomfield, C. J., \& Barber, B. L. (2011). Developmental experiences during extracurricular activities and Australian adolescents' self-concept: Particularly important for youth from disadvantaged schools. Journal of Youth and Adolescence, 40(5), 582-594.

Bolier, L., Haverman, M., Westerhof, G. J., Riper, H., Smit, F., \& Bohlmeijer, E. (2013). Positive psychology interventions: A meta-analysis of randomized controlled studies. BMC Public Health, 13(1), 119.

Bollen, K.A., \& Long, J. S. (1993). Testing Structural Equation Models. Newbery Park, CA: Sage.

Bollen, Kenneth A., \& Long, J. S. (1993). Testing Structural Equation Models. SAGE.

Borelli, J. L., \& Prinstein, M. J. (2006). Reciprocal, Longitudinal Associations Among Adolescents' Negative Feedback-Seeking, Depressive Symptoms, and Peer Relations. Journal of Abnormal Child Psychology, 34(2), 154-164. https://doi.org/10.1007/s10802-005-9010-y

Bradley, R., Doolittle, J., \& Bartolotta, R. (2008). Building on the data and adding to the discussion: The experiences and outcomes of students with emotional disturbance. Journal of Behavioral Education, 17(1), 4-23.

Breslau, J., Lane, M., Sampson, N., \& Kessler, R. C. (2008). Mental disorders and subsequent educational attainment in a US national sample. Journal of Psychiatric Research, 42(9), 708-716. https://doi.org/10.1016/j.jpsychires.2008.01.016

Bridgeland, J. M., DiIulio Jr, J. J., \& Morison, K. B. (2006). The silent epidemic: Perspectives of high school dropouts. Civic Enterprises. Retrieved from http://eric.ed.gov/?id=ED513444

Brooks-Gunn, J., \& Duncan, G. J. (1997). The effects of poverty on children. The Future of Children, 55-71.

Cappella, E., Hamre, B. K., Kim, H. Y., Henry, D. B., Frazier, S. L., Atkins, M. S., \& Schoenwald, S. K. (2012). Teacher Consultation and Coaching within Mental Health Practice: Classroom and Child Effects in Urban Elementary Schools. 
Journal of Consulting and Clinical Psychology, 80(4), 597-610.

https://doi.org/10.1037/a0027725

Cardemil, E. V., Reivich, K. J., Beevers, C. G., Seligman, M. E. P., \& James, J. (2007). The prevention of depressive symptoms in low-income, minority children: Twoyear follow-up. Behaviour Research and Therapy, 45(2), 313-327. https://doi.org/10.1016/j.brat.2006.03.010

Cohen, G. L., Garcia, J., Apfel, N., \& Master, A. (2006). Reducing the Racial Achievement Gap: A Social-Psychological Intervention. Science, 313(5791), 1307-1310. https://doi.org/10.1126/science.1128317

Cohen, G. L., Garcia, J., Purdie-Vaughns, V., Apfel, N., \& Brzustoski, P. (2009). Recursive processes in self-affirmation: Intervening to close the minority achievement gap. Science, 324(5925), 400-403.

Cohen, G. L., \& Sherman, D. K. (2014). The psychology of change: Self-affirmation and social psychological intervention. Annual Review of Psychology, 65, 333-371.

Cole, D. A., Martin, J. M., Peeke, L. A., Seroczynski, A. D., \& Fier, J. (1999). Children’s Over- and Underestimation of Academic Competence: A Longitudinal Study of Gender Differences, Depression, and Anxiety. Child Development, 70(2), 459473. https://doi.org/10.1111/1467-8624.00033

Cole, D. A., \& Maxwell, S. E. (2003). Testing mediational models with longitudinal data: Questions and tips in the use of structural equation modeling. Journal of Abnormal Psychology, 112(4), 558-577.

Cole, D. A., Maxwell, S. E., Martin, J. M., Peeke, L. G., Seroczynski, A. D., Tram, J. M., ... Maschman, T. (2001). The Development of Multiple Domains of Child and Adolescent Self-Concept: A Cohort Sequential Longitudinal Design. Child Development, 72(6), 1723-1746.

Deci, E., \& Ryan, R. M. (1985). Intrinsic motivation and self-determination in human behavior. Springer Science \& Business Media.

DiPerna, J. C., \& Elliott, S. N. (1999). Development and Validation of the Academic Competence Evaluation Scales. Journal of Psychoeducational Assessment, 17(3), 207-225. https://doi.org/10.1177/073428299901700302 
Dishion, T. J., Nelson, S. E., \& Kavanagh, K. (2003). The family check-up with high-risk young adolescents: Preventing early-onset substance use by parent monitoring. Behavior Therapy, 34(4), 553-571.

Dumont, M., \& Provost, M. A. (1999). Resilience in Adolescents: Protective Role of Social Support, Coping Strategies, Self-Esteem, and Social Activities on Experience of Stress and Depression. Journal of Youth and Adolescence, 28(3), 343-363. https://doi.org/10.1023/A:1021637011732

Durlak, J. A., Weissberg, R. P., Dymnicki, A. B., Taylor, R. D., \& Schellinger, K. B. (2011). The impact of enhancing students' social and emotional learning: A metaanalysis of school-based universal interventions. Child Development, 82(1), 405432.

Eccles, J., Wigfield, A., Harold, R. D., \& Blumenfeld, P. (1993). Age and gender differences in children's self-and task perceptions during elementary school. Child Development, 64(3), 830-847.

Eisenberg, D., Golberstein, E., \& Hunt, J. B. (2009). Mental Health and Academic Success in College. The B.E. Journal of Economic Analysis \& Policy, 9(1). https://doi.org/10.2202/1935-1682.2191

Elliott, D. S., \& Ageton, S. S. (1980). Reconciling race and class differences in selfreported and official estimates of delinquency. American Sociological Review, 95-110.

Eskreis-Winkler, L., Shulman, E. P., Young, V., Tsukayama, E., Brunwasser, S. M., \& Duckworth, A. L. (2016). Using Wise Interventions to Motivate Deliberate Practice. Journal of Personality and Social Psychology, 111(5), 728-744. https://doi.org/10.1037/pspp0000074

Evans, S. W., \& Weist, M. D. (2004). Commentary: Implementing Empirically Supported Treatments in the Schools: What Are We Asking? Clinical Child and Family Psychology Review, 7(4), 263-267. https://doi.org/10.1007/s10567-0046090-0

Farahmand, F. K., Grant, K. E., Polo, A. J., \& Duffy, S. N. (2011). School-based mental health and behavioral programs for low-income, urban youth: A systematic and meta-analytic review. Clinical Psychology: Science and Practice, 18(4), 372-390. 
Farb, A. F., \& Matjasko, J. L. (2012). Recent advances in research on school-based extracurricular activities and adolescent development. Developmental Review, $32(1), 1-48$.

Farmer, E. M. Z., Burns, B. J., Phillips, S. D., Angold, A., \& Costello, E. J. (2003). Pathways Into and Through Mental Health Services for Children and Adolescents. Psychiatric Services, 54(1), 60-66. https://doi.org/10.1176/appi.ps.54.1.60

Fazel, M., Hoagwood, K., Stephan, S., \& Ford, T. (2014). Mental health interventions in schools 1. The Lancet. Psychiatry, 1(5), 377-387. https://doi.org/10.1016/S22150366(14)70312-8

Filozof, E. M., Albertin, H. K., Jones, C. R., Steme, S. S., Myers, L., \& McDermott, R. J. (1998). Relationship of Adolescent Self-Esteem to Selected Academic Variables. Journal of School Health, 68(2), 68-72. https://doi.org/10.1111/j.17461561.1998.tb07194.x

Firth, J., Torous, J., Nicholas, J., Carney, R., Pratap, A., Rosenbaum, S., \& Sarris, J. (2017). The efficacy of smartphone-based mental health interventions for depressive symptoms: A meta-analysis of randomized controlled trials. World Psychiatry, 16(3), 287-298.

Firth, J., Torous, J., Nicholas, J., Carney, R., Rosenbaum, S., \& Sarris, J. (2017). Can smartphone mental health interventions reduce symptoms of anxiety? A metaanalysis of randomized controlled trials. Journal of Affective Disorders, 218, 1522.

Franklin, C. G., Kim, J. S., Ryan, T. N., Kelly, M. S., \& Montgomery, K. L. (2012). Teacher involvement in school mental health interventions: A systematic review. Children and Youth Services Review, 34(5), 973-982.

Freudenberg, N., \& Ruglis, J. (2007a). Peer reviewed: Reframing school dropout as a public health issue. Preventing Chronic Disease, 4(4).

Freudenberg, N., \& Ruglis, J. (2007b). Reframing school dropout as a public health issue. Retrieved from http://academicworks.cuny.edu/hc_pubs/143/

Froehlich, T. E., Lanphear, B. P., Epstein, J. N., Barbaresi, W. J., Katusic, S. K., \& Kahn, R. S. (2007). Prevalence, Recognition, and Treatment of Attention- 
Deficit/Hyperactivity Disorder in a National Sample of US Children. Archives of Pediatrics \& Adolescent Medicine, 161(9), 857-864.

https://doi.org/10.1001/archpedi.161.9.857

Goodman, R. (1997). The Strengths and Difficulties Questionnaire: A research note. Journal of Child Psychology and Psychiatry, 38(5), 581-586.

Goodman, R. (2001). Psychometric properties of the strengths and difficulties questionnaire. Journal of the American Academy of Child \& Adolescent Psychiatry, 40(11), 1337-1345.

Gottfried, A. E. (1990). Academic intrinsic motivation in young elementary school children. Journal of Educational Psychology, 82(3), 525-538. https://doi.org/10.1037/0022-0663.82.3.525

Graczyk, P. A., Atkins, M. S., Jackson, M. M., Letendre, J. A., Kim-Cohen, J., Baumann, B. L., \& McCoy, J. (2005). Urban Educators' Perceptions of Interventions for Students With Attention Deficit Hyperactivity Disorder: A Preliminary Investigation. Behavioral Disorders, 30(2), 95-104.

Graham, J. W., Taylor, B. J., Olchowski, A. E., \& Cumsille, P. E. (2006). Planned missing data designs in psychological research. Psychological Methods, 11(4), 323-343.

Guay, F., Marsh, H. W., \& Boivin, M. (2003a). Academic self-concept and academic achievement: Developmental perspectives on their causal ordering. Journal of Educational Psychology, 95(1), 124.

Guay, F., Marsh, H. W., \& Boivin, M. (2003b). Academic self-concept and academic achievement: Developmental perspectives on their causal ordering. Journal of Educational Psychology, 95(1), 124-136. https://doi.org/10.1037/00220663.95.1.124

Hanushek, E. A., Kain, J. F., \& Rivkin, S. G. (2004). Why public schools lose teachers. Journal of Human Resources, 39(2), 326-354.

Harter, S. (1985). Manual for the self-perception profile for children. Denver, CO: University of Denver. 
Harter, Susan. (1985). Manual for the self-perception profile for children:(Revision of the perceived competence scale for children). University of Denver.

Harter, Susan. (1993). Causes and Consequences of Low Self-Esteem in Children and Adolescents. In R. F. Baumeister (Ed.), Self-Esteem: The Puzzle of Low SelfRegard (pp. 87-116). https://doi.org/10.1007/978-1-4684-8956-9_5

Harter, Susan. (2000). Is self-esteem only skin-deep? The inextricable link between physical appearance and self-esteem. Reclaiming Children and Youth, 9(3), 133.

Harter, Susan. (2012). Self-perception profile for adolescents: Manual and questionnaires. Denver, CO: Univeristy of Denver, Department of Psychology.

Hartley, M. T. (2010). Increasing Resilience: Strategies for Reducing Dropout Rates for College Students with Psychiatric Disabilities. American Journal of Psychiatric Rehabilitation, 13(4), 295-315. https://doi.org/10.1080/15487768.2010.523372

Helmke, A., \& van Aken, M. A. G. (1995). The causal ordering of academic achievement and self-concept of ability during elementary school: A longitudinal study. Journal of Educational Psychology, 87(4), 624-637. https://doi.org/10.1037/0022-0663.87.4.624

Hernandez, D. J. (2011a). Double Jeopardy: How Third-Grade Reading Skills and Poverty Influence High School Graduation. Annie E. Casey Foundation.

Hernandez, D. J. (2011b). Double Jeopardy: How Third-Grade Reading Skills and Poverty Influence High School Graduation. Retrieved from https://eric.ed.gov/?id=ED518818

Heuer, R., \& Stullich, S. (2011). Comparability of State and Local Expenditures among Schools within Districts: A Report from the Study of School-Level Expenditures. Office of Planning, Evaluation and Policy Development, US Department of Education.

Hill, C. R., \& Hughes, J. N. (2007). An examination of the convergent and discriminant validity of the Strengths and Difficulties Questionnaire. School Psychology Quarterly, 22(3), 380-406. https://doi.org/10.1037/1045-3830.22.3.380 
Hinshaw, S. P. (1992). Externalizing behavior problems and academic underachievement in childhood and adolescence: Causal relationships and underlying mechanisms. Psychological Bulletin, 111(1), 127-155.

Hoagwood, K. E., Serene Olin, S., Kerker, B. D., Kratochwill, T. R., Crowe, M., \& Saka, N. (2007). Empirically based school interventions targeted at academic and mental health functioning. Journal of Emotional and Behavioral Disorders, 15(2), 66-92.

Hoglund, W. L. G., Klingle, K. E., \& Hosan, N. E. (2015). Classroom risks and resources: Teacher burnout, classroom quality and children's adjustment in high needs elementary schools. Journal of School Psychology, 53(5), 337-357. https://doi.org/10.1016/j.jsp.2015.06.002

Ingersoll, R. M. (2001). Teacher Turnover, Teacher Shortages, and the Organization of Schools: (384452004-001) [Data set]. https://doi.org/10.1037/e384452004-001

Johnson, S. B., Riis, J. L., \& Noble, K. G. (2016). State of the art review: Poverty and the developing brain. Pediatrics, 137(4), e20153075.

Johnson, S. M., Kardos, S. M., Kauffman, D., Liu, E., \& Donaldson, M. L. (2004). The support gap: New teachers' early experiences in high-income and low-income schools. Education Policy Analysis Archives, 12, 61.

https://doi.org/10.14507/epaa.v12n61.2004

Kaplan, D. S., Damphousse, K. R., \& Kaplan, H. B. (1994). Mental Health Implications of Not Graduating from High School. The Journal of Experimental Education, 62(2), 105-123. https://doi.org/10.1080/00220973.1994.9943834

Kataoka, S. H., Zhang, L., \& Wells, K. B. (2002). Unmet Need for Mental Health Care Among U.S. Children: Variation by Ethnicity and Insurance Status. American Journal of Psychiatry, 159(9), 1548-1555. https://doi.org/10.1176/appi.ajp.159.9.1548

Kovacs, M. (1992). Children's depression inventory: Manual. Multi-Health Systems North Tonawanda, NY.

Langley, A. K., Nadeem, E., Kataoka, S. H., Stein, B. D., \& Jaycox, L. H. (2010). Evidence-Based Mental Health Programs in Schools: Barriers and Facilitators of 
Successful Implementation. School Mental Health, 2(3), 105-113. https://doi.org/10.1007/s12310-010-9038-1

Lindhiem, O., Bennett, C. B., Rosen, D., \& Silk, J. (2015). Mobile technology boosts the effectiveness of psychotherapy and behavioral interventions: A meta-analysis. Behavior Modification, 39(6), 785-804.

MacKinnon, D. P., Lockwood, C. M., Hoffman, J. M., West, S. G., \& Sheets, V. (2002). A Comparison of Methods to Test Mediation and Other Intervening Variable Effects. Psychological Methods, 7(1), 83.

Mann, M. (Michelle), Hosman, C. M. H., Schaalma, H. P., \& de Vries, N. K. (2004). Self-esteem in a broad-spectrum approach for mental health promotion. Health Education Research, 19(4), 357-372. https://doi.org/10.1093/her/cyg041

Mardia, K. V. (1970). Measures of multivariate skewness and kurtosis with applications. Biometrika, 57(3), 519-530. https://doi.org/10.1093/biomet/57.3.519

Marsh, H. W. (1990a). A multidimensional, hierarchical model of self-concept: Theoretical and empirical justification. Educational Psychology Review, 2(2), $77-$ 172. https://doi.org/10.1007/BF01322177

Marsh, H. W. (1990b). Causal ordering of academic self-concept and academic achievement: A multiwave, longitudinal panel analysis. Journal of Educational Psychology, 82(4), 646.

Marsh, H. W., Byrne, B. M., \& Shavelson, R. J. (1988). A multifaceted academic selfconcept: Its hierarchical structure and its relation to academic achievement. Journal of Educational Psychology, 80(3), 366-380. https://doi.org/10.1037/0022-0663.80.3.366

Marsh, H. W., \& O'Mara, A. (2008). Reciprocal Effects Between Academic SelfConcept, Self-Esteem, Achievement, and Attainment Over Seven Adolescent Years: Unidimensional and Multidimensional Perspectives of Self-Concept. Personality and Social Psychology Bulletin, 34(4), 542-552. https://doi.org/10.1177/0146167207312313

Marsh, H. W., Parada, R. H., \& Ayotte, V. (2004). A Multidimensional Perspective of Relations Between Self-Concept (Self Description Questionnaire II) and 
Adolescent Mental Health (Youth Self-Report). Psychological Assessment, 16(1), 27-41. https://doi.org/10.1037/1040-3590.16.1.27

Marsh, H. W., \& Seaton, M. (2013). Academic self-concept. International Guide to Student Achievement, 62-63.

Marsh, H. W., \& Shavelson, R. (1985). Self-Concept: Its Multifaceted, Hierarchical Structure. Educational Psychologist, 20(3), 107-123. https://doi.org/10.1207/s15326985ep2003_1

Marsh, H. W., \& Yeung, A. S. (1997). Causal effects of academic self-concept on academic achievement: Structural equation models of longitudinal data. Journal of Educational Psychology, 89(1), 41.

Marsh, H., \& Yeung, A. (1997). Causal Effects of Academic Self-Concept on Academic Achievement. Journal of Educational Psychology, 89(1), 41-54.

McConnell, A. R. (2011a). The multiple self-aspects framework: Self-concept representation and its implications. Personality and Social Psychology Review, 15(1), 3-27.

McConnell, A. R. (2011b). The Multiple Self-Aspects Framework: Self-Concept Representation and Its Implications. Personality and Social Psychology Review, 15(1), 3-27. https://doi.org/10.1177/1088868310371101

McLeod, J. D., \& Kaiser, K. (2004). Childhood Emotional and Behavioral Problems and Educational Attainment. American Sociological Review, 69(5), 636-658. https://doi.org/10.1177/000312240406900502

Merikangas, K. R., He, J., Burstein, M., Swanson, S. A., Avenevoli, S., Cui, L., ... Swendsen, J. (2010). Lifetime prevalence of mental disorders in US adolescents: Results from the National Comorbidity Survey Replication-Adolescent Supplement (NCS-A). Journal of the American Academy of Child \& Adolescent Psychiatry, 49(10), 980-989.

Miyake, A., Kost-Smith, L. E., Finkelstein, N. D., Pollock, S. J., Cohen, G. L., \& Ito, T. A. (2010). Reducing the Gender Achievement Gap in College Science: A Classroom Study of Values Affirmation. Science, 330(6008), 1234-1237. https://doi.org/10.1126/science.1195996 
Muris, P., Meesters, C., \& Fijen, P. (2003). The Self-Perception Profile for Children: Further evidence for its factor structure, reliability, and validity. Personality and Individual Differences, 35(8), 1791-1802. https://doi.org/10.1016/S01918869(03)00004-7

Muthen, B. O., \& Satorra, A. (1995). Complex Sample Data in Structural Equation Modeling. Sociological Methodology, 25, 267. https://doi.org/10.2307/271070

Mychailyszyn, M. P., Brodman, D. M., Read, K. L., \& Kendall, P. C. (2012). Cognitivebehavioral school-based interventions for anxious and depressed youth: A metaanalysis of outcomes. Clinical Psychology: Science and Practice, 19(2), 129-153.

Ogle, R. R., Frazier, S. L., Nichols-Lopez, K., Cappella, E., \& others. (2016). Nonacademic self-concept among urban youth: Associations with academic success. School Mental Health, 8(2), 278-291.

O’Mara, A. J., Marsh, H. W., Craven, R. G., \& Debus, R. L. (2006). Do Self-Concept Interventions Make a Difference? A Synergistic Blend of Construct Validation and Meta-Analysis. Educational Psychologist, 41(3), 181-206. https://doi.org/10.1207/s15326985ep4103_4

Owens, J. S., Goldfine, M. E., Evangelista, N. M., Hoza, B., \& Kaiser, N. M. (2007). A critical review of self-perceptions and the positive illusory bias in children with ADHD. Clinical Child and Family Psychology Review, 10(4), 335-351.

Oyserman, D., Bybee, D., \& Terry, K. (2006). Possible selves and academic outcomes: How and when possible selves impel action. Journal of Personality and Social Psychology, 91(1), 188.

Palardy, G. J. (2013). High school socioeconomic segregation and student attainment. American Educational Research Journal, 50(4), 714-754.

Reardon, S. F. (2013). The widening income achievement gap. Educational Leadership, $70(8), 10-16$.

Reinke, W. M., Stormont, M., Herman, K. C., Puri, R., \& Goel, N. (2011). Supporting children's mental health in schools: Teacher perceptions of needs, roles, and barriers. School Psychology Quarterly, 26(1), 1-13. https://doi.org/10.1037/a0022714 
Retelsdorf, J., Köller, O., \& Möller, J. (2014). Reading achievement and reading selfconcept-Testing the reciprocal effects model. Learning and Instruction, 29, 2130 .

Richardson, M., Moore, D. A., Gwernan-Jones, R., Thompson-Coon, J., Ukoumunne, O., Rogers, M., ... Morris, C. (2015). Non-pharmacological interventions for attention-deficit/hyperactivity disorder (ADHD) delivered in school settings: Systematic reviews of quantitative and qualitative research. Health Technology Assessment (Winchester, England), 19(45), 1.

Rolfsnes, E. S., \& Idsoe, T. (2011). School-based intervention programs for PTSD symptoms: A review and meta-analysis. Journal of Traumatic Stress, 24(2), 155165.

Rones, M., \& Hoagwood, K. (2000). School-Based Mental Health Services: A Research Review. 19.

Rosenberg, M., Schooler, C., Schoenbach, C., \& Rosenberg, F. (1995). Global SelfEsteem and Specific Self-Esteem: Different Concepts, Different Outcomes. American Sociological Review, 60(1), 141-156. https://doi.org/10.2307/2096350

Rylance, B. J. (1997). Predictors of High School Graduation or Dropping Out for Youths with Severe Emotional Disturbances Predictors of High School Graduation or Dropping Out for Youths with Severe Emotional Disturbances. Behavioral Disorders, 23(1), 5-17. https://doi.org/10.1177/019874299702300104

Santiago, C. D., Kaltman, S., \& Miranda, J. (2013). Poverty and Mental Health: How Do Low-Income Adults and Children Fare in Psychotherapy?: Poverty and Mental Health. Journal of Clinical Psychology, 69(2), 115-126. https://doi.org/10.1002/jclp.21951

Schleider, J. L., \& Weisz, J. R. (2017). Little treatments, promising effects? Metaanalysis of single-session interventions for youth psychiatric problems. Journal of the American Academy of Child \& Adolescent Psychiatry, 56(2), 107-115.

Seligman, M. E., Steen, T. A., Park, N., \& Peterson, C. (2005). Positive psychology progress: Empirical validation of interventions. American Psychologist, 60(5), 410. 
Shapka, J. D., \& Keating, D. P. (2005). Structure and Change in Self-Concept During Adolescence. Canadian Journal of Behavioural Science/Revue Canadienne Des Sciences Du Comportement, 37(2), 83.

Shavelson, R. J., Hubner, J. J., \& Stanton, G. C. (1976a). Self-concept: Validation of construct interpretations. Review of Educational Research, 46(3), 407-441.

Shavelson, R. J., Hubner, J. J., \& Stanton, G. C. (1976b). Self-Concept: Validation of Construct Interpretations. Review of Educational Research, 46(3), 407-441. https://doi.org/10.3102/00346543046003407

Sherman, D. K., Bunyan, D. P., Creswell, J. D., \& Jaremka, L. M. (2009). Psychological vulnerability and stress: The effects of self-affirmation on sympathetic nervous system responses to naturalistic stressors. Health Psychology : Official Journal of the Division of Health Psychology, American Psychological Association, 28(5), 554-562. https://doi.org/10.1037/a0014663

Sibley, M. H., Pelham Jr, W. E., Molina, B. S., Gnagy, E. M., Waschbusch, D. A., Garefino, A. C., ... Karch, K. M. (2012). Diagnosing ADHD in adolescence. Journal of Consulting and Clinical Psychology, 80(1), 139.

Sibley, M. H., Pelham, W. E., Molina, B. S., Waschbusch, D. A., Gnagy, E. M., Babinski, D. E., \& Biswas, A. (2010). Inconsistent self-report of delinquency by adolescents and young adults with ADHD. Journal of Abnormal Child Psychology, 38(5), 645-656.

Silverman, A., Logel, C., \& Cohen, G. L. (2013). Self-affirmation as a deliberate coping strategy: The moderating role of choice. Journal of Experimental Social Psychology, 49(1), 93-98.

Silverman, W. K., \& Ollendick, T. H. (2005). Evidence-based assessment of anxiety and its disorders in children and adolescents. Journal of Clinical Child and Adolescent Psychology, 34(3), 380-411.

Somerville, L. H. (2013). Special issue on the teenage brain: Sensitivity to social evaluation. Current Directions in Psychological Science, 22(2), 121-127. https://doi.org/10.1177/0963721413476512 
Sowislo, J. F., \& Orth, U. (2013). Does low self-esteem predict depression and anxiety? A meta-analysis of longitudinal studies. Retrieved from http://psycnet.apa.org/journals/bul/139/1/213/

Steele, C. M. (1988). The Psychology of Self-Affirmation: Sustaining the Integrity of the Self. In L. Berkowitz (Ed.), Advances in Experimental Social Psychology (Vol. 21, pp. 261-302). https://doi.org/10.1016/S0065-2601(08)60229-4

Steinberg, L., \& Morris, A. S. (2001). Adolescent development. Annual Review of Psychology, 52(1), 83-110.

Steiner, H., \& Remsing, L. (2007). Practice parameter for the assessment and treatment of children and adolescents with oppositional defiant disorder. Journal of the American Academy of Child \& Adolescent Psychiatry, 46(1), 126-141.

Suh, S., Suh, J., \& Houston, I. (2007). Predictors of Categorical At-Risk High School Dropouts. Journal of Counseling \& Development, 85(2), 196-203.

Sum, A., Khatiwada, I., McLaughlin, J., \& Palma, S. (2009). The consequences of dropping out of high school. Center for Labor Market Studies Publications. Retrieved from http://www.ibm.com/connect/ibm/attachments/Y012593Q38406K31/The_Conseq uences_of_Dropping_Out_of_High_School.pdf

Tatet, E. S. (1999). Teaching in under-resourced schools: The teach for America example. Theory Into Practice, 38(1), 37-45. https://doi.org/10.1080/00405849909543829

Taylor, V. J., \& Walton, G. M. (2011). Stereotype Threat Undermines Academic Learning. Personality and Social Psychology Bulletin, 37(8), 1055-1067. https://doi.org/10.1177/0146167211406506

The Strengths and Difficulties Questionnaire: A Research Note - Goodman - 1997 Journal of Child Psychology and Psychiatry - Wiley Online Library. (n.d.). Retrieved April 7, 2019, from https://onlinelibrary.wiley.com/doi/full/10.1111/j.1469-7610.1997.tb01545.x 
Thomaes, S., Bushman, B. J., Castro, B. O. de, Cohen, G. L., \& Denissen, J. J. A. (2009). Reducing Narcissistic Aggression by Buttressing Self-Esteem: An Experimental Field Study. Psychological Science, 20(12), 1536-1542. https://doi.org/10.1111/j.1467-9280.2009.02478.x

Thomaes, S., Bushman, B. J., de Castro, B. O., \& Reijntjes, A. (2012). Arousing "gentle passions" in young adolescents: Sustained experimental effects of value affirmations on prosocial feelings and behaviors. Developmental Psychology, 48(1), 103-110. https://doi.org/10.1037/a0025677

Thornberry, T. P., Moore, M., \& Christenson, R. L. (1985). The Effect of Dropping Out of High School on Subsequent Criminal Behavior*. Criminology, 23(1), 3-18. https://doi.org/10.1111/j.1745-9125.1985.tb00323.x

Valentine, J. C., DuBois, D. L., \& Cooper, H. (2004a). The Relation Between SelfBeliefs and Academic Achievement: A Meta-Analytic Review. Educational Psychologist, 39(2), 111-133. https://doi.org/10.1207/s15326985ep3902_3

Valentine, J. C., DuBois, D. L., \& Cooper, H. (2004b). The Relation Between SelfBeliefs and Academic Achievement: A Meta-Analytic Review. Educational Psychologist, 39(2), 111-133. https://doi.org/10.1207/s15326985ep3902_3

Walton, G. M. (2014). The new science of wise psychological interventions. Current Directions in Psychological Science, 23(1), 73-82.

Walton, G. M., \& Cohen, G. L. (2011). A Brief Social-Belonging Intervention Improves Academic and Health Outcomes of Minority Students. Science, 331(6023), 14471451. https://doi.org/10.1126/science. 1198364

Walton, G. M., \& Wilson, T. D. (2018). Wise interventions: Psychological remedies for social and personal problems. Psychological Review, 125(5), 617.

Wood, S. J., \& Cronin, M. E. (1999). Students with emotional/behavioral disorders and transition planning: What the follow-up studies tell us. Psychology in the Schools, 36(4), 327-345. https://doi.org/10.1002/(SICI)15206807(199907)36:4<327::AID-PITS6>3.0.CO;2-P

Yeager, D. S., \& Walton, G. M. (2011). Social-psychological interventions in education: They're not magic. Review of Educational Research, 81(2), 267-301. 
Yeager, D., Walton, G., \& Cohen, G. L. (2013). Addressing achievement gaps with psychological interventions. Phi Delta Kappan, 94(5), 62-65. 


\section{APPENDIX}

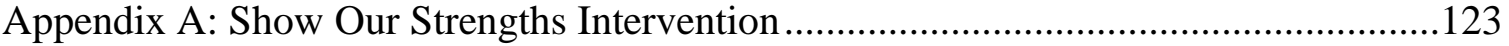

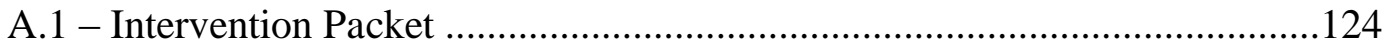

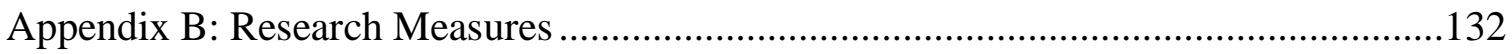

B.1 - Where I Do Well Questionnaire ..........................................................133

B.2 -Self-Perception Profile for Adolescents ..................................................135

B.3 -Strengths and Difficulties Questionnaire ...............................................130 
AppendixA: Show Our Strengths Intervention 


\section{WEEK 1:}

From the list below, choose the word that is most like you. Put the number 1 in the blank next to it. If more than one is like you, choose the one you think is most important. If the one you want to choose isn't on the list below, you may write it in. Then number each one from 1-14 in order of how like you or how important to you each item is.

Then spend a few minutes writing about why your top pick is important. Don't worry about spelling or grammar; just write until you are told to stop writing, for about the next 10 minutes. This won't be graded and there are no right answers, so be honest.

$\begin{array}{llll}\text { _Athlete } & \ldots \text { Student } & \text { _Son/Daughter } & \text { _Actor } \\ \text { _Brother/Sister } & \ldots \text { Friend } & \ldots \text { Person of Faith } & \text { _Comedian } \\ \text { _Artist } & \ldots \text { Man/Woman } & \text { _Musician } & \ldots \text { Niece/Nephew } \\ \text { Cousin } & \ldots \text { Boyfriend/Girlfriend } & \end{array}$




\section{WEEK 2:}

Last time you chose the most important part of yourself, and you wrote about why. Please read what you wrote last week. Then, from the list below, please circle all of the strengths and values that go along with the part of yourself you picked last week. If some are missing, you may add them to the list.

Creativity — making or designing new or interesting things

Curiosity — wanting to find out or learn new things

Judgment—-To make good or wise decisions, to think well

Love of learning-Enjoyment of learning new or challenging things

Perspective - Can see the same thing in different ways

Bravery —Doing the right thing even if you're afraid

Teamwork-Being able to work with others

Perseverance-Being able to stick with difficult things

Honesty-Always telling the truth

Social intelligence-Understanding how other people think and feel

Fairness-Treating others equally

Leadership — Being able to lead or guide others

Forgiveness-Being able to forgive yourself and others

Humility—Being humble

Prudence_-Being able to make decisions based on reason

Self-regulation-Being able to control your behavior or emotions

Appreciation of beauty and excellence 
Gratitude-Being thankful for the good things in your life

Hope-Having a belief that the future will be good or get better

Humor-Being able to laugh, even when things are difficult; being funny

Spirituality - Having a connection with God, religion or a higher power 


\section{WEEK 3:}

The important parts of ourselves, and the strengths that come with them, can help us in many different ways. Last week you picked the strengths and values that go along with the most important part of yourself. Look at the strengths you chose before. Then fill in the first blank in each sentence below with one of those strengths, and the second blank with the important part of yourself, and write a sentence or two about how that strength can help you be a student, help you with your family, and help you with your peers.

Example: My perseverance (strength) as an_athlete_(most important part of yourself) can help me as a student by keeping me going when I'm working on a tough assignment.

My as a can help me as a STUDENT by:

My as a can help me with my

FAMILY by:

My as a can help me with my

\section{PEERS by:}




\section{WEEK 4:}

Last week you wrote about how your most important part of yourself and the strengths that come with it can help in different parts of your life. Read what you wrote last week. Then, pick two or three goals that are important to you — you can pick from the list below or write your own. How can the most important part of yourself help you achieve each goal? What strengths does that part of yourself give you that can help you achieve those goals?

Spend a few minutes writing about how you can achieve those goals - if you have extra time, try listing the steps you need to take to achieve your goals.

Example: My goal is to get into college. To do that, I need to get good grades, to go to school every day, and to pass my FSA exams. To get good grades, I need to turn in all of my homework and study for tests. My important part of myself is athlete. Athletes are good at working hard and practicing to get better. I can work hard and practice on homework and studying just like I do on sports, and that will help me get good grades and then I'll get into college.

Some goals:

Graduate high school; Get into college (or get into a specific college); Get a job (or get a specific job); Learn a new skill (an instrument, a sport, etc.); Have healthy relationships 


\section{WEEK 5:}

The creators of these journal ideas are working on a program to help middle school youth who are having trouble in school. We're hoping that you will help us to make the program better. One of the ways we'd like your help is identifying ways that teens like you can connect with others who value the same things.

It can be hard to find other teens who value the same things you do, or want to spend their time doing the same things you do. Where can you find others who have the same important parts of themselves as you? For example, are there clubs that have your interest as a focus, or could they start one? Are there teams or after school activities they could join? What about other places in the neighborhood (Boys and Girls clubs, YMCA, others)? What advice would you give to a middle schooler that's like you about how they can find others like them?

Example: The most important part of myself is actor. If you're an actor like me, you can try out for plays at your school, or take a drama class if your school has one. You can meet other actors that way and get to do what you love! Sometimes there are after school programs that do theater programs and put on plays that you can join. 


\section{WEEK 6:}

Below is a problem that a child or teen might experience. Imagine you're speaking to a middle schooler with the same most important part of themselves as you. What would you tell them? How can they use the strengths that come with that part of themselves to solve their problem?

Sample problem: A student at the local middle school who has the same most important part of themselves as you do is struggling in school. They did ok last year, but this year is hard, and their grades are falling behind, especially in math. They got a D on the last test they took, and if they don't do well on the test at the end of next week, the grade at the end of the marking period will be very low, and the student is freaking out about the test and their grade in the class. What would you tell them? How can they use their strengths to deal with the situation? Offer as much as you can and be as specific as possible. 
Appendix B: Research Measures 


\section{Where I Do Well}

Directions: Circle your favorite area or part of yourself from the list below. If you have more than one, pick the most important to you. Then circle one number for each question. Each question asks about the favorite area that you circle below. If your favorite area or part of yourself is not on the list, write it in next to other.

\section{Athlete Student Son/Daughter Actor Brother/Sister Friend Person of Faith (Being religious) Artist Comedian Man/Woman}

\section{Other:}

1. Compared to other students, how well do you expect to perform in your favorite area this year?

$\begin{array}{cccccccc}1 & 2 & 3 & 4 & 5 & 6 & 7 & \\ \text { Much worse } & & & \text { About the same } & & \text { Much better }\end{array}$

2. How well do you think you'll do in your favorite area this year?

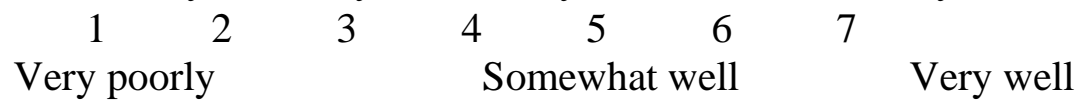

3. How good are you in your favorite area?

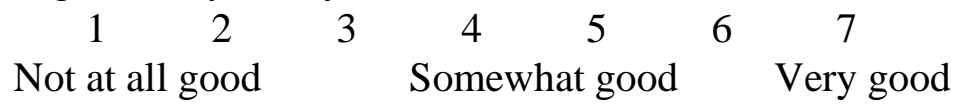

4. If you were to put all the teens you know in order from worst to best in your favorite area, where would you put yourself?

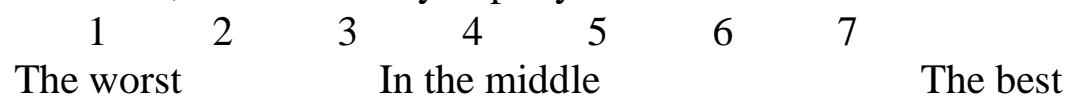

5. How have you performed in your favorite area over the last year?

$\begin{array}{cccccccc}1 & 2 & 3 & 4 & 5 & 6 & 7 & \\ \text { Very poorly } & & & \text { Somewhat well } & & \text { Very well }\end{array}$

6. How important is your favorite area to you?

$\begin{array}{lllllll}1 & 2 & 3 & 4 & 5 & 6 & 7\end{array}$

Not very important Somewhat important Very important

7. How willing are you to miss other opportunities or activities to do things in your favorite area?

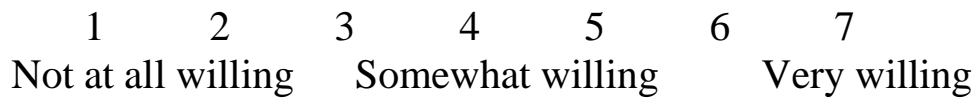


8. How many of your friends have the same favorite area as you do?

\begin{tabular}{|c|c|}
\hline None of then & $\begin{array}{lcc}3 & 4 & 5 \\
\text { About half of them }\end{array}$ \\
\hline
\end{tabular}

9. How much do you like your favorite area?

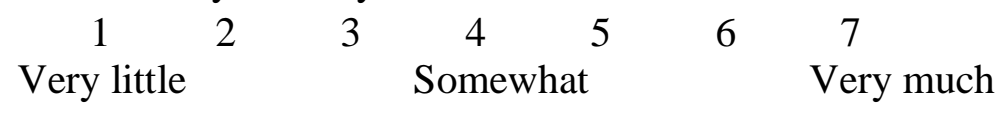

10. In general, I find doing activities in my favorite area:

$\begin{array}{ccccccc}1 & 2 & 3 & 4 & 5 & 6 & 7 \\ \text { Very boring } & & \text { Somewhat interesting } & \text { Very interesting }\end{array}$

11. How useful is your favorite area in helping you do well in school?

$\begin{array}{cclcccc}1 & 2 & 3 & 4 & 5 & 6 & 7 \\ \text { Not at all useful } & \text { Somewhat useful } & & \text { Very useful }\end{array}$

12. How useful is your favorite area in your daily life outside of school?

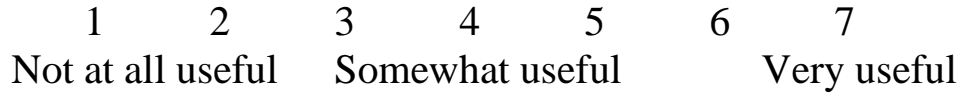

13. How useful is your favorite area for what you want to do after you graduate and go to work?

$\begin{array}{ccccccc}1 & 2 & 3 & 4 & 5 & 6 & 7 \\ \text { Not at all useful } & \text { Somewhat useful } & & \text { Very useful }\end{array}$

14. How useful is your favorite area for having good relationships with your family and friends?

$\begin{array}{cclcccc}1 & 2 & 3 & 4 & 5 & 6 & 7 \\ \text { Not at all useful } & \text { Somewhat useful } & & \text { Very useful }\end{array}$

15. Being good at my favorite area helps me to do well in other areas of my life.

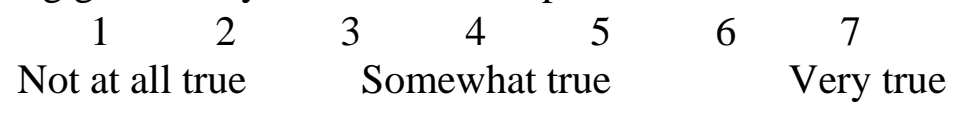


What I Am Like

Name Age Birthday

Month Day

Boy $\square$ Girl

(check one)

\begin{tabular}{|c|c|c|c|c|c|c|c|}
\hline & $\begin{array}{c}\text { Really } \\
\text { True } \\
\text { for me }\end{array}$ & $\begin{array}{c}\text { Sort of } \\
\text { True } \\
\text { for me }\end{array}$ & & & & $\begin{array}{l}\text { Sort of } \\
\text { True } \\
\text { for me }\end{array}$ & $\begin{array}{c}\text { Really } \\
\text { True } \\
\text { for me }\end{array}$ \\
\hline & \multicolumn{7}{|c|}{ Sample Sentence } \\
\hline a. & & & $\begin{array}{l}\text { Some teenagers like to } \\
\text { go to movies in their } \\
\text { spare time }\end{array}$ & BUT & $\begin{array}{l}\text { Other teenagers would } \\
\text { rather go to sports } \\
\text { events }\end{array}$ & & \\
\hline 1. & & & $\begin{array}{l}\text { Some teenagers feel that } \\
\text { they are just as smart as } \\
\text { others their age }\end{array}$ & BUT & $\begin{array}{l}\text { Other teenagers aren't } \\
\text { so sure and wonder if } \\
\text { they are as smart }\end{array}$ & & \\
\hline 2. & & & $\begin{array}{l}\text { Some teenagers find it } \\
\text { hard to make friends }\end{array}$ & BUT & $\begin{array}{l}\text { Other teenagers find it } \\
\text { pretty easy to make } \\
\text { friends }\end{array}$ & & \\
\hline 3. & & & $\begin{array}{l}\text { Some teenagers do very } \\
\text { well at all kinds of sports }\end{array}$ & BUT & $\begin{array}{l}\text { Other teenagers don't } \\
\text { feel that they are very } \\
\text { good when it comes to } \\
\text { sports }\end{array}$ & & \\
\hline 4. & & & $\begin{array}{l}\text { Some teenagers are not } \\
\text { happy with the way they } \\
\text { look }\end{array}$ & BUT & $\begin{array}{l}\text { Other teenagers are } \\
\text { happy with the way they } \\
\text { look }\end{array}$ & & \\
\hline 5. & & & $\begin{array}{l}\text { Some teenagers feel that } \\
\text { they are ready to do well } \\
\text { at a part-time job }\end{array}$ & BUT & $\begin{array}{l}\text { Other teenagers feel that } \\
\text { they are not quite ready } \\
\text { to handle a part-time job }\end{array}$ & & \\
\hline 6. & & & $\begin{array}{l}\text { Some teenagers feel that } \\
\text { if they are romantically } \\
\text { interested in someone, } \\
\text { that person will like them } \\
\text { back }\end{array}$ & BUT & $\begin{array}{l}\text { Other teenagers worry } \\
\text { that when they like } \\
\text { someone romantically, } \\
\text { that person won't like } \\
\text { them back }\end{array}$ & & \\
\hline 7. & & & $\begin{array}{l}\text { Some teenagers usually } \\
\text { do the right thing }\end{array}$ & BUT & $\begin{array}{l}\text { Other teenagers often } \\
\text { don't do what they know } \\
\text { is right }\end{array}$ & & \\
\hline 8. & & & $\begin{array}{l}\text { Some teenagers are able } \\
\text { to make really close } \\
\text { friends }\end{array}$ & BUT & $\begin{array}{l}\text { Other teenagers find it } \\
\text { hard to make really close } \\
\text { friends }\end{array}$ & & \\
\hline 9. & & & $\begin{array}{l}\text { Some teenagers are } \\
\text { often disappointed with } \\
\text { themselves }\end{array}$ & BUT & $\begin{array}{l}\text { Other teenagers are } \\
\text { pretty pleased with } \\
\text { themselves }\end{array}$ & & \\
\hline
\end{tabular}




\begin{tabular}{|c|c|c|c|c|c|c|c|}
\hline & $\begin{array}{l}\text { Really } \\
\text { True } \\
\text { for me }\end{array}$ & $\begin{array}{l}\text { Sort of } \\
\text { True } \\
\text { for me }\end{array}$ & & & & $\begin{array}{l}\text { Sort of } \\
\text { True } \\
\text { for me }\end{array}$ & $\begin{array}{l}\text { Really } \\
\text { True } \\
\text { for me }\end{array}$ \\
\hline 10. & & & $\begin{array}{l}\text { Some teenagers are } \\
\text { pretty slow in finishing } \\
\text { their school work }\end{array}$ & BUT & $\begin{array}{l}\text { Other teenagers can do } \\
\text { their school work quickly }\end{array}$ & & \\
\hline 11. & & & $\begin{array}{l}\text { Some teenagers know } \\
\text { how to make classmates } \\
\text { like them }\end{array}$ & BUT & $\begin{array}{l}\text { Other teenagers don't } \\
\text { know how to make } \\
\text { classmates like them }\end{array}$ & & \\
\hline 12. & & & $\begin{array}{l}\text { Some teenagers think } \\
\text { they could do well at just } \\
\text { about any new athletic } \\
\text { activity }\end{array}$ & BUT & $\begin{array}{l}\text { Other teenagers are } \\
\text { afraid they might not do } \\
\text { well at a new athletic } \\
\text { activity }\end{array}$ & & \\
\hline 13. & & & $\begin{array}{l}\text { Some teenagers wish } \\
\text { their body was different }\end{array}$ & BUT & $\begin{array}{l}\text { Other teenagers like their } \\
\text { body the way it is }\end{array}$ & & \\
\hline 14. & & & $\begin{array}{l}\text { Some teenagers feel that } \\
\text { they don't have enough } \\
\text { skills to do well at a job }\end{array}$ & BUT & $\begin{array}{l}\text { Other teenagers feel that } \\
\text { they do have enough } \\
\text { skills to do a job well }\end{array}$ & & \\
\hline 15. & & & $\begin{array}{l}\text { Some teenagers are not } \\
\text { dating the people they } \\
\text { are really attracted to }\end{array}$ & BUT & $\begin{array}{l}\text { Other teenagers are } \\
\text { dating those people they } \\
\text { are attracted to }\end{array}$ & & \\
\hline 16. & & & $\begin{array}{l}\text { Some teenagers often } \\
\text { get in trouble because of } \\
\text { things they do }\end{array}$ & BUT & $\begin{array}{l}\text { Other teenagers usually } \\
\text { don't do things that get } \\
\text { them in trouble }\end{array}$ & & \\
\hline 17. & & & $\begin{array}{l}\text { Some teenagers don't } \\
\text { know how to find a close } \\
\text { friend with whom they } \\
\text { can share secrets }\end{array}$ & BUT & $\begin{array}{l}\text { Other teenagers do know } \\
\text { how to find a close friend } \\
\text { with whom they can } \\
\text { share secrets }\end{array}$ & & \\
\hline 18. & & & $\begin{array}{l}\text { Some teenagers don't } \\
\text { like the way they are } \\
\text { leading their life }\end{array}$ & BUT & $\begin{array}{l}\text { Other teenagers do like } \\
\text { the way they are leading } \\
\text { their life }\end{array}$ & & \\
\hline 19. & & & $\begin{array}{l}\text { Some teenagers do very } \\
\text { well at their classwork }\end{array}$ & BUT & $\begin{array}{l}\text { Other teenagers don't do } \\
\text { very well at their } \\
\text { classwork }\end{array}$ & & \\
\hline 20. & & & $\begin{array}{l}\text { Some teenagers don't } \\
\text { have the social skills to } \\
\text { make friends }\end{array}$ & BUT & $\begin{array}{l}\text { Other teenagers do have } \\
\text { the social skills to make } \\
\text { friends }\end{array}$ & & \\
\hline 21. & & & $\begin{array}{l}\text { Some teenagers feel that } \\
\text { they are better than } \\
\text { others their age at sports }\end{array}$ & BUT & $\begin{array}{l}\text { Other teenagers don't } \\
\text { feel they can play as well }\end{array}$ & & \\
\hline 22. & & & $\begin{array}{l}\text { Some teenagers wish } \\
\text { their physical appearance } \\
\text { was different }\end{array}$ & BUT & $\begin{array}{l}\text { Other teenagers like their } \\
\text { physical appearance the } \\
\text { way it is }\end{array}$ & & \\
\hline
\end{tabular}




\begin{tabular}{|c|c|c|c|c|c|c|c|}
\hline & $\begin{array}{c}\text { Really } \\
\text { True } \\
\text { for me }\end{array}$ & $\begin{array}{l}\text { Sort of } \\
\text { True } \\
\text { for me }\end{array}$ & & & & $\begin{array}{l}\text { Sort of } \\
\text { True } \\
\text { for me }\end{array}$ & $\begin{array}{c}\text { Really } \\
\text { True } \\
\text { for me }\end{array}$ \\
\hline 23. & & & $\begin{array}{l}\text { Some teenagers feel they } \\
\text { are old enough to get and } \\
\text { keep a paying job }\end{array}$ & BUT & $\begin{array}{l}\text { Other teenagers do not } \\
\text { feel that they are old } \\
\text { enough, yet, to really } \\
\text { handle a job well }\end{array}$ & & \\
\hline 24. & & & $\begin{array}{l}\text { Some teenagers feel that } \\
\text { people their age will be } \\
\text { romantically attracted to } \\
\text { them }\end{array}$ & BUT & $\begin{array}{l}\text { Other teenagers worry } \\
\text { about whether people } \\
\text { their age will be attracted } \\
\text { to them }\end{array}$ & & \\
\hline 25. & & & $\begin{array}{l}\text { Some teenagers feel } \\
\text { really good about the way } \\
\text { they act }\end{array}$ & BUT & $\begin{array}{l}\text { Other teenagers don't } \\
\text { feel that good about the } \\
\text { way they often act }\end{array}$ & & \\
\hline 26. & & & $\begin{array}{l}\text { Some teenagers do know } \\
\text { what it takes to develop a } \\
\text { close friendship with a } \\
\text { peer }\end{array}$ & BUT & $\begin{array}{l}\text { Other teenagers don't } \\
\text { know what to do to form } \\
\text { a close friendship with a } \\
\text { peer }\end{array}$ & & \\
\hline 27. & & & $\begin{array}{l}\text { Some teenagers are } \\
\text { happy with themselves } \\
\text { most of the time }\end{array}$ & BUT & $\begin{array}{l}\text { Other teenagers are } \\
\text { often not happy with } \\
\text { themselves }\end{array}$ & & \\
\hline 28. & & & $\begin{array}{l}\text { Some teenagers have } \\
\text { trouble figuring out the } \\
\text { answers in school }\end{array}$ & BUT & $\begin{array}{l}\text { Other teenagers almost } \\
\text { always can figure out the } \\
\text { answers }\end{array}$ & & \\
\hline 29. & & & $\begin{array}{l}\text { Some teenagers } \\
\text { understand how to get } \\
\text { peers to accept them }\end{array}$ & BUT & $\begin{array}{l}\text { Other teenagers don't } \\
\text { understand how to get } \\
\text { peers to accept them }\end{array}$ & & \\
\hline 30. & & & $\begin{array}{l}\text { Some teenagers don't do } \\
\text { well at new outdoor } \\
\text { games }\end{array}$ & BUT & $\begin{array}{l}\text { Other teenagers are } \\
\text { good at new games right } \\
\text { away }\end{array}$ & & \\
\hline 31. & & & $\begin{array}{l}\text { Some teenagers think } \\
\text { that they are good } \\
\text { looking }\end{array}$ & BUT & $\begin{array}{l}\text { Other teenagers think } \\
\text { that they are not very } \\
\text { good looking }\end{array}$ & & \\
\hline 32. & & & $\begin{array}{l}\text { Some teenagers feel like } \\
\text { they could do better at } \\
\text { work they do for pay }\end{array}$ & BUT & $\begin{array}{l}\text { Other teenagers feel that } \\
\text { they are doing really well } \\
\text { at work they do for pay }\end{array}$ & & \\
\hline 33. & & & $\begin{array}{l}\text { Some teenagers feel that } \\
\text { they are fun and } \\
\text { interesting on a date }\end{array}$ & BUT & $\begin{array}{l}\text { Other teenagers wonder } \\
\text { about how fun and } \\
\text { interesting they are on a } \\
\text { date }\end{array}$ & & \\
\hline 34. & & & $\begin{array}{l}\text { Some teenagers do } \\
\text { things they know they } \\
\text { shouldn't do }\end{array}$ & BUT & $\begin{array}{l}\text { Other teenagers hardly } \\
\text { ever do things they know } \\
\text { they shouldn't do }\end{array}$ & & \\
\hline
\end{tabular}




\begin{tabular}{|c|c|c|c|c|c|c|c|}
\hline & $\begin{array}{l}\text { Really } \\
\text { True } \\
\text { for me } \\
\end{array}$ & $\begin{array}{l}\text { Sort of } \\
\text { True } \\
\text { for me }\end{array}$ & & & & $\begin{array}{l}\text { Sort of } \\
\text { True } \\
\text { for me }\end{array}$ & $\begin{array}{c}\text { Really } \\
\text { True } \\
\text { for me }\end{array}$ \\
\hline 35. & & & $\begin{array}{l}\text { Some teenagers find it } \\
\text { hard to make friends they } \\
\text { can really trust }\end{array}$ & BUT & $\begin{array}{l}\text { Other teenagers are able } \\
\text { to make close friends } \\
\text { they can really trust }\end{array}$ & & \\
\hline 36. & & & $\begin{array}{l}\text { Some teenagers like the } \\
\text { kind of person they are }\end{array}$ & BUT & $\begin{array}{l}\text { Other teenagers often } \\
\text { wish they were someone } \\
\text { else }\end{array}$ & & \\
\hline 37. & & & $\begin{array}{l}\text { Some teenagers feel that } \\
\text { they are pretty intelligent }\end{array}$ & BUT & $\begin{array}{l}\text { Other teenagers question } \\
\text { whether they are } \\
\text { intelligent }\end{array}$ & & \\
\hline 38. & & & $\begin{array}{l}\text { Some teenagers know } \\
\text { how to become popular }\end{array}$ & BUT & $\begin{array}{l}\text { Other teenagers do not } \\
\text { know how to become } \\
\text { popular }\end{array}$ & & \\
\hline 39. & & & $\begin{array}{l}\text { Some teenagers do not } \\
\text { feel that they are very } \\
\text { athletic }\end{array}$ & BUT & $\begin{array}{l}\text { Other teenagers feel that } \\
\text { they are very athletic }\end{array}$ & & \\
\hline 40 . & & & $\begin{array}{l}\text { Some teenagers really } \\
\text { like their looks }\end{array}$ & BUT & $\begin{array}{l}\text { Other teenagers wish } \\
\text { they looked different }\end{array}$ & & \\
\hline 41. & & & $\begin{array}{l}\text { Some teenagers feel that } \\
\text { they are really able to } \\
\text { handle the work on a } \\
\text { paying job }\end{array}$ & BUT & $\begin{array}{l}\text { Other teenagers wonder } \\
\text { if they are really doing as } \\
\text { good a job at work as } \\
\text { they should be doing }\end{array}$ & & \\
\hline 42. & & & $\begin{array}{l}\text { Some teenagers usually } \\
\text { don't go out with people } \\
\text { they would really like to } \\
\text { date }\end{array}$ & BUT & $\begin{array}{l}\text { Other teenagers do go } \\
\text { out with people they } \\
\text { really want to date }\end{array}$ & & \\
\hline 43. & & & $\begin{array}{l}\text { Some teenagers usually } \\
\text { act the way they know } \\
\text { they are supposed to }\end{array}$ & BUT & $\begin{array}{l}\text { Other teenagers often } \\
\text { don't act the way they } \\
\text { are supposed to }\end{array}$ & & \\
\hline 44. & & & $\begin{array}{l}\text { Some teenagers don't } \\
\text { understand what they } \\
\text { should do to have a } \\
\text { friend close enough to } \\
\text { share personal thoughts } \\
\text { with }\end{array}$ & BUT & $\begin{array}{l}\text { Other teenagers do } \\
\text { understand what to do to } \\
\text { have a close friend with } \\
\text { whom they can share } \\
\text { personal thoughts. }\end{array}$ & & \\
\hline 45. & & & $\begin{array}{l}\text { Some teenagers are very } \\
\text { happy being the way they } \\
\text { are }\end{array}$ & BUT & $\begin{array}{l}\text { Other teenagers often } \\
\text { wish they were different }\end{array}$ & & \\
\hline
\end{tabular}

Susan Harter, Ph.D., University of Denver, 2012 


\section{Strengths and Difficulties Questionnaire}

For each item, please mark the box for Not True, Somewhat True or Certainly True. It would help us if you answered all items as best you can even if you are not absolutely certain. Please give your answers on the basis of how things have been for you over the last six months.

Your name.

Male/Female

Date of birth

\begin{tabular}{|c|c|c|c|}
\hline & $\begin{array}{c}\text { Not } \\
\text { True }\end{array}$ & $\begin{array}{c}\text { Somewhat } \\
\text { True }\end{array}$ & $\begin{array}{c}\text { Certainly } \\
\text { True }\end{array}$ \\
\hline I try to be nice to other people. I care about their feelings & & & \\
\hline I am restless, I cannot stay still for long & & & \\
\hline I get a lot of headaches, stomach-aches or sickness & & & \\
\hline I usually share with others, for example CD's, games, food & & & \\
\hline I get very angry and often lose my temper & & & \\
\hline I would rather be alone than with people of my age & & & \\
\hline I usually do as I am told & & & \\
\hline I worry a lot & & & \\
\hline I am helpful if someone is hurt, upset or feeling ill & & & \\
\hline I am constantly fidgeting or squirming & & & \\
\hline I have one good friend or more & & & \\
\hline I fight a lot. I can make other people do what I want & & & \\
\hline I am often unhappy, depressed or tearful & & & \\
\hline Other people my age generally like me & & & \\
\hline I am easily distracted, I find it difficult to concentrate & & & \\
\hline I am nervous in new situations. I easily lose confidence & & & \\
\hline I am kind to younger children & & & \\
\hline I am often accused of lying or cheating & & & \\
\hline Other children or young people pick on me or bully me & & & \\
\hline I often offer to help others (parents, teachers, children) & & & \\
\hline I think before I do things & & L & \\
\hline I take things that are not mine from home, school or elsewhere & & L & \\
\hline I get along better with adults than with people my own age & & & \\
\hline I have many fears, I am easily scared & & [ & \\
\hline I finish the work I'm doing. My attention is good & & $\square$ & \\
\hline
\end{tabular}


VITA

\section{ROBERT RAY OGLE}

2018-2019

Clinical Psychology Predoctoral Internship -

Community Services Institute

Springfield, Massachusetts

2016-2018

Ruth L. Kirschstein National Research Service Award Individual Fellowship

National Institute of Child Health and Development

2012-Present

Doctoral Candidate in Clinical Psychology

Florida International University

Miami, Florida

2009-2010

Post-Baccalaureate Certificate

Clinical Psychology

Columbia University

New York, NY

\section{SELECTED PUBLICATIONS AND PRESENTATIONS}

Ogle, R. R., Frazier, S. L., Helseth, S. A., Cromer, K., \& Lesperance, N. (2017). Does Poverty Moderate Psychosocial Treatment Efficacy for ADHD? A Systematic Review. Journal of Attention Disorders, 1087054717707044.

Ogle, R. R., Frazier, S. L., Nichols-Lopez, K., \& Cappella, E. (2016). Non-academic selfconcept among urban youth: Associations with academic success. School Mental Health, $8(2), 278-291$.

Frazier, S. L., Mehta, T. G., Atkins, M. S., Glisson, C., Green, P. D., Gibbons, R. D., ... \& Ogle, R. R. (2015). The social context of urban classrooms: Measuring student psychological climate. The Journal of Early Adolescence, 35(5-6), 759-789.

Boustani, M. M., Frazier, S. L., Becker, K. D., Bechor, M., Dinizulu, S. M., Hedemann, E. R., Ogle, R.R., \& Pasalich, D. S. (2015). Common elements of adolescent prevention programs: Minimizing burden while maximizing reach. Administration and Policy in Mental Health and Mental Health Services Research, 42(2), 209-219.

Ogle, R.R., \& Frazier, S.L. (2015). Student-driven interventions for children's mental health: Results of a Pilot Study. Symposium presented at the 2015 Association for Behavioral and Cognitive Therapies Annual Conference, Chicago, IL. 
Boustani, M. M., Frazier, S. L., Becker, K., Bechor, M., Dinizulu, S. M., Hedemann, E. R et al. (2012, October). Common elements of adolescent prevention programming: Minimizing the burden while maximizing the reach. Presented at The National Conference in Clinical Child and Adolescent Psychology. Lawrence, KS. 